\title{
JULIANA PASSOS DE ALMEIDA
}

\section{Avaliação de linguagem por ressonância magnética funcional em indivíduos com epilepsia do lobo temporal secundária a esclerose mesial temporal}

Tese apresentada à Faculdade de Medicina da Universidade de São Paulo para obtenção do título de Doutor em Ciências

Programa de Neurologia

Orientador: Prof. Dr. Luiz Henrique Martins Castro

(Versão corrigida. Resolução CoPGr 6018/11, de 1 de novembro de 2011. A versão original está disponível na Biblioteca FMUSP) 


\section{Dados Internacionais de Catalogação na Publicação (CIP)}

Preparada pela Biblioteca da

Faculdade de Medicina da Universidade de São Paulo

Creprodução autorizada pelo autor

\section{Almeida, Juliana Passos de}

Avaliação de linguagem por ressonância magnética funcional em indivíduos com epilepsia do lobo temporal secundária a esclerose mesial temporal / Juliana Passos de Almeida. -- São Paulo, 2017.

Tese(doutorado)--Faculdade de Medicina da Universidade de São Paulo.

Programa de Neurologia.

Orientador: Luiz Henrique Martins Castro.

Descritores: 1.Epilepsia do lobo temporal 2.Esclerose mesial temporal 3.Linguagem 4.Imagem por ressonância magnética 5.Lateralidade de linguagem

USP/FM/DBD-021/17 


\section{DEDICATÓRIA}

Ao Luiz Eduardo e ao Pedro dedico mais este momento de imensa alegria 


\section{AGRADECIMENTOS}

Aos pacientes portadores de esclerose mesial temporal e às suas famílias que doaram generosamente o seu tempo, com a esperança de contribuir para a produção de novo conhecimento, mesmo sabendo que poderiam não ser diretamente beneficiados.

Aos meus pais, João e América, exemplos de integridade e ética, por terem me ensinado o valor da busca pelo aprendizado.

Ao meu marido, Luiz Eduardo, minha referência em tudo que faço, pelo seu companheirismo e pela constante sintonia.

Às minhas irmãs Raquel, Marina e Clara por terem sempre acreditado em mim de modo incondicional.

Ao Prof. Dr. Luiz Henrique Martins Castro, com grande admiração, pela confiança, pelo exemplo e por todos os ensinamentos e oportunidades que fez questão de me oferecer, ao longo de tantos anos de convivência.

À Bettina Martins Castro, companheira inseparável em absolutamente todas as fases dessa empreitada, pela sua sincera amizade, competência e constante gentileza que tornaram o caminho infinitamente mais leve.

À Dra Carmen Lisa Jorge, pela amizade, por ser para mim exemplo de profissionalismo e pelas incontáveis contribuições ao longo deste trabalho e de toda a minha formação. A sua imensa vocação são fontes constantes de inspiração em minha vida.

Dra Rosa Maria Valério pela amizade, pelo afinco e dedicação que tanto ajudaram a tornar esse estudo viável e pela contribuição não somente na qualificação da tese, como durante toda a minha formação.

Ao Dr.Valmir Passarelli, pelo companheirismo desde a época em que éramos residentes, pela generosidade e partipação ativa em inúmeras etapas desse projeto, da coleta à análise dos dados.

Ao Dr. Wen Hung Tzu, brilhante neurocirugião, responsável por todos as neurocirurgias realizadas no grupo de pacientes deste estudo.

Ao Dr. Humberto Castro Lima pela grande ajuda na análise dos dados de vídeo-EEG.

Ao Dr. Paulo Puglia pelo fundamental auxílio na realização das arteriografias cerebrais para os testes de Wada.

Ao Prof. Dr. Ricardo Nitrini e à Dra Ana Carolina Coan pelas valiosas contribuições na qualificação da tese. 
Ao Dr. Edson Amaro Jr e à Dra Paula Ricci Arantes, pelo suporte e ensinamentos em ressonância magnética funcional.

Ao Khalil Taverna Chaim pela paciência e pelo auxílio precioso nas fases de programação e análise dos dados de neuroimagem.

Ao João Ricardo Sato, pelas valiosas idéias para o desenho do estudo.

Ao Carlos Morais, pela presteza e paciência dando suporte em informática.

À Dra Clarice Listik, pelo empenho e ajuda na análise dos dados das respostas comportamentais.

À todos os biomédicos da ressonância magnética funcional, em particular, ao Ricardo Nunes, Daniel Medeiros, Kleber Garcia, Luciana, Rosane e Rafael, pela colaboração na aquisição das imagens.

Às secretárias da ressonância magnética Mara e Adelinda Arruda e à toda equipe de enfermagem do serviço de ressonância magnética do Inrad, pelo atendimento aos participantes.

À Patrícia Ramos, pela análise estatítica.

Ao Dr. Alexandre Valotta, pelo fornecimento de dados histopatológicos.

À Thais Figueira, pela ajuda nos procedimentos burocráticos.

Aos amigos e colegas do LIM44, Dra Maria Concepción Garcia Otaduy, Raymundo Machado de Azevedo Neto, Eun Joo Park, Joana Bisol Balardin, Katarine Lyra, Marcelo Capela, Ana Paula Valadares, Andrea Cristina Pardini, Gilson Vieira, Katerina Lukasova e, em especial, Lucas Lessa e Mariana Penteado Nucci da Silva, pelo apoio constante, generoso e paciente. 
"Os limites do meu mundo são os limites da minha linguagem." 
Esta tese está de acordo com as seguintes normas, em vigor no momento desta publicação:

Referências: adaptado de International Committee of Medical Journals Editors (Vancouver).

Universidade de São Paulo. Faculdade de Medicina. Divisão de Biblioteca e Documentação. Guia de apresentação de dissertações, teses e monografias. Elaborado por Anneliese Carneiro da Cunha, Maria Julia de A. L. Freddi, Maria F. Crestana, Marinalva de Souza Aragão, Suely Campos Cardoso, Valéria Vilhena. 3a ed. São Paulo: Divisão de Biblioteca e Documentação; 2011.

Abreviaturas dos títulos dos periódicos de acordo com List of Journals Indexed in Index Medicus. 


\section{SUMÁRIO}

Lista de Figuras

Lista de tabelas

Lista de gráficos

Lista de Anexos

Lista de siglas e abreviaturas

Resumo

Abstract

1 INTRODUÇÃO

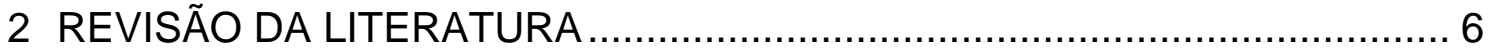

2.1 Modelo neurobiológico clássico de linguagem ……............................. 6

2.2 Críticas ao modelo tradicional de linguagem ...................................... 7

2.3 Lateralidade de linguagem: Princípios gerais .................................... 9

2.4 Métodos diagnósticos de localização e lateralização de linguagem......... 10

2.4.1 Teste de Wada e outros métodos para lateralização

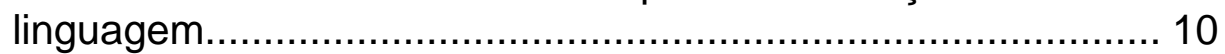

2.4.2 RMf de linguagem ....................................................... 14

2.5 Modelo anatômico-funcional de linguagem .................................... 22

2.5.1 Construção do modelo anatômico funcional ............................ 22

2.5.2 Regiões anatômicas ativadas em tarefas de linguagem a partir de estímulos visuais.................................................... 23

2.6 Linguagem e epilepsia do lobo temporal (ELT) ………................... 24

2.6.1 Distúrbios de linguagem em pacientes com ELT ..................... 24

2.6.2 Esclerose mesial temporal e linguagem................................ 26

2.6.3 Lateralidade atípica de linguagem e ELT/EMT ………............ 29

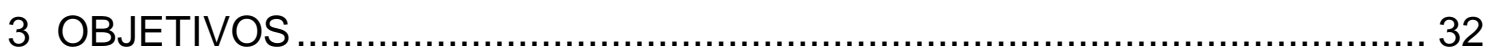

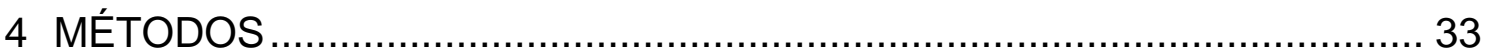

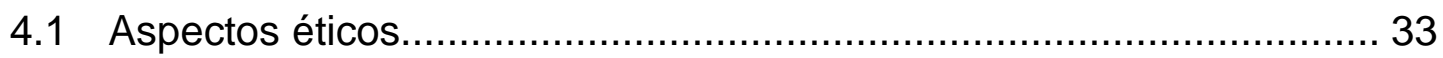

4.2 Desenho do estudo................................................................. 33

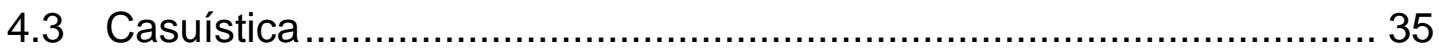

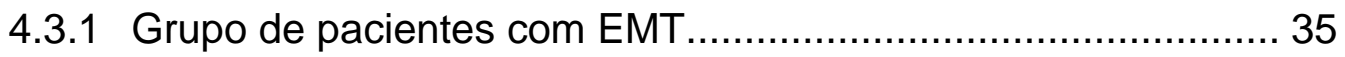

4.3.2 Critérios de inclusão e exclusão............................................ 35

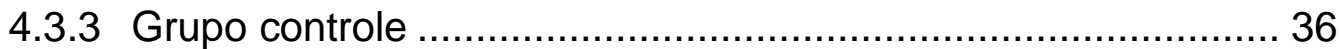

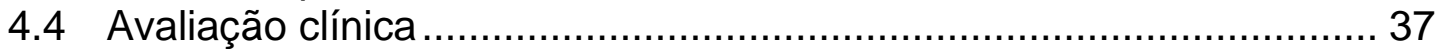

4.5 Monitorização por vídeo-EEG.................................................... 38

4.5.1 Aspectos gerais........................................................... 38

4.5.2 Classificação de concordância interictal .................................. 39

4.5.3 Classificação de concordância ictal ........................................ 40

4.5.4 Classificação final de concordância (classificação EEG/RM) ... 40

4.6 Teste de Wada e índice de lateralidade (IL-Wada) ............................ 41

4.7 Ressonância magnética funcional ................................................... 43

4.7.1 Preparação para o exame de RMf e aplicação de questionários...................................................................... 43

4.7.2 Posicionamento dos sujeitos.................................................. 44

4.7.3 Protocolo de aquisição das imagens....................................... 45 
4.7.4 Instrumentos para apresentação do paradigma e coleta de respostas comportamentais ................................................. 46

4.7.5 Paradigma de linguagem ................................................. 46

4.7.6 Análise estatística das imagens de RM funcional ................... 49

4.7.7 Seleção de regiões cerebrais de interesse (Region of interest $\mathrm{ROI})$

4.7.8 Cálculo do Índice de Lateralidade (IL-RMf) ........................... 51

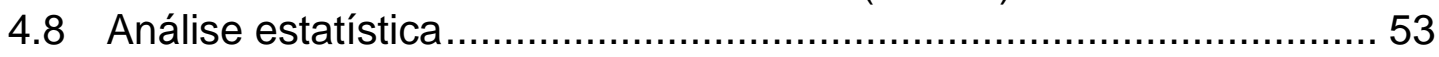

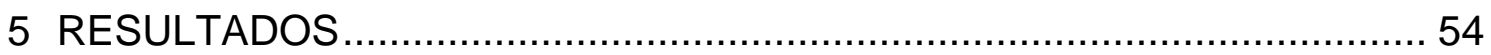

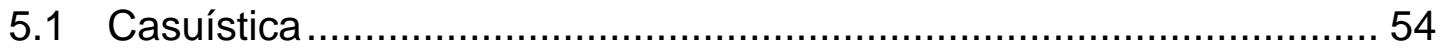

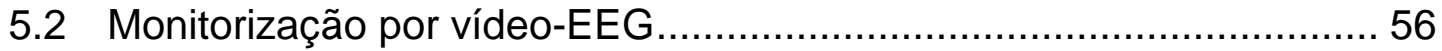

5.3 Classificação de concordância EEG/ RM ......................................... 56

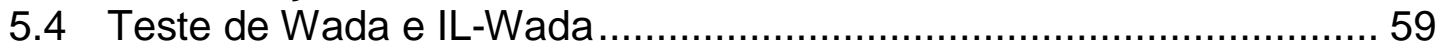

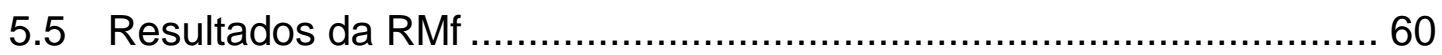

5.5.1 Questionários de avaliação antes e após a RMf........................6 60

5.5.2 Dados comportamentais do paradigma de RMf ........................ 61

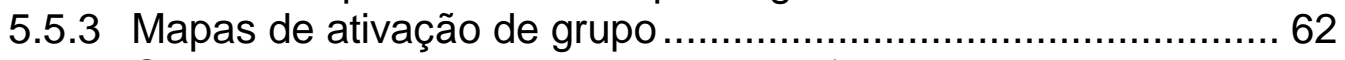

5.5.4 Comparações entre IL-Wada e IL-RMf .................................... 66

5.6 Lateralização de linguagem (IL-RMf) em EMTE, EMTD e controles para as diferentes regiões de interesse ........................................... 68

5.7 Lateralização de linguagem (IL-RMf) e concordância EEG/RM .......... 71

5.7.1 Comparação da lateralidade de linguagem nos subgrupos EMTE concordante e EMTE discordante ................................. 72

5.7.2 Comparação da lateralidade de linguagem nos subgrupos EMTD concordante e EMTD discordante................................. 73

5.7.3 Comparação da lateralidade de linguagem entre subgrupos EMTE e EMTD concordantes e discordantes ........................... 74

5.8 Lateralização de linguagem (IL-RMf) e variáveis clínicas...................... 76

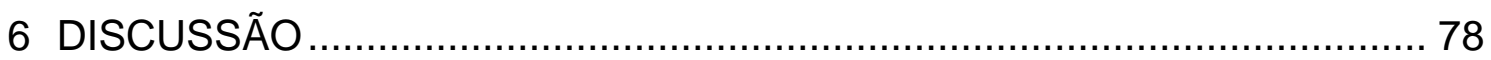

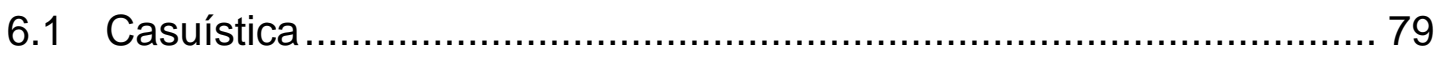

6.2 Monitorização por vídeo-EEG................................................... 80

6.3 Ressonância magnética funcional .................................................. 82

6.3.1 Questionários de avaliação de humor e ansiedade .................. 83

6.3.2 Respostas comportamentais............................................... 84

6.3.3 Paradigma de NRL: mapas de ativação de grupo..................... 85

6.3.4 Paradigma de NRL: comparações entre IL-Wada e IL-RMf...... 86

6.4 Lateralização atípica de linguagem e EMT ...................................... 87

6.5 Lateralização de linguagem e atividade epileptiforme ......................... 90

6.6 Lateralização de linguagem e idade do início da epilepsia, tempo de epilepsia e presença de IPI ....................................................... 92

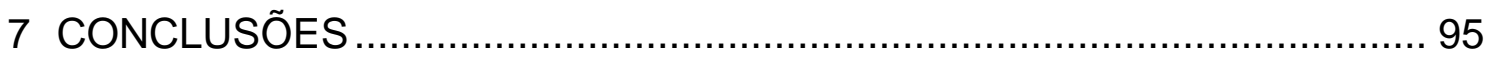

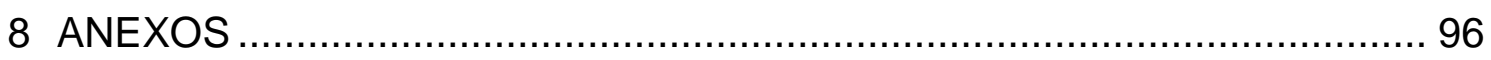

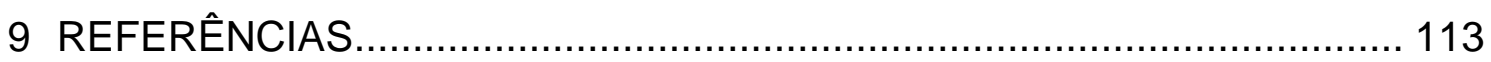




\section{LISTA DE FIGURAS}

Figura 1. General Linear Model e variação do dado ao longo do tempo para um dado voxel. Em azul, variação do dado original (variação do sinal BOLD); em vermelho, resíduos (erro); em verde, variação dos eventos no modelo experimental

Figura 2. Fluxograma dos participantes com as diferentes etapas da coleta de dados para o grupo de pacientes e grupo controle

Figura 3. Exemplos de composição das telas em um bloco de condição ativa (frases) e de um bloco de condição controle (não-frases). O sujeito é.orientado a responder no momento da apresentação da tela composta por uma cruz $(+)$. Cada bloco éCcomposto por 10 telas, 5 telas com estímulos e 5 telas com cruz (+)

Figura 4. Desenho geral do paradigma de nomeação responsiva à leitura com apresentação em bloco. Apresentação de blocos de condição ativa e blocos de condição controle de modo aleatorizado (a), linha temporal (b), cada bloco foi composto por cinco estímulos (c)

Figura 5. Regiões cerebrais de interesse utilizando a segmentação do Atlas aparc2009 sobre o template MNI.

Figura 6. Classificação final de concordância EEG/RM para grupo de pacientes EMTE e EMTD

Figura 7. Grupo controle $(n=22)$. Áreas da superfície cortical dos mapas de ativação de grupo para o contraste condição ativa > condição controle (clusters constituídos por voxels com valores de $Z>2.3$, corrigidos para comparações múltiplas $(p<0,05)$. Vistas laterais do hemisfério esquerdo, direito, vistas superior, inferior, anterio e posterior do cérebro. $D=l a d o$ direito, nos cortes axiais. 
Figura 8. Grupo EMTE ( $n=24)$. Áreas da superfície cortical dos mapas de ativação de grupo para contraste condição ativa > condição controle (clusters constituídos por voxels com valores de $Z>2.3$, corrigidos para comparações múltiplas $(p<0,05)$. Vistas laterais do hemisfério esquerdo, direito, vistas posterior superior e inferior do cérebro. $D=l a d o$ direito, nos cortes axiais

Figura 9. Grupo EMTD ( $n=22)$. Áreas da superfície cortical dos mapas de ativação de grupo para o contraste condição ativa > condição controle (clusters constituídos por voxels com valores de Z>2.3, corrigidos para comparações múltiplas $(p<0,05)$. Vistas laterais do hemisfério esquerdo, direito, vistas posterior superior e inferior do cérebro. $D=l a d o$ direito, nos cortes axiais 


\section{LISTA DE TABELAS}

Tabela 1. Características dos pacientes EMTE, EMTD e controles. Os resultados das variáveis medidas são expressos em média e desvio-padrão. 55

Tabela 2. Número de pacientes classificados como concordantes e discordantes de acordo com a classificação interictal, ictal e classificação final de concordância EEG/RM estrutural

Tabela 3. Características dos controles e pacientes EMTE e EMTD, após classificação EEG/RM em subgrupos concordantes e discordantes.

Tabela 4. Resultados das respostas comportamentais (porcentagem de acertos) para os grupos EMTE, EMTD e controles.

Tabela 5. Valores dos coeficientes de correla1). 1). =0,001) e GTI $(p=0,001)$. al temporal direita.MTD e controleses $\operatorname{EMTD}(\mathrm{ROI})$.

Tabela 6. Nabela 6.I (86\%). A menor concord vidualmente, de uperior; GTM=Giro temporal ml direita.MTD e controleRMf

Tabela 7. Propor7 TD, entado observada tendênci como at7 TD, ende acordo com a lateralidade de linguagem por RMf, para cada regiegieralidade de.

Tabela 8. Resultados dos IL-RMf por ROI para os grupos EMTE, EMTD e controles. Os resultados são expressos em valores de média e desvio-padrão .. 69

Tabela 9. Resultados dos IL-RMf por ROI para os grupos EMTEc, EMTEd, EMTDc, EMTDd e controles. Os resultados são expressos em valores de média e desvio-padrão

Tabela 10. Resultados dos IL-RMf e aspectos clesultados dos IL-RMf squerdascargas à eexpressos em valores de malores de lesultados 


\section{LISTA DE GRÁFICOS}

Gráfico 1. Resultados da pontuação nos questionários préie pós realização do exame de $\mathrm{RM}$ funcional e de desempenho nas tarefas comportamentais: comparação entre os grupos EMTE, EMTD e controles. À esquerda do gráfico, valores antes do exame da RMf e àidireta, valores após o exame de RMf

Gráfico 2. Resultados da avaliação de ansiedade através das escalas idate-E e idate-T para os grupos EMTE, EMTD e controles.

Gráfico 3. Resultados de IL-RMf médio $X$ ROI para os grupos EMTE, EMTD e controles. No gráfico são mostrados em destaque os resultados estatisticamente significativos para as comparações 2 X2 entre os grupos...... 70

Gráfico 4. Paradigma de nomeação responsiva à leitura: Comparação IL-RMf médio por ROI entre os grupos EMTEc, EMTEd e controles

Gráfico 5. Paradigma de nomeação responsiva à leitura: Comparação IL-RMf médio por ROI entre os grupos EMTDc, EMTDd e controles

Gráfico 6. Paradigma de nomeação responsiva à leitura: Comparação IL-RMf médio por ROI entre os grupos EMTEc X EMTDc X Controles....

Gráfico 7. Paradigma de nomeação responsiva à leitura: Comparação IL-RMf médio por ROI entre os grupos EMTEc, EMTDd e grupo controle 


\section{LISTA DE ANEXOS}

Anexo 1. Documento de aprovação pela Comissão de Ética para Análise de Projetos de Pesquisa (CAPPesq) do HCFMUSP

Anexo 2. Termo de Consentimento Livre e Esclarecido................................ 98

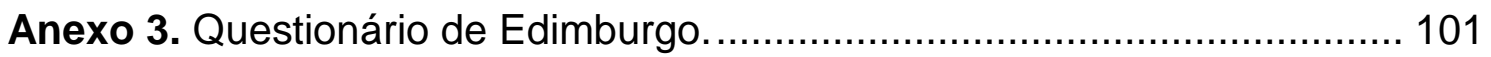

Anexo 4. Inventário de depressão de Beck - BDI. ..................................... 102

Anexo 5. Escala VAMS (Visual Analog Mood Scale). ............................... 105

Anexo 6. Inventário de ansiedade traço-estado (IDATE). ........................... 106

Anexo 7. Resultados da monitorização por vídeo-EEG e da concordância

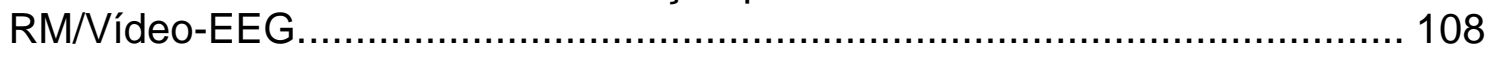

Anexo 8. Resultados dos valores de IL-Wada individuais. Valores totais e para cada fator de linguagem separadamente.

Anexo 9. Resultados das pontuações nas escalas VAMS para os fatores estresse, ansiedade, comprometimento cognitivo e desconforto entre os grupos EMTE, EMTD e controles antes e após o exame de RMf.

Anexo 10. Descrição anatômica dos voxels com as coordenadas MNI e locais de picos de ativação de cada cluster significativo (local máxima).

Anexo 11. Descrição das variáveis clínicas relacionadas à epilepsia, frequência de descargas a esquerda e IL-RMf por ROI, para cada paciente. 112 


\section{LISTA DE SIGLAS E ABREVIATURAS}

ANOVA Análise de Variância, do inglês Analysis of Variance

AVC Acidente vascular cerebral

BET Ferramenta do FSL para extração do cérebro, do inglês Brain Extration Tool

BOLD Sinal dependente do nível de oxigenação sanguínea, do inglês Blood Oxigenation Level Dependent

CAPPesq Comissão de Ética para Análise de Projetos de Pesquisa

Desoxi-Hb desoxi-hemoglobina

EEC estimulação elétrica cortical

EEG Eletroencefalograma

ELT Epilepsia do lobo temporal

EMTE Epilepsia do lobo temporal secundária a esclerose mesial temporal esquerda

EMTD Epilepsia do lobo temporal secundária a esclerose mesial temporal direita

EMTEc Epilepsia do lobo temporal secundária a esclerose mesial temporal direita concordante (de acordo com a classificação EEG/RM)

EMTEd Epilepsia do lobo temporal secundária a esclerose mesial temporal direita discordante

EMTDc Epilepsia do lobo temporal secundária a esclerose mesial temporal esquerda concordante (de acordo com a classificação EEG/RM) 
EMTDd Epilepsia do lobo temporal secundária a esclerose mesial temporal esquerda discordante

FEAT Ferramenta do FSL para Análises Estatísticas das Imagens de RMf, do inglês FMRI Expert Analysis Tool

FILM Ferramenta do FSL para Modelagem Linear do Sinal de RM, do inglês

FMRIB's Improved Linear Model

FLIRT Ferramenta do FSL para Registro Linear de Imagens, do inglês FMRIB's Linear Image Resgistration Tool

FDG-PET Flúor-deoxi-glicose PET

FRH Função de Resposta Hemodinâmica

FSL Software de Bibliotecas do FMRIB para análise de imagens de RMf, do inglês FMRIB Software Library

GFS giro frontal superior

GFM giro frontal médio

GFI giro frontal inferior

GTS giro temporal superior

GTM giro temporal médio

GTI giro temporal inferior

GA giro angular

GOT/F porção ventral ao longo do sulco occipito-temporal-Giro fusiforme

GLM Modelo Linear Geral, do inglês General Linear Model

GRE-EPI Imagem por Sequência de Pulsos do Tipo Gradiente Eco Planar, do inglês Gradient Echo Type Echo Planar Imaging 
GUI Interface Gráfica do Usuário, do inglês Graphical User Interface.

HC Hospital das Clínicas da Faculdade de Medicina da Universidade de São FMUSP Paulo

HD Hemisfério Direito

HE Hemisfério Esquerdo

IL-RMf Índice de lateralidade de linguagem por RMf

IL-Wada Índice de lateralidade por teste de Wada

IPI Insulto precipitante inicial

MAEs Medicações anti-epilépticas

MCFLIRT Ferramenta de Correção de Movimento e Registro de Imagem do FMRIB, do inglês Motion Correction FMRIB's Linear Image Registration Tool

$\mathrm{Oxi-Hb} \quad$ oxi-hemoglobina

PET Tomografia por Emissão de Pósitrons, do inglês Positron Emission Tomography

QI Quociente de Inteligência

RM Ressonância magnética

RMf Ressonância magnética funcional

ROI Região de interesse, do inglês region of interest

USP Universidade de São Paulo

WLG Modelo de linguagem de Wernicke Lichteim Geshwind. 


\section{RESUMO}

Almeida JP. Avaliação de linguagem por ressonância magnética funcional em indivíduos com epilepsia do lobo temporal secundária a esclerose mesial temporal [Tese]. São Paulo: "Faculdade de Medicina, Universidade de São Paulo"; 2017.

Introdução: A lateralização atípica de linguagem (LAL) é mais frequentemente observada em indivíduos com epilepsia no hemisfério esquerdo. Pacientes com epilepsia secundária a esclerose mesial temporal (EMT) apresentam alta frequência de LAL. A presença de EMTE, diretamente ou por efeitos à distância, perturbaria a determinação típica de lateralidade de linguagem (LL). Estudos de LL com RMf, em populações homogêneas de pacientes com EMT são escassos. Os padrões regionais de reorganização, nesta população, assim como os fatores clínicos e funcionais associados à LAL são pouco conhecidos. Os objetivos deste estudo foram (1) Validar paradigma de linguagem em RMf capaz de ativar áreas frontais e temporais de linguagem (2) Avaliar LL regional, em população homogênea de pacientes com EMT e verificar o papel de variáveis clínicas e da atividade epileptiforme na determinação de LAL. Foram avaliados 46 pacientes com EMT unilateral (24 EMTE e 22 EMTD) e 24 controles saudáveis, destros. Todos os participantes foram submetidos a RMf de linguagem com paradigma de nomeação responsiva à leitura (NRL) desenvolvido em língua portuguesa. O paradigma foi eficaz em ativar áreas de linguagem. A correlação entre IL-RMf e IL-Wada foi estatisticamente significativa no GFM $(0,387 ; \mathrm{p}<0,01)$; GFI $(0,594, p<0,001)$; GTS $(0,357$, $p<0,05)$; GTM $(0,509, p<0,001)$ e GTI $(0,489, p<0,001)$. Os pacientes foram classificados em discordantes e concordantes (EEG/RM), após monitorização prolongada por vídeo-EEG. As classificações individuais de $L L$ do teste de Wada e RMf foram concordantes em 84\%(GFM), 86\% (GFI), 74\%(GTS), $83 \%(\mathrm{GTM})$ e $86 \%(\mathrm{GTI})$ dos casos. A frequência de LAL variou de 17 a $33 \%$, para EMTE; 14 a 17\%, para EMTD e de 0 a 10\%, no grupo controle. Os grupos EMTEc e EMTEd apresentaram menores valores de IL-RMf, em relação ao grupo controle no GFM e GFI ( $p \leq 0.05)$. Adicionalmente, o grupo EMTEd apresentou menor IL-RMf no GTM ( $p \leq 0.01)$ e GTI ( $p \leq 0.05)$. O grupo EMTDd apresentou menor IL-RMf no GFM; GFI; GTM e GTI ( $p \leq 0.05)$. A ocorrência de mais de 5 descargas/hora no período interictal associou-se a LAL no GFM $(p \leq 0.01)$. Início da epilepsia, maior tempo de epilepsia e presença de IPI não foram associadas a LAL. Concluiu-se que a presença de EMT associou-se a LAL nas regiões frontais e temporais, sugerindo reorganização de linguagem envolvendo amplas regiões cerebrais, distantes da zona epileptogênica. $O$ achado de LAL observada no grupo EMTDd sugere que a atividade epileptiforme temporal esquerda pode influenciar a reorganização de linguagem, independentemente da presença de lesão estrutural à esquerda. A maior frequência de descargas à esquerda associou-se a LAL.

Descritores: 1.Epilepsia do Lobo temporal, 2.Esclerose Mesial Temporal, 3.Linguagem, 4.Imagem por ressonância magnética, 5.Lateralidade de linguagem 


\section{ABSTRACT}

Almeida JP. FMRI language lateralization in patients with epilepsy secondary to mesial temporal sclerosis [Thesis]. São Paulo: "Faculdade de Medicina, Universidade de São Paulo"; 2017.

Atypical language lateralization (ALL) is associated with left hemisphere epilepsy, especially in epilepsy secondary to left mesial temporal sclerosis (MTS). Recent findings indicate that MTS, directly or by an at-distance effect may disrupt typical language lateralization (LL). Language-fMRI investigations in homogeneous MTS populations are scarce. Frontal and temporal language reorganization patterns in this population remain incompletely understood, as well as clinical factors associated with ALL. Our objectives were (1) To validate an $\mathrm{fMRI}$ paradigm effective to activate frontal and temporal language areas (2) To evaluate regional LL patterns in a homogeneous population of MTS patients and to investigate clinical factors associated with ALL. We studied forty-six right-handed patients (24 left MTS and 22 right MTS) and 24 controls. Patients and controls were similar in age and gender. Left and right MTS groups were comparable in terms of clinical variables. All participants underwent a language fMRI with reading response-naming paradigm (RRN) task developed in Brazilian Portuguese. The task effectively activated frontal and temporal language areas, with a high concordance with the Wada test. All patients were classified as concordant and discordant after video-EEG monitoring. Correlation between Wada test and fMRI LIs was significant in MFG (0.387; $p<0.01)$; IFG (0.594, p<0.001); STG (0.357, $p<0.05)$; MTG $(0.509, p<0.001)$ e ITG $(0.489$, $\mathrm{p}<0.001)$. Individual $\mathrm{LI}$ classifications with Wada test and $\mathrm{PMRI}$ were concordant in $84 \%$ (MFG), $86 \%$ (IFG), $74 \%$ (STG), 83\%(MTG) e $86 \%$ (ITG). The frequency of ALL was $17-33 \%$, in left MTS; $14-17 \%$, in right MTS and $0-10 \%$, in controls. Both concordant and discordant-left MTS patients presented lower LI than controls in MFG and IFG ( $p \leq 0.05)$. Additionally, discordant left MTS group presented lower LI in MTG $(p \leq 0.01)$ and ITG $(p \leq 0.05)$. Discordant right MTS group presented lower LI in MFG; IFG; MTG and ITG $(p \leq 0.05)$. Interictal leftsided spike frequency $(<5 / h)$ was associated with lower $\mathrm{LI}(p \leq 0.01)$ in MTG. In conclusion, MTS was associated with frontal and temporal language reorganization. Presence of ALL in discordant RMTS group suggests that left temporal epileptic activity may influence language reorganization, even in the absence of a left structural lesion. Higher left-sided spike frequency in MTS was associated with a left-right shift of speech representation.

Descriptors: 1.Temporal Lobe Epilepsy, 2.Mesial Temporal Sclerosis, 3.Language, 4.Functional MRI, 5. Language Lateralization 


\section{INTRODUÇÃO}

Cerca de 95\% dos indivíduos destros saudáveis apresentam dominância de linguagem à esquerda (Springer et al; 1999; Pujol et al; 1999; Knecht et al; 2000). A prevalência de lateralização atípica de linguagem (representação bilateral ou à direita) em indivíduos saudáveis com dominância manual à esquerda ou ambidestros é maior que em indivíduos destros (22\% versus 4-6\%). Associações observadas entre dominância manual, lateralidade hemisférica de linguagem e história familiar de dominância manual indicam papel de fatores genéticos na herança de dominância manual e na lateralidade de linguagem (dominância genética) (Szaflarski et al; 2002).

Estudos em populações de pacientes com lesões no hemisfério esquerdo demonstram maior prevalência de associação entre dominância manual esquerda e dominância de linguagem à direita (Rasmussen e Milner, 1977; Loring et al; 1990; Vargha-Khadem et al; 1985; Woods et al; 1988). Nestes casos, a dominância manual à esquerda é descrita como dominância patológica, isto é, possivelmente associada a migração de linguagem 0 hemisfério direito após lesões hemisféricas à esquerda, de instalação precoce.

A dominância de linguagem parece ser estabelecida em torno dos 6 anos de idade. $O$ início da epilepsia no lobo temporal (ELT) dominante antes desta idade estaria associado a padrões de organização de linguagem atípicos, sobretudo em nomeação e leitura. Estudos com populações heterogêneas de pacientes com ELT mostram que fatores como tempo de duração da doença e idade do insulto precipitante inicial associam-se a maior prevalência de dominância atípica de linguagem (Rasmussen e Milner, 1977; Helmstaedter et al; 1997, Springer et al; 1999).

A determinação da lateralização de linguagem durante a avaliação clínica pré-operatória é importante em pacientes com epilepsia focal, porque a representação de linguagem pode determinar o prognóstico de declínio de memória verbal e déficit de nomeação pós operatório (Binder et al., 2008; Sabsevitz et al., 2003). 
O método classicamente utilizado para determinar lateralidade de linguagem pré-operatória é o teste de Wada. O teste de Wada é um método invasivo durante o qual a atividade em um dos hemisférios cerebrais é temporariamente suprimida após cateterização e infusão intracarotídea unilateral do agente anestésico (Wada, 1949). O teste de Wada, além de invasivo, avalia apenas a função de linguagem hemisférica, não sendo capaz de acessar padrões de lateralidade regionais (Seghier et al; 2011). Com a implementação crescente de novos métodos de avaliação pré-operatória de linguagem, como a Ressonância magnética funcional (RMf), alguns autores já se referem ao teste de Wada como um método em declínio (Baxendale et al., 2009).

A RMf é um método não invasivo para lateralização de linguagem, amplamente utilizado em muitos centros em substituição ao teste de Wada (Abou-Khalil et al., 2007). Além de ser um método não invasivo, uma vantagem adicional da RMf é permitir a avaliação regional de lateralidade de linguagem.

Observa-se a dissociação inter-hemisférica de linguagem em 3\% dos casos em estudos de RMf (Kurthen et al; 1992). Nestes casos, a lateralidade de linguagem para a região frontal pode ser diferente daquela para a região temporal. A localização da lesão determina diferentes padrões de lateralidade regionais de linguagem. Pacientes com epilepsia frontal estão mais propensos a apresentar lateralidade de linguagem atípica para a região frontal, enquanto aqueles com epilepsia do lobo temporal apresentam linguagem atípica tanto para o giro frontal inferior (GFI) quanto para o giro temporal superior (GTS). Maior duração da epilepsia associa-se a maior prevalência de lateralidade atípica no GTS (Duke et al; 2012).

Durante a RMf de linguagem, diferentes tarefas podem ser utilizadas. É consenso que o paradigma de geração de palavras promove ativação robusta do GFI esquerdo e ativações menos intensas do GTS (Palmer et al; 2001). À medida que componentes semânticos são associados à tarefa de produção de linguagem, observa-se maior ativação de regiões posteriores de linguagem (Springer et al; 1999). O paradigma de nomeação responsiva à leitura mostrouse eficaz em ativar de modo robusto áreas temporais e frontais de linguagem (Gaillard et al; 2002). Além disto, utilizar este paradigma pode ser desejável em RMf de linguagem em indivíduos com EMT uma vez que é demonstrado que o 
desempenho em tarefa de nomeação está particularmente comprometida nesta população (Bell e Davies, 1998).

Vasta literatura sobre processamento de linguagem produzida nas últimas duas décadas sugere que outras regiões cerebrais além do GFI e GTS, descritos no modelo clássico de linguagem (Broca,1861; Wernicke, 1874; Lichtheim,1885; Geschwind, 1965) são relevantes na função de linguagem. O modelo anatômico-funcional descrito por Price (2012) contempla estas novas informações, associando processamentos de aspectos específicos de linguagem ( $p$ ex. recuperação de palavras, associação léxico-semântica) a regiões cerebrais além das áreas de Wernicke e Broca. Este conhecimento vem sendo recentemente incorporado nos estudos de dominância de linguagem por RMf.

Outro aspecto relevante em termos de metodologia de RMf de linguagem é o método utilizado para calcular o índice de lateralidade (IL-RMf). O IL-RMf obtido deve ser reprodutível, o que não é garantido na grande maioria dos estudos clássicos de RMf. O mesmo paciente pode ser classificado como tendo linguagem à esquerda, bilateral ou à direita a depender do limiar arbitrariamente escolhido. Métodos mais robustos e reprodutíveis para 0 cálculo do IL-RMf, vêm se consolidando na literatura principalmente nos últimos cinco anos (Wilke \& Lizdba, 2007).

Considerando o grupo de pacientes com epilepsia do lobo temporal (ELT), aqueles com diagnóstico de esclerose mesial temporal (EMT) são os que mais frequentemente apresentam dominância atípica de linguagem, fato ainda pouco compreendido (Jansky et al; 2003; Weber et al; 2006) e que contraria a noção intuitiva de que o acometimento de estruturas temporais neocorticais (e não hipocampais) teria maior impacto sobre reorganização de linguagem.

EMT é a principal causa de epilepsia refratária ao tratamento medicamentoso em adultos. O quadro clínico e história natural nesta situação são relativamente bem conhecidos. As crises epilépticas surgem, em geral, na infância tardia ou na adolescência. É frequente antecedente de insulto precipitante inicial, comumente história de convulsão febril na primeira infância ou crise febril complicada (crise prolongada, unilateral ou múltiplas crises em um mesmo episódio febril). Segue-se um intervalo livre de crises e apenas após alguns anos inicia-se a epilepsia (Engel e Spencer, 1997). Na ELT unilateral 
secundária a etiologias diversas, a monitorização com EEG invasivo e não invasivo demonstra que a atividade epiléptica ictal/interictal pode não ser concordante com a lesão estrutural, ou seja, pode ter localização predominantemente contralateral, bilateral ou ambígua ((Williamson et al., 1993; Ebner \& Hoppe, 1995; King et al., 1997, Castro et al., 2008).

Estudos de dominância de linguagem utilizando o teste de Wada em populações homogêneas de pacientes com EMT sugerem que a reorganização de linguagem podem associar-se a características clínicas da doença. Jansky et al (2006) e Rathore et al (2009) mostraram associação entre dominância atípica de linguagem e (a) presença de insulto precipitante inicial que não crise febril, (b) início da epilepsia antes dos seis anos de idade, (c) intervalo curto entre o insulto precipitante inicial (IPI) e o início da epilepsia, e (d) presença de alterações extra-temporais no eletroencefalograma (EEG). O uso do teste de Wada não permitiu acessar variações regionais de reorganização de linguagem. No estudo de Rathore et al (2009) são observadas algumas limitações. A dominância atípica de linguagem pode ter sofrido efeito de variáveis genéticas, uma vez que pacientes com dominância manual à esquerda não foram excluídos do estudo. Outras variáveis patológicas podem ter contribuído para os achados, uma vez que foram incluídos pacientes com anormalidades extra-temporais na RM e EEG.

Jansky et al (2003), também utilizando teste de Wada, mostraram que a dominância atípica de linguagem foi mais prevalente em pacientes que exibiram alta frequência de atividade epileptiforme interictal temporal esquerda. Embora não tenha verificado o papel da lateralidade da atividade epileptiforme, este estudo sugeriu que fatores funcionais podem estar associados a maior prevalência de representação de linguagem bilateral ou à direita.

Estudos com RMf para avaliação de lateralidade de linguagem em populações homogêneas com EMT são escassos. O mesmo grupo anteriormente citado (Jansky et al; 2006), utilizando RMf confirmou a associação de frequência de atividade epileptiforme interictal e dominância atípica de linguagem em um grupo de 28 pacientes com EMTE. O paradigma utilizado foi o de geração de palavras, que sabidamente ativa melhor o GFI, porém não áreas temporais de linguagem. É possível que a lateralidade atípica tenha sido subestimada, já que 
reorganizações dissociadas de linguagem são descritas em pacientes com epilepsia. Apenas um grupo com EMTD foi utilizado como controle, embora se saiba que estes pacientes apresentam distúrbios de linguagem com mais frequência que a população saudável (Messas et al; 2008; Oddo et al; 2003). A técnica para cálculo de lateralidade utilizada foi dependente de limiar e realizada para os 3/4 laterais do hemisfério, o que não permite a análise de lateralidade em regiões de interesse específicas. Neste estudo considerou apenas a atividade epiléptica interictal.

O segundo estudo com RMf em um grupo homogêneo de pacientes com EMT, avaliou 12 pacientes utilizando paradigma com componente semântico (ouvir sentenças passivamente). Observou-se maior prevalência de lateralidade atípica de linguagem para o grupo EMTE em relação aos controles saudáveis e associação de lateralidade atípica com idade precoce de início da epilepsia. O estudo avaliou apenas a lateralidade de linguagem nas regiões temporais. Fatores associados à atividade epiléptica não foram explorados (Miró et al; 2014). 


\section{REVISÃO DA LITERATURA}

\subsection{Modelo neurobiológico clássico de linguagem}

A organização das bases neurais para o processamento de linguagem começou a ser construída no século XIX, a partir dos estudos seminais de Broca (1861), Wernicke (1874) e Lichtheim (1885) reavivados e popularizados na década de 60 por Geschwind (1965).

Nesta época, o estudo do processamento de linguagem baseava-se amplamente em modelos lesionais. As síndromes afásicas clássicas foram primeiramente postuladas por Lichtheim, que se baseou em estudos prévios, principalmente de Broca e Wernicke (Broca, 1861; Wernicke, 1874). Broca descreveu um paciente chamado Leborgne, que havia perdido a capacidade de articular a fala e relacionou este distúrbio a lesão centrada na porção posterior do GFI do hemisfério esquerdo, área posteriormente conhecida como área de Broca. Nos anos seguintes, muitos outros casos foram descritos, e, em alguns, observou-se que as lesões eram um pouco mais posteriores. Em 1874, Wernicke publicou um artigo tentando explicar estas diferenças de localização anatômica (Wernicke, 1974). No relato, Wernicke descrevia um paciente com discurso fluente, contendo parafasias fonêmicas e semânticas, com dificuldade de compreensão associada. A partir destas informações e estudando um segundo paciente com síndrome similar, Wernicke concluiu que a porção posterior do GTS era o centro auditivo de reconhecimento das palavras. Wernicke desenvolveu o embrião da teoria geral de processamento de linguagem, sugerindo que os aspectos receptivos da linguagem (imagens acústicas das palavras) se localizariam adjacentes ao córtex sensitivo primário e que os aspectos expressivos da linguagem (imagens motoras da fala) se localizavam próximos ao córtex motor. (Wernicke, 1874 revisado por Eggert, 1977). Segundo Wernicke, para que o som chegasse a conter um significado, várias 
associações deveriam ser feitas entre a imagem acústica da palavra e as imagens de várias outras memórias sensoriais que compõem um particular objeto. Portanto, uma conexão anatômica deveria existir não só entre os dois centros de linguagem, como também entre sistemas de representação conceituais distribuídos por todo o córtex e estes dois centros principais. De acordo com este modelo, a compreensão envolveria a ativação da imagem acústica da palavra o que por sua vez, ativaria um conjunto de memórias de imagens sensoriais e motoras, que, reunidas, formariam o conceito da palavra.

Posteriormente Lichtheim descreveu as síndromes de afasia definindo sete síndromes clínicas: afasia de Broca, afasia de Wernicke, distúrbio motor puro, surdez pura para palavras, afasia transcortical sensitiva, afasia transcortical motora e afasia de condução. Segundo Lichtheim as regiões anatômicas envolvidas eram a área de Broca, Wernicke, tratos eferentes a partir do córtex motor, tratos aferentes do córtex auditivo para a área de Wernicke, substância branca profunda conectando a área de Broca ao lobo parietal, substância branca conectando o lobo parietal ao lobo temporal ou porções do lobo parietal inferior e conexões entre Wernicke e Broca.

Geshwind (1971) reavivou estes conceitos na década de 70 e ampliaram a lista de síndromes afásicas de Lichtheim, acrescentando anomia, afasia global e afasia expressiva pura. O modelo de Wernicke-Lichteim-Geschwind permaneceu como o modelo neurobiológico de linguagem dominante até a última década.

\subsection{Críticas ao modelo tradicional de linguagem}

O modelo de Wernicke-Lichteim-Geschwind (WLG) sobreviveu praticamente intacto por muitos anos, por conter conceitos relevantes e de grande aplicabilidade clínica. Mas, a despeito de seu impacto até os dias atuais, diversas linhas diferentes de estudos têm revelado as limitações deste modelo tradicional para explicar toda a neurobiologia da linguagem. 
Em termos de considerações anatômicas, o modelo clássico mostrou-se inadequado. Mohr e colaboradores (1978), relacionaram os achados clínicos encontrados em 20 pacientes com diagnóstico de acidente vascular cerebral, cuja autópsia revelava uma lesão restrita à área clássica de Broca, a porção posterior do GFI do hemisfério esquerdo. Todos os pacientes apresentavam um quadro de mutismo, seguido de melhora rápida, evoluindo para quadro de disartria. Os autores também demonstraram que os achados clássicos da síndrome de Broca, caracterizada por mutismo, estereotipias verbais e agramatismos estavam associados a lesões mais extensas, envolvendo, além da área de Broca, opérculo, ínsula e córtex adjacente suprido pela divisão superior da artéria cerebral média esquerda.

Inúmeras observações demonstram que, nos quadros de afasias, alguns achados não podem ser explicados pelo modelo tradicional. Pacientes com afasia de Broca podiam apresentar leves déficits de compreensão de sentenças. Além disso são encontrados diversos tipos de erros parafásicos distribuídos entre os diferentes tipos de afasia e podem ser encontradom agramatismo isolado e afasia anômica isolada, entre outros.

As síndromes clínicas de afasias são compreendidas atualmente como uma combinação variável de sintomas. A maneira como estes sintomas se agrupam ou se dissociam não pode ser explicado por síndromes homogêneas. Isto sugere que o comprometimento da função de linguagem muitas vezes se dá em um sistema representacional ou na conexão entre estes sistemas, cuja arquitetura interna é complexa e multidimensional (Poeppel e Hickok, 2004).

Finalmente, os subsistemas linguísticos por sua vez não conseguem se encaixar de modo muito especificado no modelo tradicional de WLG. Segundo este modelo a linguagem é simplesmente fracionada em expressão (produção) e recepção (compreensão). Os subsistemas linguísticos, mais recentemente classificados nos domínios sintaxe, semântica e fonológico, parecem ter rica estrutura interna, com numerosos sub-componentes e formas alternativas de se inter-relacionar (Poeppel e Hickok, 2004).

Nos últimos anos, novos métodos para avaliação de linguagem, como a RMf, estudando populações de indivíduos saudáveis têm trazido grandes contribuições para melhor entendimento da organização cerebral de linguagem, indo além do modelo tradicional, lesional. 


\subsection{Lateralidade de linguagem: Princípios gerais}

A linguagem é lateralizada no hemisfério cerebral esquerdo, mas pode, ocasionalmente, ser encontrada no hemisfério direito. Os fatores que influenciam a especialização hemisférica nas funções de linguagem não são completamente compreendidos.

A dominância hemisférica de linguagem pode ser determinada estudando comprometimento de linguagem em populações saudáveis após lesão cerebral aguda, como acidente vascular cerebral (AVC). Esta pode também ser avaliada com métodos diagnóstico invasivos, como o teste de Wada e, mais recentemente, não invasivos, como a RMf.

Um dos fatores associados à dominância de linguagem é a dominância manual. Desde a descrição de Paul Broca no século XIX de dominância de linguagem à esquerda em destros, especula-se que o reverso: dominância de linguagem à direita em sinistros, pode ser verdadeiro. Este fato tem sido amplamente aceito como "a regra de Broca", embora Broca nunca tivesse explicitamente postulado tal afirmação (Harris, 1993).

A dominância hemisférica de linguagem à esquerda foi confirmada em estudos com populações de indivíduos saudáveis. Avaliando lateralização de linguagem por RMf, observa-se em diferentes estudos que cerca de $95 \%$ dos indivíduos destros apresentam dominância de linguagem à esquerda (Springer et al; 1999; Pujol et al; 1999; Knecht et al; 2000).

A prevalência de linguagem à direita ou bilateral em indivíduos sinistros foi também claramente demonstrada por estudo com RMf (Szaflarski et al; 2002). A prevalência de lateralização atípica de linguagem em indivíduos saudáveis com dominância manual à esquerda ou ambidestros é maior que nos indivíduos destros (22\% versus 4-6\%). Neste estudo, associações observadas entre dominância manual, lateralidade hemisférica de linguagem e história familiar de dominância manual podem indicar um fator genético comum subjacente à herança de dominância manual e lateralidade de linguagem (dominância genética). 
Estudos em populações de pacientes neurológicos, utilizando teste de Wada, mostram uma maior prevalência de dominância manual esquerda e dominância de linguagem à direita (Rasmussen e Mllner, 1977; Loring et al; 1990; Vargha-Khadem et al; 1985; Woods et al; 1988). Nestes casos a dominância manual à esquerda é descrita como dominância patológica, isto é poderia estar associada à migração de linguagem para o outro hemisfério após lesões hemisféricas à esquerda que ocorreram numa fase precoce do desenvolvimento.

A variabilidade observada na dominância manual e na dominância de linguagem indica que existem graus de liberdade com os quais o cérebro pode fundamentar a localização da linguagem. Compreender melhor quais os fatores associados à lateralização e quais as limitações à reorganização cerebral de linguagem tem fundamental importância para definição do prognóstico póscirúrgico e para programação de estratégias de reabilitação (Knecht, 2000).

A avaliação de dominância de linguagem tem sido indicada na fase préoperatória de indivíduos que serão submetidos à ressecções nas vizinhanças de áreas de linguagem. Esta abordagem é especialmente utilizada na cirurgia de epilepsia, auxiliando no planejamento de ressecções mais ou menos extensas de acordo com o risco de declínio pós-operatório de linguagem.

\subsection{Métodos diagnósticos de localização e lateralização de linguagem}

\subsubsection{Teste de Wada e outros métodos para lateralização linguagem}

Além da observação de indivíduos com lesão cerebral aguda, grande parte do conhecimento sobre dominância de linguagem é proveniente de estudos com métodos diagnósticos invasivos para localização e lateralização de linguagem, como a estimulação elétrica cortical (EEC) e o teste de Wada. 
Devido à natureza invasiva destes procedimentos, sua indicação ocorre apenas em populações de indivíduos com doença neurológica. Portanto o conhecimento sobre localização e dominância hemisférica de linguagem, antes do uso de métodos não invasivos, advém de estudos nestas populações.

A EEC é considerada o método padrão-ouro para mapeamento de linguagem e é utilizada desde a década de 1930. Para testar funções de linguagem é necessário que o paciente permaneça acordado e capaz de realizar tarefas como contar e nomear objetos. A craniotomia emprega combinação de anestésico local e anestésico geral de curta duração. Após a abertura da dura-máter, é possível regular a sedação de modo que o paciente possa cooperar com os testes. Durante a estimulação cortical solicita-se ao paciente que conte números ou nomeie objetos enquanto o neurocirurgião estimula a superfície cortical. Áreas que, quando estimuladas, produzem afasia são consideradas essenciais para a função de linguagem. Apesar da excelente resolução espacial, a principal limitação deste método é a necessidade de craniotomia para expor a lesão e as áreas adjacentes que podem ser lesadas durante a ressecção. A EEC, por definição,, não pode ser realizada em avaliação pré-operatória. A EEC não está disponível em muitos centros, pois requer treinamento específico da equipe envolvida. Esta técnica também requer ampla cooperação do paciente, o que nem sempre é possível. Finalmente, a técnica é limitada pela dificuldade em examinar a profundidade dos sulcos (cerca de $2 / 3$ da superfície cortical), assim como estruturas profundas como o lobo temporal mesial e estruturas distantes da região estimulada (Tharin e Golby, 2007).

Nos casos em que a EEC não está indicada, como por exemplo na avaliação de linguagem pré-operatória, o teste de Wada permite determinar a dominância hemisférica de linguagem. O teste de Wada é um método diagnóstico invasivo, durante o qual a atividade em um dos hemisférios cerebrais é temporariamente suprimida após cateterização e infusão de anestésico em uma das carótidas (Wada, 1949). O anestésico utilizado é o amobarbital, e, mais recentemente, o etomidato (Passarelli et al; 2014). O método para determinar a dominância de linguagem com este teste é variável, podendo ser utilizados critérios subjetivos (avaliação clínica de linguagem) ou objetivos 
(escala de pontos e cálculo de índice de lateralidade a partir da quantidade de acertos para cada hemisfério).

Devido à longa experiência com este método, o teste de Wada é considerado como padrão-ouro para a lateralização hemisférica de linguagem. Com a implementação crescente de novos métodos de avaliação préoperatória de linguagem, alguns autores já se referem ao teste de Wada como um método em declínio (Baxendale, 2009).

As principais limitações do método são a falta de padronização entre os centros e a natureza invasiva do procedimento. Os protocolos utilizados não são padronizados entre os serviços, não sendo definidos de forma homogênea os aspectos de linguagem testados, os estímulos utilizados, a maneira de pontuar 0 desempenho e tampouco o ponto de corte para determinação de lateralidade atípica. A arteriografia cerebral pode apresentar taxas de complicações de mais de $3 \%$ em alguns serviços. Estas complicações variam desde acidentes vasculares cerebrais, sangramento no local de punção, dissecção arterial e reação alérgica ao contraste (Loddenkemper, 2008). Além disso, o curto período de tempo disponível para a realização dos testes durante o efeito do anestésico e o risco de sedação excessiva podem limitar a validade dos testes (Baxendale, 2009). Tecnicamente, o teste pode ser difícil de interpretar se houver passagem de anestésico para o outro hemisfério, por variações anatômicas de fluxo arterial. Em termos de lateralização da função do lobo temporal mesial, em grande parte dos indivíduos esta região não é suprida pela artéria carótida interna. Portanto a inibição da função do lobo temporal mesial parece ocorrer de modo indireto e pode ser incompleta (Tharin e Golby, 2007).

O teste de Wada, ao avaliar a função de linguagem para todo 0 hemisfério, não permite acessar a contribuição de regiões específicas para o processamento de linguagem (Seghier et al; 2011).

Do ponto de vista teórico, a contribuição do teste de Wada para melhor compreensão da organização normal de linguagem é limitada, uma vez que o teste tem baixa resolução espacial (fornece apenas o dado referente ao hemisfério) e não costuma ser indicado na ausência de lesão estrutural.

Considerando as limitações da EEC e do teste de Wada, o surgimento de métodos não invasivos para avaliação de linguagem, como o PET (pósitron 
emission tomographic) cerebral e a RMf, nas últimas duas décadas tem sido motivo de grande interesse científico e de grande número de publicações.

O PET cerebral merece destaque entre os métodos não invasivos por ser um dos primeiros métodos utilizados na avaliação funcional de linguagem. O PET é um método diagnóstico que cria imagens tridimensionais e tomográficas da distribuição de radiofármacos emissores de pósitrons nos diferentes órgãos e tecidos. Durante o exame de FDG-PET, flúor radioativo ligado a glicose é administrado ao paciente. As regiões que apresentarem maior metabolismo captarão mais glicose que as demais. A captação da glicose ligada ao marcador radioativo no momento em que o paciente realiza uma tarefa comportamental é comparada com aquela obtida em uma situação controle, criando mapas funcionais. A especificidade da imagem de PET depende do desenho e implementação da tarefa comportamental e da tarefa controle. As desvantagens do PET incluem: resolução espacial moderada de no máximo $4 \mathrm{~mm}$ e baixa resolução temporal, já que existe atraso do tempo entre o momento da realização da tarefa e o momento da captação da glicose pela célula. O PET é relativamente invasivo uma vez que o exame envolve a administração de um marcador radioativo, o que limita o número de estudos para um mesmo indivíduo e exclui populações específicas como crianças e gestantes. Além disso é um método de alto custo, que exige equipe dedicada e, idealmente, um aparelho ciclotron para produzir os marcadores (Tharin e Golby, 2007).

A RMf constitui o método não invasivo mais amplamente utilizado, podendo ser indicado principalmente para lateralização de linguagem. Muitos serviços já utilizam este recurso como parte do protocolo de avaliação pré-operatória de linguagem, em substituição ao teste de Wada (Abou-Khalil, 2007).

Descrevemos, a seguir, os princípios gerais da técnica de RM funcional e aspectos específicos da RMf de linguagem. 


\subsubsection{RMf de linguagem}

\subsubsection{Princípios gerais de RMf}

RMf é um método útil para o estudo de funções cognitivas. A obtenção de imagens de RMf baseia-se na observação bem estabelecida de que o aumento da atividade neuronal associa-se a aumento de fluxo sanguíneo cerebral regional, que ocorre de modo finamente regulado. $\mathrm{O}$ aumento do fluxo sanguíneo regional, por sua vez, aumenta a taxa local de oxi-hemoglobina/ desoxi-hemoglobina (oxi-Hb/desoxi-Hb). A razão pela qual ocorre esta hiperperfusao de luxo, que leva a taxa de oxi-Hb a superar a taxa de desoxi-Hb no local em que a atividade neuronal aumenta, não é completamente compreendida. Algumas teorias sugerem que esta seria uma maneira de prover uma reserva antecipada para a atividade neural, um gradiente necessário para a liberação de oxigênio para os substratos neurais ou um meio de clarear produtos tóxicos (Moonen et al; 2000). O efeito final da excitação neuronal é, então, uma queda paradoxal na concentração de desoxi-hemoglobina, o que, por sua vez, aumenta a intensidade do sinal (Logothetis, 2008).

O aumento da intensidade do sinal ocorre porque o sinal BOLD (Blood Oxigenation Level Dependent) é um sinal sensível a alterações da homogeneidade do campo magnético. Ogawa et al (1990) demonstraram que o contraste BOLD (blood oxygen level dependent) é um contraste endógeno que reflete as características magnéticas da hemoglobina, dependente de seu nível de concentração de oxigênio. A oxi-hemoglobina (oxi-Hb) é diamagnética, ou seja, não causa distorções no campo magnético e a desoxi-hemoglobina (desoxi-Hb), é paramagnética, distorcendo o campo magnético, reduzindo o sinal BOLD detectado pela máquina.

Durante o estudo de RMf as imagens obtidas sensíveis ao contraste BOLD, são colhidas enquanto o indivíduo realiza uma tarefa experimental. A tarefa experimental, que ocorre sincronizada com a coleta das imagens, intercala no mínimo duas condições, a condição ativa, momento em que o indivíduo realiza determinada tarefa, e a condição controle, momento em que o indivíduo não realiza a tarefa. 
O conjunto destes diferentes estados mentais que se intercalam ao longo da coleta de imagens é chamado de paradigma (Gaillard, 2004). O paradigma pode ser apresentado de acordo com dois modelos principais: em bloco ou relacionado a eventos. No paradigma em bloco, os indivíduos intercalam blocos de condição ativa com blocos de condição controle. No paradigma relacionado a eventos, a realização de uma única condição ativa é comparada à condição controle.

O desenho do paradigma é parte fundamental do planejamento de qualquer avaliação por RMf. O contraste entre as duas condições deve ser suficiente para evocar uma resposta hemodinâmica. O paradigma deve ser realizado de forma que este contraste entre a condição ativa e a condição controle seja justamente o aspecto do processamento cognitivo que se deseja estudar, garantindo a especificidade das variações do sinal BOLD que forem encontradas. Além disto, o pesquisador deve garantir que o participante seja capaz de compreender e realizar adequadamente as tarefas.

As mudanças de sinal BOLD que ocorrem ao longo da realização das tarefas são, no entanto, transitórias e de ordem muito pequena, muitas vezes podendo ser confundidas com o ruído do aparelho. Essa é a razão pela qual, ao se desenhar um estudo experimental, um número grande de imagens é colhida ao longo do tempo, alternando-se momentos de maior e menor aporte de oxigênio ao tecido (condição ativa versus condição controle) com o objetivo de que seja possível aplicar testes estatísticos para verificar se a mudança de sinal BOLD encontrada é significativa (Huettel et al; 2008).

Para a análise dos dados a nível individual (first level analysis), vários métodos estatísticos podem ser aplicados. Os tempos em que os estímulos são aplicados (efeitos) ao longo do experimento são utilizados para se construir um modelo do dado (design matrix). O conjunto dos efeitos que serão modelados ao longo do experimento é chamado de evento. Em um modelo, mais de um evento pode ser avaliado para o mesmo experimento (se for utilizado mais de um contraste (p. ex. evento 1: condição ativa 1>condição controle + evento 2: condição ativa 2 > condição controle).

O modelo do dado passa por alguns ajustes que leva em consideração a maneira como a resposta hemodinâmica se comporta durante determinada atividade neural. A resposta hemodinâmica, desencadeada após um estímulo e 
que, em última instância, resultará num maior sinal BOLD, não ocorre exatamente no mesmo momento em que o estímulo é aplicado ao paciente. Após a estimulação, ocorre um aumento gradual do sinal BOLD, que pode ser precedido por uma pequena queda inicial, que atinge o ápice por volta de seis segundos, e é seguido por um declínio até a linha de base, com duração de aproximadamente 10s, podendo cair ainda mais para um período de negativação que pode variar de 10-15s, até se estabilizar (Friston et al; 2007). Portanto, o modelo do dado deve ser ajustado ao modelo da resposta hemodinâmica. A função resposta hemodinâmica canônica é a função matemática que irá modelar o comportamento do sinal BOLD.

Vários métodos estatísticos visam a determinar a significância da mudança de sinal entre a condição ativa e a condição controle em dado voxel. O modelo de regressão linear (do inglês, general linear model, GLM) é um método estatístico bastante utilizado. Este método baseia-se em ajustar a função de resposta hemodinâmica obtida durante a realização de cada tarefa, com a função de resposta hemodinâmica canônica e descrever as variações de intensidade de sinal (sinal durante condição ativa versus sinal durante condição controle) de cada voxel a partir das condições experimentais de interesse (Huettel et al; 2008).

Um bom acoplamento entre o modelo do experimento e o dado obtido para aquele voxel ao longo do tempo significa que o dado foi provavelmente causado pelo estímulo. A ideia é encontrar a combinação linear de eventos que mais se aproxima do curso de variação do dado obtido ao longo do tempo (Figura 1).

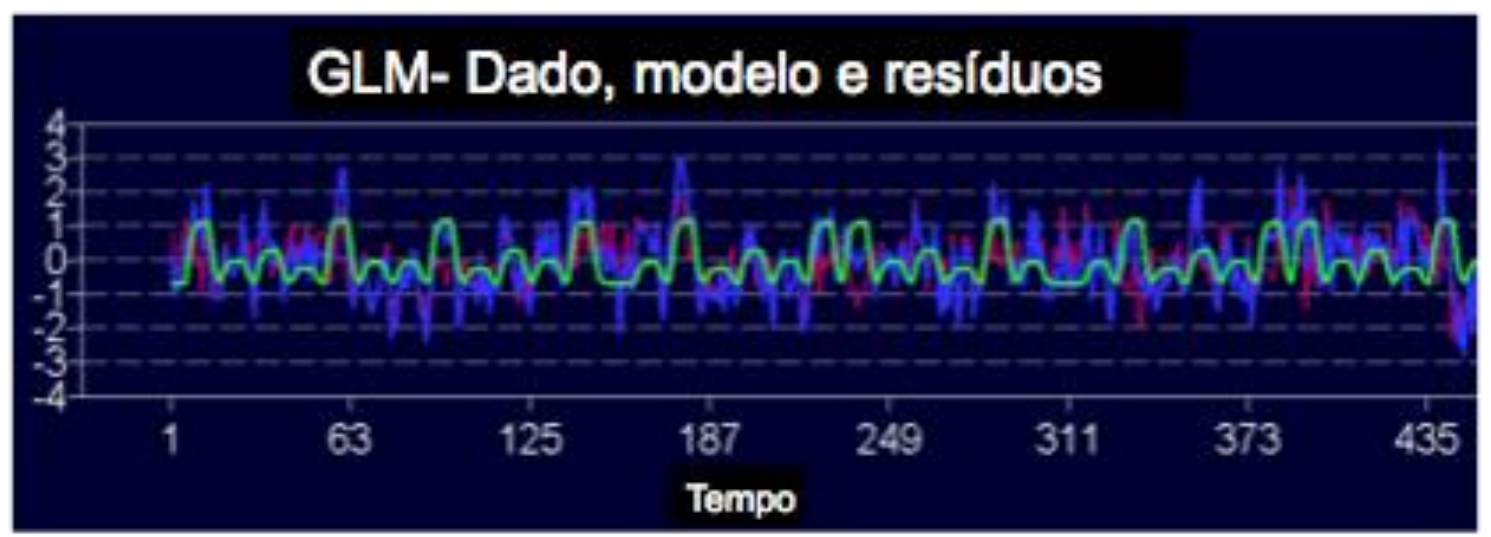

Figura 1. General Linear Model e variação do dado ao longo do tempo para um dado voxel. Em azul, variação do dado original (variação do sinal BOLD); em vermelho, resíduos (erro); em verde, variação dos eventos no modelo experimental 
Através do GLM, para cada evento é calculado um valor de beta ou estimativa paramétrica (PE: parameter estimate). Esse valor indica o quanto a combinação linear de eventos (variação do modelo) está acoplada à variação do dado ao longo tempo que foi obtida para aquele voxel. Após este processamento é gerada uma imagem "PE', além de uma imagem "COPE" (combinação linear de estimativas paramétricas), sendo COPE1, COPE 2 e assim por diante, a depender do número de eventos avaliados. Cada imagem COPE é acompanhada por uma imagem VARCOPE que incorpora os valores do erro-padrão, relacionados ao ruído.

Mapas de ativação são também gerados, baseados nos valores estatísticos t, p ou z, calculados automaticamente por um software.

Finalmente, alguns passos são ainda muito importantes na fase de préprocessamento das imagens. A fase chamada de pré-processamento das imagens visa a eliminar ou reduzir os sinais produzidos por artefatos de movimentos, corrigir o tempo de aquisição entre diferentes fatias e aplicar filtros espaciais. Esta fase é crítica porque tem como objetivo evitar que estes parâmetros sejam interpretados erroneamente como variações do sinal BOLD. Durante a aquisição das imagens, mesmo após treinamento e após a fixação da cabeça, algum grau de movimentação do participante pode ocorrer. A correção de movimento realinha as imagens a pontos de referência comuns, assegurando que cada voxel corresponda a cada ponto anatômico esperado, para cada ponto do tempo. Uma correção é aplicada baseada na estimativa do índice de movimento de rotação e translação ao longo do experimento. Esta estimativa é calculada para cada volume, tendo o primeiro volume da série como referência, de modo a tornar alinhados todos os volumes adquiridos. A correção de tempo de aquisição entre as fatias tem como objetivo alinhar todas as séries temporais, levando em conta o tempo de defasagem na aquisição entre as fatias de um mesmo volume. A aplicação de filtro espacial visa aumentar a relação sinal-ruído das imagens, minimizando a influência de ruídos fisiológicos não associados ao efeito BOLD e ruídos do equipamento (Huettel et al; 2008).

Após realizada a análise no nível individual (first level analysis), é realizada a análise de segundo nível (higher level analysis). Nesta fase são 
gerados mapas de ativação para um dado grupo de sujeitos, considerando-se a média de ativação para todos os indivíduos do grupo, para determinado contraste de interesse. Nesta fase podem ser gerados ainda mapas de ativação de grupo resultantes de comparações entre grupos, ou seja, mapas que mostram diferenças nas ativações cerebrais entre grupos.

\subsubsection{Lateralização de linguagem por RMf}

No exame de RMf, os resultados das ativações obtidas para cada voxel podem ser expressos na forma de um valor único, ou índice de lateralidade (IL), que pode ser obtido utilizando-se diferentes metodologias. A obtenção do IL com a RMf (IL-RMf) permite a comparação com o teste de Wada. Elevadas taxas de concordância entre o IL-RMf e o IL obtido através do teste de Wada (IL-Wada) têm sido publicadas, permitindo a validação do método de RMf para uso clínico.

Desmond et al (1995) mostraram que a dominância de linguagem por RMf foi concordante com o teste de Wada para sete pacientes com diagnóstico de epilepsia refratária do lobo temporal. Neste estudo foi considerado dominante o hemisfério que mostrou aumento da ativação no GFI durante tarefa de decisão semântica a partir de estímulo visual.

No ano seguinte, Binder et al (1996) encontraram altas taxas de concordância entre o IL-RMf e IL-Wada ( $r=0.96$; $95 \%$ CIS 0.90 to 0.98 ; $\mathrm{p}<0.0001)$. Neste estudo foram avaliados 22 pacientes com diagnóstico de epilepsia refratária provavelmente focal, de diversas etiologias. O IL-RMf foi obtido considerando o número de voxels ativados (acima de um limiar prédeterminado) para cada hemisfério, utilizando um paradigma de decisão semântica a partir de estímulo auditivo.

Recentemente, este grupo publicou um estudo comparativo IL-RMf versus IL-Wada com o maior número de pacientes até o momento $(n=229)$. Os autores, utilizando o mesmo paradigma do estudo anterior e cálculo de IL dependente de limiar, mostraram concordância de 86\% entre IL-Wada e IL-RMf (Janecek, 2013). 
Nesta publicação, os resultados das mais de duas dezenas de estudos comparativos entre lateralidade de linguagem por RMf versus lateralidade por teste de Wada foram revisados. Em média, a taxa de concordância entre os dois métodos, considerando todos os estudos, foi de $85 \%$. Excetuando-se um estudo (Binder, 1996), todos os demais estudos que mostraram 0\% de discordância tinham menos de 8 participantes (Desmond et al; 1995, Bahn et al; 1997; Hertz-Panier et al; 1997; Baciu et al; 2005; Liegois, 2002).

Os preditores de discordância, no estudo com 229 pacientes, foram presença de linguagem bilateral na RMf (57\% de discordância) e linguagem bilateral no teste de Wada (40\% de discordância). A lateralidade na RMf foi o mais forte preditor de discordância entre os métodos, sendo maior a discordância quanto menor o IL-RMf (menor lateralização à esquerda). Uma possível explicação para este achado é a de que a RMf parece ser mais sensível que o teste de Wada para mostrar processamento de linguagem à direita. Em alguns pacientes com representação parcial de linguagem à direita, o componente de linguagem no hemisfério direito pode ser incapaz de sustentar minimamente o desempenho de linguagem quando o hemisfério esquerdo é anestesiado, fazendo com que o paciente pareça completamente lateralizado à esquerda no teste de Wada. Nesta mesma revisão, a presença de discordância extrema, definida como lateralidade de linguagem oposta nos dois testes, foi identificada em quatro pacientes. Todos os pacientes eram destros e apresentavam foco epiléptico à direita. Em um deles observou-se baixa ativação hemisférica durante a RMf como possível fator de discordância, já que o IL-RMf dependeria de uma quantidade muito pequena de voxels ativados. Outro mecanismo aventado para explicar a discordância entre os testes é a presença de dissociação inter-hemisférica de linguagem.

A dissociação inter-hemisférica de linguagem é mostrada em 3\% dos casos de avaliação de linguagem por RMf. Nestes casos, a lateralidade de linguagem para a região frontal pode ser diferente daquela para a região temporal (Kurthen et al; 1992).

A avaliação regional (e não hemisférica) de lateralidade de linguagem, representa uma vantagem da RMf sobre o teste de Wada. Diferentes regiões podem estar mais ou menos propensas a distribuição atípica de linguagem, 
sendo grande a possibilidade de diferentes combinações de dominância regional nos pacientes com lateralidade atípica de linguagem. A dissociação da lateralidade de linguagem é descrita quando diferentes lateralidades são encontradas para diferentes regiões (geralmente frontais e temporais) no mesmo indivíduo.

Em população de pacientes com epilepsia foi demonstrado que a dominância manual à esquerda associa-se a dominância atípica de linguagem para o GFI, mas não para o GTS. Este fato poderia ser explicado pela maior proximidade do GFI ao córtex motor primário. Variações regionais da lateralidade de linguagem parecem ainda estar associadas ao processo fisiopatológico subjacente (Berl et al; 2014).

Finalmente, ao longo desta fase de validação da RMf, o aspecto metodológico utilizado para obtenção do IL tem sido motivo de intenso debate.

Na literatura clássica sobre lateralização de linguagem por RMf, a maioria dos estudos utilizava para o cálculo de IL os voxels (número de voxels ou escore $t / z$ do voxel) sobreviventes a determinado limiar em cada hemisfério cerebral. Este cálculo tradicional de IL apresenta inúmeras limitações, desde não considerar variações regionais, mostrar grande vulnerabilidade a outliers estatísticos e, principalmente, estar sujeito ao efeito do limiar utilizado. A depender do limiar, escolhido arbitrariamente, o índice de lateralidade obtido é capaz de classificar o mesmo paciente como típico ou atípico para linguagem (Nagata et al; 2001). Assim, métodos alternativos independentes de limiar estatístico têm sido sugeridos (Nagata et al; 2001; Suarez et al; 2009).

Em 2007, considerando a necessidade de se desenvolver um método reprodutível e tecnicamente robusto para cálculo do IL, implementou-se a chamada LI-Tool (Wilke e Lizdba, 2007).

Com este recurso, a lateralização pode ser calculada após diversos passos de processamento que visam a aumentar a confiabilidade $e$ reprodutibilidade do IL. Para calcular o IL de modo independente de limiar, o método estatístico utilizado na Toolbox é a técnica de bootstrap. Este método permite a construção de um histograma composto pelos valores de IL obtidos após diversas reamostragens dos voxels ativados e para um grande espectro de limiares estatísticos. A LI-Tool permite ainda conferir um maior peso a 
voxels sobreviventes a limiares mais altos (weighted) e com mais voxels ativos ao seu redor (clustering), o que reduz o efeito de voxels outliers sobre o valor do IL final. Este método permite ainda o cálculo para múltiplas regiões de interesse pré-definidas.

\subsubsection{Paradigmas de linguagem}

A tarefa classicamente utilizada nos primeiros estudos de RMf com 0 objetivo de lateralizar linguagem é a de geração de palavras. Este paradigma promove robusta ativação do GFI e giro frontal médio (GFM) à esquerda (Palmer et al; 2001).

Está bem estabelecido que tarefas que incluem um componente semântico ativam de modo robusto áreas de linguagem no lobo temporal (Springer et al; 1999).

Nos últimos anos o paradigma de decisão semântica por estímulo auditivo tem sido utilizado com frequência por ser um paradigma para o qual se demonstrou ativação robusta de áreas de linguagem frontais e temporais. $O$ seu uso foi consolidado principalmente após demonstração de que, utilizando este paradigma, a presença de lateralização temporal à esquerda associa-se com pior prognóstico de memória verbal no pós-operatório (Binder et al; 2008).

No entanto, deve ser considerado que as provas mais utilizadas na prática clínica, com boa sensibilidade para detectar déficits de linguagem, sobretudo em populações de pacientes com epilepsia do lobo temporal, são provas de nomeação. O paradigma de nomeação responsiva à leitura mostrouse eficaz em ativar de modo robusto áreas temporais e frontais de linguagem (Gaillard et al; 2002). Esta tarefa é particularmente interessante em RMf de linguagem em estudos com indivíduos com EMT uma vez que, é demonstrado que o desempenho em provas de nomeação se encontra comprometido nesta população (Bell e Davies, 1998).

Ao elaborar o paradigma, a condição controle deve reproduzir o processamento sensorial primário, de decisão ou a resposta motora utilizada na condição ativa. Para a tarefa de nomeação responsiva à leitura a condição 
controle deve conter símbolos, fontes falsas ou pseudo-palavras com apresentação visual semelhante à condição ativa (Gaillard, 2004).

Em muitos paradigmas clássicos para lateralização de linguagem em RMf os sujeitos são instruídos a responder ( $p$ ex. gerar palavras) apenas mentalmente (covert). Paradigmas que possibilitam a monitorização da resposta do paciente (overt) apresentam a vantagem de avaliar o grau de engajamento do sujeito durante a tarefa. Paradigmas com respostas orais promovem padrões robustos de localização e lateralização. É importante que nesta situação seja garantido que não houve artefato de imagem por movimentação excessiva da cabeça (Konrad et al; 2012).

\subsection{Modelo anatômico-funcional de linguagem}

\subsubsection{Construção do modelo anatômico funcional}

Ao longo dos últimos 20 anos, muitos estudos de RMf e PET de linguagem tem foram publicados, acrescentando novas informações anatômicas ao modelo clássico de WLG.

As conclusões destas muitas centenas de artigos foram recentemente revisadas e agrupadas de acordo com o aspecto de linguagem estudado (Price, 2012). Nesta extensa revisão, a autora descreveu os padrões de ativação cerebral encontrados durante a realização de diferentes tarefas ou processamentos de linguagem em populações de indivíduos saudáveis.

Os termos utilizados nos diferentes estudos para descrever os aspectos funcionais e anatômicos foram minimamente ajustados, buscando uniformizar a nomenclatura para a mesma região anatômica (por exemplo, considerando intercambiáveis os termos pars opercularis, área de Broca, GFI e BA44). As áreas cerebrais que, de modo consistente, nos diferentes estudos, foram associadas ao processamento da compreensão e produção da linguagem falada e escrita foram organizadas em um modelo anatômico e funcional. 
De acordo com este modelo, alguns processos estão localizados em estruturas específicas, (p. ex o processamento motor da fala), enquanto outros envolvem um padrão de ativação distribuído em múltiplas áreas. Cada área, por sua vez, pode estar associada a múltiplas funções.

Hipóteses acerca das conexões existentes entre estas regiões não são contempladas no modelo, sendo objeto de intensa pesquisa até os dias atuais.

\subsubsection{Regiões anatômicas ativadas em tarefas de linguagem a partir de estímulos visuais}

Tendo como referência o modelo sugerido por Price (2012), os aspectos anatômicos/funcionais relacionados ao processamento de linguagem a partir da leitura até a nomeação da palavra descrita podem ser identificados. As referências bibliográficas, detalhando aspectos metodológicos utilizados para cada afirmação em particular podem ser encontradas consultando a metaanálise original.

A região cerebral ativada especificamente durante a leitura de palavras é a região ventral ao longo do sulco occipitotemporal esquerdo (também referida como porção medial do giro fusiforme), A porção mais posterior relaciona-se à extração das características visuais e a região mais anterior, ao processamento léxico-semântico da palavra escrita.

A via relacionada à conversão da informação lexical (ortográfica) em informação semântica (significado) compreende a região ventral do córtex occipitotemporal esquerdo e o GFI esquerdo. O GFI e, de modo menos consistente, o GFS, as porções mais anteriores do giro temporal inferior (GTI), médio (GTM) e GTS estão envolvidas com o acesso ao conteúdo semântico. À medida que a dificuldade da tarefa aumenta, ocorre envolvimento crescente das porções mais posteriores dos giros temporais.

A recuperação da palavra a partir de um conceito e a conexão entre o processamento semântico e o plano articulatório envolve o GFM e regiões posteriores do GTM e do GTI esquerdos. O GFI associa-se ao plano articulatório e produção da fala. 


\subsection{Linguagem e epilepsia do lobo temporal (ELT)}

\subsubsection{Distúrbios de linguagem em pacientes com ELT}

A epilepsia do lobo temporal (ELT) é a causa mais frequente de epilepsia com crises focais em adultos. A ELT compreende um grupo heterogêneo de doenças cuja principal característica é a presença de crises que se originam no lobo temporal mesial ou lateral, de etiologia, idade de início, prognóstico e resposta ao tratamento médico e cirúrgico diversos. Dentre as causas de ELT estão a esclerose mesial temporal, lesões estruturais do lobo temporal secundárias a tumores benignos e malignos, doenças infecciosas, doença cerebrovascular, auto-imune, malformações do desenvolvimento cortical e trauma, além de formas hereditárias.

Em 1980, Mayeux e colaboradores demonstraram pela primeira vez a existência de acentuado prejuízo de nomeação por confrontação visual em pacientes com ELT esquerda. Estes autores demonstraram relação entre o desempenho nos testes de inteligência verbal, aprendizado e memória com o desempenho nos testes de nomeação. Desde então, ao se avaliar as funções de memória verbal, o déficit de nomeação deve ser levado em consideração como um fator confundidor na avaliação de memória. Atualmente, tanto o risco de declínio de nomeação pós operatório quanto o desempenho nos testes de nomeação por confrontação visual são incluídos na avaliação neuropsicológica da maioria dos programas de tratamento de epilepsia (Mayeux et al; 1980; Busch et al; 2013).

Muitos estudos corroboram esta afirmação, encontrando déficits de nomeação em mais de $40 \%$ dos pacientes com epilepsia do lobo temporal esquerdo ou bilateral (Bell et al; 2003; Loring et al; 1994). Cerca de 1/3 dos pacientes com epilepsia do lobo temporal esquerda refratária relatam dificuldades graves na vida diária para encontrar palavras durante a fala espontânea (Lomlomdjian, 2011).

Em tarefas de nomeação os pacientes gastam mais tempo para encontrar palavras. Mesmo quando a palavra alvo é identificada e semanticamente 
acessada, existe uma dificuldade no acesso lexical (palavra na ponta da língua) que não se beneficia muito com pistas fonéticas. As dificuldades em encontrar palavras nestes pacientes classicamente são avaliadas com testes de nomeação por confrontação visual. É bem demonstrado que tarefas que utilizam definições (nomeação responsiva) se mostraram mais sensíveis que tarefas de nomeação por confrontação visual para detectar déficits préoperatórios de linguagem em pacientes com ELT esquerda (Bell et al; 2003; Hamberger et al; 2003).

O comprometimento de linguagem e os fatores associados a este achado em ELT podem ser analisados em estudos que comparam o desempenho pré e pós-operatório de linguagem destes pacientes. A ressecção do lobo temporal esquerdo para tratamento de ELT associa-se a declínio de linguagem no pós-operatório. Estudo avaliando 24 pacientes com epilepsia não-lesional mostrou queda no desempenho no teste de nomeação de Boston após ressecção do lobo temporal esquerdo. O fator associado a maior declínio no desempenho foi idade mais tardia de início da epilepsia (Davies et al; 2005)

Outro estudo com série de casos de 59 pacientes foi realizado para determinar a prevalência ou exacerbação de baixo desempenho na tarefa de nomeação responsiva após lobectomia temporal anterior e identificar os preditores de declínio. Observou-se exacerbação significativa da dificuldade em encontrar palavras, persistente após um ano da cirurgia em $25 \%$ dos pacientes submetidos a ressecção temporal anterior esquerda. Esta dificuldade foi pior em pacientes que apresentavam dominância de linguagem à esquerda, maior idade no momento da avaliação e para aqueles cuja avaliação havia sido realizada antes de um ano após a cirurgia (Langfitt, 1996).

Pacientes com ELT direito também parecem apresentar algum grau de comprometimento de linguagem. Em uma meta-análise recente, (Doering e Trinka, 2014) foram selecionados 31 estudos que realizaram avaliação interictal de linguagem em pacientes com epilepsia, incluindo pelo menos duas modalidades diferentes de linguagem. A maioria das publicações selecionadas avaliou o desempenho de pacientes com epilepsia do lobo temporal principalmente em tarefas de nomeação. De 28 estudos, 9 encontraram pior desempenho entre pacientes com epilepsia do lobo temporal esquerdo em relação àqueles com epilepsia do lobo temporal direito. No entanto, 11 estudos 
não encontraram qualquer diferença entre ambos os grupos. Comparando os resultados individuais de cada paciente em cada estudo com dados normativos, notou-se que $55 \%$ dos pacientes com ELT esquerdo e $36 \%$ dos pacientes com ELT direito apresentaram significativo déficit de nomeação por confrontação visual.

Embora estes estudos avaliados sejam muito heterogêneos em relação ao número de testes de linguagem, seleção de pacientes e controles e apresentação dos resultados, pelo menos $17 \%$ dos pacientes com ELTE apresentaram déficits em mais de uma modalidade de linguagem, sendo nomeação, compreensão de leitura, fala espontânea e produção de discurso as funções mais frequentemente afetadas.

Em sua grande maioria, os estudos de linguagem em ELT avaliam populações de pacientes com epilepsia secundária a diversas etiologias, incluindo lesões que acometem estruturas neocorticais ou mesiais do lobo temporal.

Não é surpresa que a linguagem seja comprometida por lesões que acometem as porções anteriores do neocórtex temporal esquerdo, nas vizinhanças do córtex perissilviano. No entanto, a causa mais comum de epilepsia do lobo temporal é a esclerose mesial temporal (EMT), doença caracterizada pelo acometimento de estruturas hipocampais. Os fatores associados a distúrbios de linguagem em pacientes com lesão nas estruturas mesiais temporais não só à esquerda, como também à direita, ainda não são bem compreendidos.

Os estudos que avaliam linguagem em populações homogêneas de pacientes com esclerose mesial temporal são escassos na literatura e serão revistos a seguir.

\subsubsection{Esclerose mesial temporal e linguagem}

EMT é a causa mais comum de epilepsia do lobo temporal. A principal característica histopatológica da esclerose mesial temporal é o padrão de perda neuronal segmentar associada a astrogliose do hipocampo. O hipocampo é uma estrutura que apresenta elevada epileptogenicidade, e que, ao mesmo tempo, é vulnerável a lesões provocadas por crises epilépticas e outros insultos cerebrais. 
O quadro clínico da ELT secundária a EMT é relativamente bem conhecido. As crises epilépticas surgem, em geral, na infância tardia ou na adolescência. É frequente antecedente de insulto precipitante inicial, sendo comum história de convulsão febril na primeira infância ou crise febril complicada (crise prolongada, unilateral ou múltiplas crises em um mesmo episódio febril). Segue-se intervalo livre de crises e, apenas após alguns anos, inicia-se a epilepsia (Engel e Spencer, 1997). O diagnóstico clínico de ELT secundária a EMT requer a presença de uma constelação de sintomas e sinais clínicos (Berg \& Scheffer, 2011).

O quadro típico é caracterizada por crises do lobo temporal mesial, RM de encéfalo mostrando hipersinal em T2, atrofia e perda da arquitetura interna hipocampal, eletrencefalograma mostrando atividade epileptiforme na região temporal e estudo anátomo-patológico compatível com esclerose hipocampal (Blumke et al., 2013). Em aproximadamente 3-19\% dos casos de EMT unilateral, a monitorização com EEG invasivo e não invasivo mostra que o início da atividade epiléptica ictal não é concordante com a lesão estrutural, podendo ser contra-lateral, bilateral ou ambígua (Williamson, 1993).

Pacientes com ELT secundária a EMT apresentam pior desempenho em tarefas de linguagem, sobretudo em testes de nomeação, quando comparados a pacientes com ELT sem EMT (Bell e Davies, 1998).

Estudo realizado em nosso meio incluiu 19 pacientes com EMT unilateral (esquerda ou direita) avaliando desempenho em tarefas de correlação entre figura e palavra, definição de palavras, nomeação por confrontação visual, nomeação responsiva e geração de lista de palavras.

Pacientes com EMT esquerda apresentaram pior desempenho em definição de palavras. Ambos os grupos de pacientes, EMT esquerda e EMT direita apresentaram pior desempenho em testes de nomeação em relação aos indivíduos saudáveis (Messas et al; 2008).

Apesar do grupo de pacientes com EMT esquerda ser o mais estudado, dificuldades de nomeação são descritas em $46 \%$ dos pacientes com esclerose hipocampal independente do lado da zona epileptogênica (Oddo et al; 2003). 
O déficit de linguagem pode se acentuar após o tratamento cirúrgico para epilepsia. Cerca de $25 \%$ dos pacientes com EMT apresentam declínio de nomeação após ressecção do lobo temporal anterior (Davies et al; 1998).

Alguns mecanismos fisiopatológicos são aventados para explicar o déficit de nomeação nos pacientes com ELT secundária a EMT.

Várias evidências apontam para uma conexão funcional e anatômica entre o hipocampo e estruturas temporais neocorticais. Estudos anatômicos mostram que existem projeções hipocampais para o neocórtex temporal via subiculum e córtex entorrinal (Ojemann et al; 1988). Atrofia do lobo temporal extra-hipocampal é descrita em associação a esclerose hipocampal (Moran et al; 2001). Registro de crises epilépticas com eletrodos subdurais e profundos mostram que as crises que se iniciam no hipocampo se propagam para o neocórtex temporal (Spencer et al; 1987).

Uma linha de estudo sugere que a relação do hipocampo com a linguagem se dá através do processamento de memória semântica, como por exemplo, na recuperação de nomes de objetos. Esta teoria é consistente com a hipótese de que a nomeação e definição de palavras aprendidas há menos tempo seriam mais afetadas (Bell et al; 2000). Outra linha discute que os déficits de nomeação em pacientes com EMT estariam associados a dificuldades na recuperação de informações lexicais (Trebuchon et al; 2009). Evidências de estudo com estimulação elétrica cortical indicam que 0 hipocampo estaria diretamente associado ao processamento de nomeação (Hamberger et al; 2007). O hipocampo pode estar associado a processamento de linguagem por funções associativas de alta complexidade. Durante a produção e a compreensão de sentenças ou histórias (seja durante o discurso falado, lido ou ouvido) é necessário que as diferentes representações de tempo, espaço, sintáticas e lexicais que compõem o discurso sejam geradas, reunidas, integradas e mantidas em tempo real (on line). Alguns autores propõem que grande parte do processamento de linguagem que envolve este nível de associações cognitivas necessita do sistema de memória declarativa, papel chave das estruturas hipocampais (Duff e Brown-Schimidt, 2012). 


\subsubsection{Lateralidade atípica de linguagem e ELT/EMT}

A determinação da lateralização de linguagem durante a avaliação clínica pré-operatória é importante em pacientes com epilepsia focal, porque a representação de linguagem pode determinar o prognóstico de declínio de memória verbal e déficit de nomeação pós operatório (Binder et al., 2008; Sabsevitz et al., 2003).

Estudos utilizando teste de Wada mostram maior prevalência de representação atípica de linguagem (bilateral ou direita) em pacientes destros com epilepsia temporal esquerda (4-37\%), particularmente se a epilepsia se desenvolve na infância. A dominância de linguagem parece ser estabelecida em torno dos seis anos de idade e o início da epilepsia no lobo temporal dominante antes desta idade estaria associado a padrões de organização de linguagem mais atípicos, sobretudo em nomeação e leitura (Rasmussen e Milner, 1977; Helmstaedter et al; 1997, Springer et al; 1999).

A localização do foco epiléptico determina diferentes padrões de lateralidade regionais de linguagem. Pacientes com epilepsia frontal são mais propensos a apresentar lateralidade de linguagem atípica para a região frontal, enquanto aqueles com ELT apresentam linguagem atípica tanto para o GFI quanto para o GTS. A duração da epilepsia está associada a lateralidade atípica no GTS (Duke et al; 2012).

Considerando as diversas etiologias nos pacientes com ELT, seria esperado que a frequência de linguagem atípica fosse mais alta em epilepsia temporal lateral. No entanto, isto não é confirmado em estudos com RMf de linguagem. A dominância atípica de linguagem ocorre mais frequentemente em indivíduos com EMT comparados a indivíduos com lesões próximas a áreas de linguagem (Jansky et al; 2003; Weber et al; 2006).

Até o momento, dois estudos avaliaram representação atípica de linguagem com RMf em populações relativamente homogêneas de pacientes com EMT unilateral. Além da idade de ocorrência do insulto no hemisfério cerebral esquerdo, a contribuição de fatores como presença de insulto precipitante inicial, duração da doença, lateralidade das anormalidades 
epileptiformes ictais e interictais para determinar a lateralidade de linguagem neste grupo de pacientes é muito pouco compreendida.

Rathore et al (2009) avaliaram dominância de linguagem em 124 pacientes com EMT esquerda encontrando $20 \%$ de dominância atípica neste grupo. A ocorrência de pelo menos três de quatro fatores: presença de insulto precipitante inicial que não crise febril, início da epilepsia antes dos seis anos de idade, curto intervalo entre o insulto precipitante inicial (IPI) e o início da epilepsia e presença de alterações extra-temporais no EEG estariam associadas a 95\% de chance de lateralização atípica de linguagem. A presença de IPI grave, como meningoencefalite ou estado de mal epiléptico, estaria mais associado a lateralidade atípica. Os autores concluem que a maior prevalência de lateralidade atípica nestes casos dever-se-ia a maior dano extra-hipocampal.

Este estudo avaliou lateralidade de linguagem hemisférica utilizando apenas teste de Wada, não sendo possível acessar variações regionais de modo independente. Pacientes com dominância manual à esquerda não foram excluídos do estudo. Assim nesta situação, a dominância atípica de linguagem pode sofrer efeito de variáveis genéticas. Além disso, foram incluídos pacientes com anormalidades extra-temporais na RM e EEG, sendo possível que outras variáveis patológicas associadas possam ter contribuído para os achados.

Estudo que avaliou 184 pacientes com EMT, também com o teste de Wada, observou que o grupo de pacientes com EMT esquerda apresentou, de forma significativa, dominância atípica de linguagem comparado ao grupo de EMT direita. Além disso, estes autores observaram que a representação atípica de linguagem associou-se não somente à idade de início das crises ou a presença de um insulto precipitante inicial, mas também à frequência da atividade epileptiforme inter-ictal e à presença de auras sensoriais que sugerissem envolvimento de estruturas temporais laterais. Este estudo sugere, portanto, que não apenas fatores estruturais, mas também fatores funcionais (atividade epileptiforme) podem influenciar a lateralização atípica de linguagem nos pacientes com EMT esquerda (Jansky et al; 2003).

Poucos estudos que avaliaram lateralidade de linguagem por RMf para população homogênea de pacientes com EMT foram publicados até o momento. Jansky et al (2006) avaliaram 28 pacientes com EMTE e 11 com EMTD. 
Os autores encontraram associação entre frequência de descargas epileptiformes à esquerda e desvio da linguagem para direita (índices de lateralidade de linguagem menores). Este estudo tem algumas limitações: O paradigma utilizado foi de geração de palavras, que sabidamente produz resposta mais intensa no GFI e menor nas áreas temporais de linguagem. É possível que a lateralidade atípica tenha sido subestimada, já que reorganizações dissociadas de linguagem são descritas em pacientes com epilepsia. Apenas o grupo com EMTD foi utilizado como controle, embora se saiba que estes pacientes também apresentam padrões atípicos de linguagem com mais frequência que a população saudável. A técnica para cálculo de lateralidade utilizada foi dependente de limiar e realizada para os 3/4 laterais do hemisfério, o que não permite a análise de lateralidade em regiões de interesse específicas. Neste estudo apenas a atividade epiléptica interictal foi considerada.

Miró et al (2014) avaliaram 12 pacientes com EMTE utilizando paradigma com componente semântico (ouvir sentenças passivamente). Observou-se maior freqüência de lateralidade atípica de linguagem para o grupo EMTE em relação aos controles saudáveis e associação de lateralidade atípica com idade precoce de início da epilepsia. Apenas a lateralidade para regiões temporais foram avaliadas. Fatores associados à atividade epiléptica não foram explorados.

Em aproximadamente 3-19\% dos casos de EMT unilateral, a monitorização com EEG invasivo e não invasivo mostra que o início da atividade epiléptica ictal não é concordante com a lesão estrutural, podendo ser contra-lateral, bilateral ou ambígua. De acordo com a atividade epileptiforme e a lesão estrutural, podemos classificar os indivíduos com EMT como concordantes (esclerose hipocampal e atividade epileptiforme do mesmo lado) ou discordantes (atividade epileptiforme bilateral ou contra-lateral à esclerose hipocampal) (Williamson et al; 1993; King et al; 1997). A associação da lateralidade da atividade epiléptica ictal e interictal com lateralidade de linguagem em pacientes com EMT é um aspecto pouco explorado até o momento. A presença de distúrbios de linguagem poderia estar associada a anormalidades funcionais localizadas no hemisfério esquerdo não só em indivíduos com EMTE, como também, para aqueles com EMTD. 


\section{OBJETIVOS}

1. Desenvolver paradigma de nomeação responsiva à leitura na língua portuguesa que seja eficaz em mostrar ativação de regiões cerebrais frontais e temporais associadas ao processamento de linguagem.

2. Calcular $o$ índice de lateralidade de linguagem por RMf (IL-RMf) em diversas regiões cerebrais de interesse associadas ao processamento de linguagem.

3. Verificar a concordância do IL-RMf com o índice de lateralidade de linguagem obtido por teste de Wada (IL-Wada) em pacientes com EMT unilateral.

4. Comparar o IL-RMf para cada região de interesse entre grupos de pacientes com EMT esquerda, EMT direita e grupo de controles saudáveis.

5. Comparar o IL-RMf para cada região de interesse entre os grupos de pacientes EMTE e EMTD, classificados de acordo com a concordância entre a atividade epileptiforme ictal/interictal e o lado da lesão estrutural.

6. Verificar a associação de variáveis clínicas (presença de insulto precipitante inicial, idade de início da epilepsia, tempo de epilepsia e frequência da atividade epileptiforme à esquerda) com o IL-RMf, para cada região de interesse. 


\section{MÉTODOS}

\subsection{Aspectos éticos}

Este estudo foi aprovado pela Comissão de Ética para Análise de Projetos de Pesquisa (CAPPesq) do HCFMUSP, sob protocolo número 251/0 (Anexo 1). Todos os dados foram obtidos seguindo estritamente a metodologia do projeto Cinapce - Cooperação Interinstitucional de Apoio a Pesquisas sobre o Cérebro, subprojeto 1. Todos os participantes assinaram o Termo de Consentimento Livre e Esclarecido após receberem informações sobre os objetivos e procedimentos da pesquisa (Anexo 2).

\subsection{Desenho do estudo}

O presente estudo foi realizado na Unidade de Epilepsia da Clínica Neurológica do Hospital das Clínicas da Faculdade de Medicina da Universidade de São Paulo (HC-FMUSP). Trata-se de um estudo prospectivo, controlado cujos dados foram obtidos como parte integrante do protocolo Cinapce, Cooperação Interinstitucional de Apoio a Pesquisas sobre o Cérebro (http://www.cinapce.org.br). O protocolo Cinapce foi um projeto multinstitucional de neuroimagem e epilepsia, financiado pela Fundação de Amparo à Pesquisa do Estado de São Paulo (FAPESP). O subprojeto 1, deste protocolo, foi um subprojeto temático que estudou diferentes aspectos de funções cognitivas em pacientes com ELT secundária a EMT com diferentes técnicas de neuroimagem estrutural e funcional. Todos os pacientes com diagnóstico de ELT secundária à EMT, refratários, eram convidados a participar a partir do momento em que 
concordavam com o tratamento cirúrgico. Os pacientes incluídos neste protocolo eram submetidos a uma bateria de testes pré-operatórios incluindo avaliação demográfica, avaliação clínica, neuropsicológica, fonoaudiológica, monitorização prolongada com vídeo-EEG, teste de Wada e RM estrutural/ funcional. Todas as avaliações realizadas, com exceção da avaliação por RMf, faziam parte do protocolo prévio de avaliação pré-operatória para cirurgia de epilepsia adotado no ambulatório de Epilepsia da Clínica Neurológica do Hospital do HC-FMUSP.

A coleta de dados foi realizada no período de setembro de 2009 a fevereiro de 2014. Todos os participantes realizaram avaliação clínica no ambulatório de epilepsia com uma de duas assistentes do serviço, avaliação por vídeo-EEG no serviço de vídeo-EEG do HCFMUSP, teste de Wada no setor de hemodinâmica do HCFMUSP e avaliação de linguagem por RMf no setor de Radiologia desta instituição.

O fluxograma dos participantes, com as diferentes etapas da coleta de dados, é descrito na Figura 2.

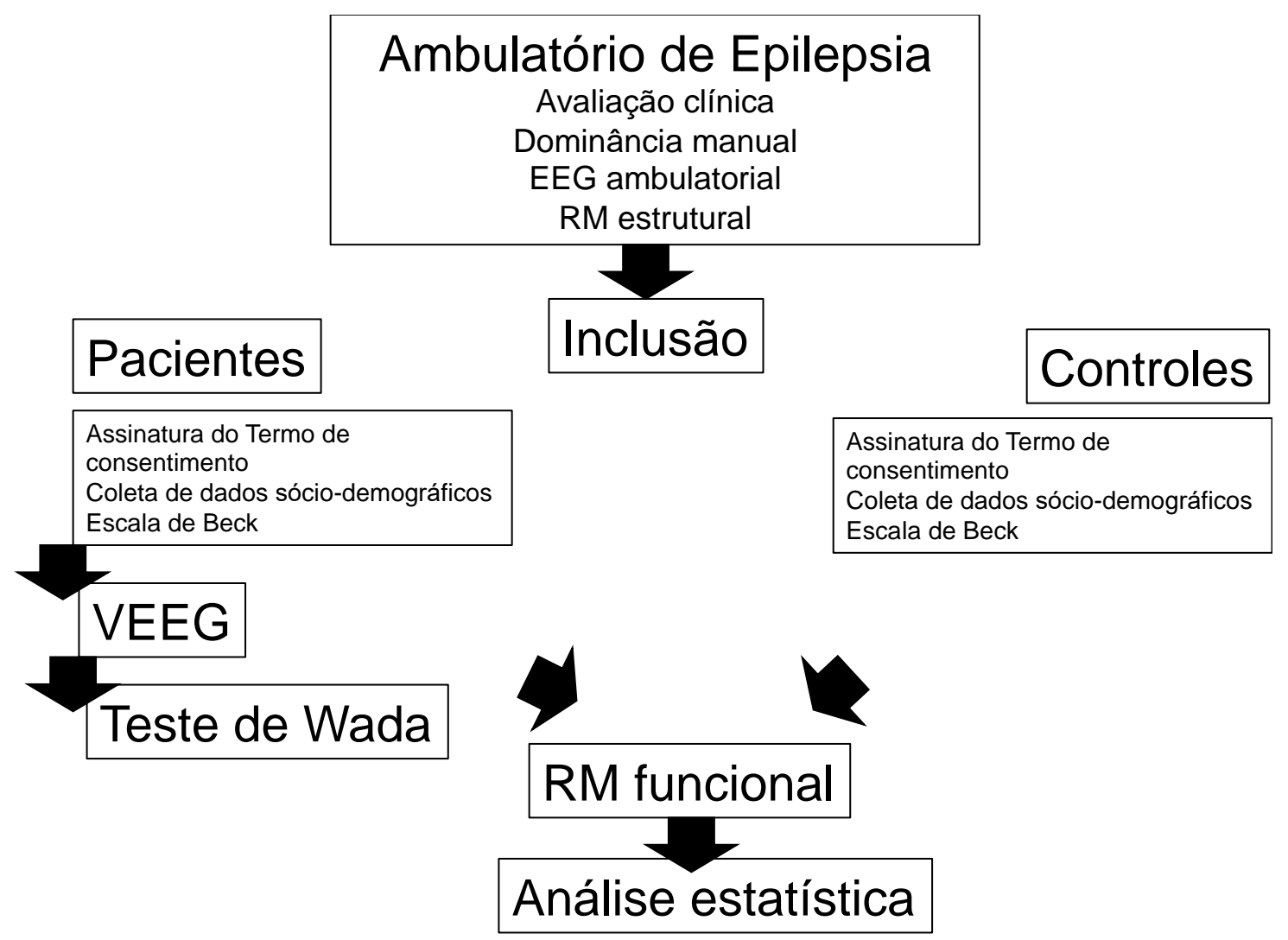

Figura 2. Fluxograma dos participantes com as diferentes etapas da coleta de dados para o grupo de pacientes e grupo controle 


\subsection{Casuística}

\subsubsection{Grupo de pacientes com EMT}

Foram estudados 24 pacientes com EMTE e 22 pacientes com EMTD.

Os pacientes apresentavam história clínica compatível com epilepsia do lobo temporal mesial, fármaco-resistente, candidatos a tratamento cirúrgico de epilepsia. Todos os pacientes realizaram EEG ambulatorial e avaliação de dominância manual com o Questionário de Edimburgo (Oldfield, 1971- Anexo 3). O diagnóstico de EMT unilateral foi estabelecido após análise de RM estrutural por um radiologista cego aos objetivos do estudo. A esclerose hipocampal unilateral foi definida pela presença de atrofia e aumento da intensidade de sinal do hipocampo na RM. Todos os estudos estruturais foram realizados no mesmo aparelho de RM 3.0T Phillips, com sequências especiais para estudo do hipocampo, T2 e FLAIR coronais, perpendiculares ao maior eixo hipocampal. A refratariedade ao tratamento medicamentoso foi definida por usência de controle de crises a despeito do uso de duas MAEs, em monoterapia ou em combinação, potencialmente eficazes, usadas até níveis ou doses máximas toleráveis (Kwan, 2010).

\subsubsection{Critérios de inclusão e exclusão}

\section{Critérios de inclusão:}

- EMT unilateral refratária ao tratamento medicamentoso.

- EEG ambulatorial normal ou com descargas epileptiformes no lobo temporal (uni ou bilaterais).

- Idade entre 18 e 55 anos.

- Escolaridade igual ou superior a oito anos.

- Dominância manual à direita, definida por pontuação na escala de Edimburgo $>50$. 


\section{Critérios de exclusão:}

- Atividade epileptiforme extra-temporal no EEG interictal.

- Outras lesões visualizadas na RM de encéfalo, exceto EMT.

- Presença de outra doença que acometa o sistema neurológico central, exceto cefaleia primária.

- Deficiência mental ou quadro psiquiátrico que pudessem limitar a colaboração para realização de RMf e avaliação cognitiva.

- Outras doenças clínicas que possam interferir nas habilidades cognitivas (como alcoolismo e uso de drogas ilícitas).

\subsubsection{Grupo controle}

Foram selecionados 22 indivíduos, amigos ou familiares dos pacientes, que os acompanhavam no momento da consulta ou posteriormente indicados pelos pacientes. Os indivíduos do grupo controle eram trazidos para avaliação e deveriam preencher os seguintes critérios para inclusão no estudo:

- Idade entre 18 e 55 anos

- Escolaridade igual ou superior a oito anos.

- Dominância manual à direita, definida com pontuação na escala de Edimburgo $>50$.

- Ausência de deficiência mental ou quadro psiquiátrico que pudessem limitar a colaboração para realização de RMf e avaliação cognitiva.

- Ausência de doença que acometa o sistema neurológico central, exceto cefaleia primária.

- Ausência de doença clínica que possa interferir nas habilidades cognitivas (como alcoolismo e uso de drogas ilícitas) 


\subsection{Avaliação clínica}

Para todos os participantes foram registrados idade, gênero, número de anos de escolaridade, pontuação no Inventário de Edimburgo e no Inventário de depressão de Beck (Anexo 4).

O Inventário de Depressão de Beck (Gorestein, 1999) consiste em escala de auto-avaliacão composta por 21 itens para avaliar a presença e intensidade da depressão. A escala avalia sintomas físicos e psiquícos de depressão como humor, pessimismo, sensação de incapacidade, insatisfação, culpa, punição, baixa auto-estima, ideias suicidas, choro, irritabilidade, isolamento social, autoimagem, dificuldades no trabalho, insônia, fadiga, apetite, perda de peso, perda de libido. Cada item pode ser pontuado de 0 a 3 . O escore total é obtido pela soma dos escores em todos os itens. Os valores do escore total são interpretados como de 1 a 10, variação normal do humor; de 11 a 16, transtorno de humor leve; de 17 a 20 depressão leve; de 21 a 30 depressão moderada; de 31 a 40 depressão grave; > 40 depressão extrema. No grupo de pacientes foram coletadas adicionalmente as informações seguintes:

- Presença de evento precipitante inicial;

- Intervalo livre de crises: Intervalo em anos entre o primeiro evento até o inicio da epilepsia;

- Idade da primeira crise;

- Idade do início da epilepsia: idade de início das crises espontâneas recorrentes;

- Duração da doença: tempo transcorrido desde a idade do insulto precipitante inicial, e, nos casos em que este era ausente, desde a idade do início da epilepsia;

- Duração da epilepsia: tempo transcorrido desde a idade do início das crises espontâneas recorrentes;

- Frequência de crises: média mensal do número de crises referidas pelo paciente nos três meses prévios ao registro de exame de vídeo-EEG; 
- Carga de medicações anti-epilépticas

- Carga de medicações sedativa

Para o cálculo da carga de medicações anti-epilépticas, todas as medicações utilizadas para dado paciente foram consideradas, e foi obtida a somatória da razão entre a dose diária de cada medicação utilizada e a sua dose média terapêutica. As doses médias terapêuticas definidas foram: fenobarbital 100 mg, fenitoína 200 mg, carbamazepina 800 mg, oxcarbazepina $1200 \mathrm{mg}$, valproato de sódio $750 \mathrm{mg}$, topiramato $100 \mathrm{mg}$, clonazepam $2 \mathrm{mg}$, clobazam $10 \mathrm{mg}$, vigabatrina $750 \mathrm{mg}$, lamotrigina $200 \mathrm{mg}$ (se utilizada em monoterapia), 100 mg (se utilizada em associação a medicação inibidora enzimática), $400 \mathrm{mg}$ (se utilizada em associação com medicação indutora enzimática) e 200 mg (se utilizada em associação com medicação indutoras e inibidoras enzimáticas).

Para a carga de medicações sedativas o mesmo cálculo foi realizado levando-se em consideração a somatória das pontuações apenas para as medicações anti-epilépticas com maior potencial sedativo: fenobarbital, topiramato, clobazam e clonazepam.

\subsection{Monitorização por vídeo-EEG}

\subsubsection{Aspectos gerais}

Todos os pacientes foram submetidos a monitorizaaci prolongada na unidade de vídeo-EEG do Hospital das Clínicas, da Faculdade de Medicina da Universidade de São Paulo, com aparelho Bio-logic (Natus Medical Incorporated), com sistema digital de vídeo-EEG sincronizado Ceegraph Vision versao 7.15.06, de 32 canais, para detecção de atividade epiléptica interictal e ictal. Em todos os pacientes foi utilizada uma modificação do sistema 10-20, de acordo com critérios aprovados pela Sociedade Americana de Eletrencefalograma em 1990. 
Uma extensão do sistema 10-20 foi utilizada para indicar a colocação de eletrodos em posições $10 \%$ inferiores aos eletrodos frontotemporais, denominados eletrodos F9/F10, T9/T10, P9/P10 e, adicionalmente, indicar a posição de eletrodos temporais anteriores, denominados T1 e T2.

As doses de drogas anti-epilépticas foram reduzidas de acordo com critérios individuais, levando-se em consideração a frequência média de crises e o risco de crises tônico-clônicas generalizadas.

As análises do EEG ictal e interictal foram realizadas por dois neurofisiologistas cegos quanto aos objetivo do estudo.

Os dados neurofisiológicos obtidos na monitorização por video-EEG ictal e interictal foram avaliados prospectivamente.

\subsubsection{Classificação de concordância interictal}

O EEG interictal foi analisado durante $1 \mathrm{~h}$ de vigília e $1 \mathrm{~h}$ de sono no primeiro e no último dias de monitorização. As descargas epileptiformes (espículas e ondas agudas) foram contabilizadas e classificadas quanto à lateralização.

Nos casos em que a atividade epileptiforme era muito frequente (> 15 descargas por minuto durante 10 minutos), a contagem e lateralização das descargas era feita até 100 descargas. A contagem final nestes casos era obtida fazendo-se uma projeção do número total de descargas para uma hora.

A partir da análise quantitativa e de lateralidade das descargas interictais foi calculada a porcentagem de descargas ipsilaterais do mesmo lado da EMT na RM estrutural.

Cada paciente foi então classificado em concordante-interictal e discordante-interictal, conforme descrito a seguir:

- Concordante-interictal: paciente no qual as descargas ipsilaterais ao lado da EMT corresponderam a $\geq 70 \%$ do número total de descargas.

- Discordante-interictal: paciente no qual as descargas ipsilaterais ao lado da EMT corresponderam a $<70 \%$ do número total de descargas. 
- Não classificáveis: Pacientes em que não houve registros de descargas epileptiformes no período interictal no primeiro e último dia de monitorização.

\subsubsection{Classificação de concordância ictal}

O início da atividade ictal foi determinado a partir do início de atividade ictal sustentada, claramente distinta da atividade elétrica cerebral de base e associada a manifestações clínicas perceptíveis na evolução da crise. Para cada crise, o EEG ictal foi analisado visualmente por montagens referencial e bipolar.

Após a análise de todas as crises registradas, cada paciente era classificado em concordante-ictal ou discordante-ictal, conforme descrito a seguir:

- Concordante-ictal:

a) Todas as crises apresentaram correlato ictal exclusivamente no lobo temporal ipsilateral à EMT ou com atividade ictal contralateral de menor frequência/amplitude, não configurando um ritmo ictal independente.

- Discordante ictal:

a) Ao menos uma das crises apresentou início eletrencefalográfico no lobo temporal contralateral à EMT ou

b) Ao menos uma das crises apresentou início bilateral sem predomínio ou predomínio contralateral à EMT ou

c) Ao menos uma das crises apresentou início ipsilateral, com posterior desenvolvimento no lado contralateral, configurando um ritmo ictal contralateral independente.

\subsubsection{Classificação final de concordância (classificação EEG/RM)}

A classificação final de concordância levou em consideração ambas as classificações (interictal e ictal). Pacientes foram classificados como discordantes quando foram classificados como discordantes em pelo menos uma das duas 
classificações (ictal ou interictal). Todos os demais pacientes foram classificados como concordantes.

Ou seja, os pacientes classificados como concordantes na classificação final não apresentaram sinais de envolvimento contralateral ao lado da EMT no período ictal e menos de $30 \%$ das descargas contralaterais no período interictal.

\subsection{Teste de Wada e índice de lateralidade (IL-Wada)}

Todos os teste de Wada foram realizados por um neuroradiologista experiente, no setor de hemodinâmica do HC-FMUS. As avaliações clínicas durante o procedimento foram realizadas por um único pesquisador utilizando protocolo padronizado para o projeto Cinapce.

Antes de iniciar o exame, o pesquisador explicava o procedimento ao paciente, respondia a eventuais dúvidas e realizava avaliação neurológica.

O procedimento iniciava-se com a realização de arteriografia cerebral com inserção de um cateter na artéria femural, progredindo até posicionamento no cateter na artéria carótida interna,. O exame era sempre iniciado com cateterização da artéria carótida interna ipsilateral à EMT, simulando o procedimento cirúrgico planejado. Em todos os testes utilizou-se o etomidato como agente anestésico. Após a administração do etomidato na artéria carótida interna (dose de 0,8mg), o pesquisador realizava avaliação de nível de consciência, campimetria por confrontação visual, linguagem, memória e força muscular. Os testes específicos de linguagem e memória eram apresentados a partir do momento em que o paciente apresentava hemiplegia contralateral. Durante a apresentação dos itens, caso houvesse recuperação parcial da força muscular ou da linguagem, um bôlus adicional de 0,4 mg de etomidato era administrado. O teste era finalizado após a apresentação de todos os itens da avaliação cognitiva. Na sequência, o mesmo procedimento era realizado pahemisfério cerebral. 
A avaliação de linguagem constava dos itens: avaliação de fala espontânea, nomeação, compreensão, leitura, repetição de palavras e repetição de sentenças. A avaliação de memória constava da apresentação de 16 itens, divididos em 4 blocos, que deveriam ser recordados após recuperação do efeito anestésico e que constavam de um objeto, um desenho de um objeto, um desenho abstrato e uma palavra (avaliando, portanto a leitura), que eram apresentados de forma alternada em cada bloco. Após cada bloco do teste de memória, avaliações de compreensão, repetição de sentenças e força muscular eram repetidas. Para pontuação de linguagem o desempenho durante todo 0 exame era considerado. Apenas os dados concernentes à lateralização de linguagem (IL-Wada), serão apresentados a seguir.

O IL-Wada foi obtido através da avaliação quantitativa de cada item de linguagem. $O$ desempenho nos itens nomeação, compreensão, leitura e repetição foram pontuados de 0-2 ( $0=$ normal, $1=$ alterado, $2=$ ausente). Um escore total para aquele hemisfério era obtido pela soma dos escores de cada item (variando de 0-8). O valor final obtido (IL-Wada) variava de 1 a -1 e era obtido com a fórmula:

(Escore total do hemisfério esquerdo - Escore total do hemisfério direito)

(Escore total do hemisfério esquerdo + Escore total do hemisfério direito)

Como variável categórica, a dominância de linguagem à esquerda foi definida para valores de IL-Wada $\geq 0,2$; bilateral para valores entre -0,2 e 0,2 e à direita para valores $<-0,2$. 


\subsection{Ressonância magnética funcional}

Todos os exames foram realizados na Unidade de Ressonância Magnética do Instituto de Radiologia do HC - FMUSP, no mesmo aparelho de RM do fabricante Philips ${ }^{\circledR}$ Achieva (Phillips Medical Systems, Holanda), de alto campo (3.0 Teslas) com participação da pesquisadora e de um biomédico.

\subsubsection{Preparação para o exame de RMf e aplicação de questionários}

Antes de iniciar o exame de RMf, todos os indivíduos receberam um treinamento para se familiarizarem com as tarefas. Um de dois examinadores realizou o treino de forma padronizada, utilizando uma bateria similar de paradigmas, com estímulos diferentes, para evitar o efeito de memorização das respostas. Antes e logo após o exame de RMf, os participantes eram instruídos a responder dois questionários de avaliação de humor e ansiedade, descritos a seguir.

a) Escala Analógica de Humor (VAMS, do inglês, Visual Analog Mood Scale), (Zuardi AW \& Karniol IG, 1981): Nesta escala o indivíduo é orientado a marcar um ponto que identifica o seu atual estado subjetivo, numa linha reta de $100 \mathrm{~mm}$, colocada entre duas palavras que descrevem estados de humor opostos. A escala é composta por 16 itens agrupados em 4 fatores: (1) ansiedade, (2) sedação física, (3) sedação mental, (4) desconforto. A análise dos dados é realizada em 4 etapas (1) medição (2) adequação do sinal do valor obtido, como positivo ou negativo, conforme tabela (3) cálculo do valor ponderado conforme pesos estabelecidos para cada item (4) cálculo do valor por fatores (Anexo 5).

b) Inventário de ansiedade traço-estado (IDATE): Este inventário foi desenvolvido por Spielberg (Spielberger CD. Et al; 1970) e validado para o português por Biaggio e Natalício (Biaggio e Natalício, 1979). Trata-se de questionário de auto-avaliação amplamente utilizado, 
composto por duas escalas distintas para avaliação do traço ansioso (IDATE-traço) e do estado ansioso (IDATE-estado). Cada escala consiste de 20 afirmações para os quais os indivíduos identificam a intensidade naquele momento (estado) e a frequência com que ocorrem cotidianamente (traço), em uma escala de 1 a 4 pontos. $O$ escore total varia de 20 a 80 pontos; maiores escores relacionam-se a maiores níveis de ansiedade (Anexo 6).

\subsubsection{Posicionamento dos sujeitos}

Todos os participantes foram posicionados em decúbito dorsal na maca do equipamento de RM, com a cabeça apoiada em posição neutra na bobina. Quando necessário foi utilizado um coxim na região dorsal da cabeça para proporcionar um posicionamento mais adequado e correta visualização da tela. Os participantes foram instruídos a evitar o movimento da cabeça durante as respostas orais. A manutenção do alinhamento da cabeça durante o exame foi assegurada posicionando-se coxins de espuma nas laterais da bobina e colocando uma fita adesiva gentilmente sobre a testa do sujeito, fixando-a à bobina, tentando evitar qualquer tipo de movimentação cefálica.

Antes da apresentação do paradigma, a pesquisadora comunicava-se com o participante por um sistema de som com microfones e alto-falantes e a instrução para o paradigma era dada. O exame era iniciado somente após a pesquisadora certificar-se de que o sujeito estava confortável, de que era capaz de visualizar toda a tela e de comunicar-se corretamente com a equipe. Finalmente, o sujeito era instruído a interromper o exame a qualquer momento, caso necessário, apertando um botão de segurança posicionado ao seu lado na maca. 


\subsubsection{Protocolo de aquisição das imagens}

Para conferir o posicionamento do sujeito dentro da máquina, a sessão iniciava-se com uma sequência localizatória (Survey) obtida nos 3 planos das estruturas anatômicas a serem estudadas. Uma sequência localizatória ponderada em T2 (sagital T2) era realizada para localizar as comissuras anterior e posterior (AC/PC, plano bicomissural) utilizadas para angulação das imagens BOLD.

Inicialmente eram adquiridas sequências de imagem estruturais: sequência ponderada em T1 com a técnica tridimensional Fast Field Echo (3DT1-FFE) no plano sagital, com os seguintes parâmetros: tempo de eco (TE) = 3,2ms; tempo de repetição $(\mathrm{TR})=7,0 \mathrm{~ms}$; tempo de inversão $(\mathrm{TI})=900 \mathrm{~ms}$; campo de visão (field of view - FOV) $=240 \times 240 \times 180 \mathrm{~mm}$; matriz= $240 \times 240 \mathrm{com}$ resolução final isotrópica do vóxel $=1 \mathrm{~mm}^{3}$ e aquisições paralelas de imagens (sensitivity encoding - SENSE). Para investigar possíveis lesões no parênquima cerebral, foram realizadas imagens axiais com a técnica FLAIR (fluid-attenuated inversion recovery) com 20 fatias, intervalo entre fatias (gap) de $4,5 \mathrm{~mm}, \mathrm{RT}=11.000 \mathrm{~ms}$, inversion time $(\mathrm{IT})=2.800 \mathrm{~ms}$, ET $=130 \mathrm{~ms}$, vóxel $0.65 \times 0.86 \times 4.5 \mathrm{~mm}^{3}$, matrix $=352 \times 210$ e FOV $=230 \times 18 \mathrm{~mm}^{2}$.

Para a aquisição das imagens funcionais utilizou-se detecção do contraste BOLD através de sequências ponderadas em T2* do tipo ecoplanar gradiente eco (EPI-GRE), com sistema de aquisição paralela SENSE. A orientação da aquisição das imagens foi paralela ao plano bicomissural AC/PC, com espessura de $3 \mathrm{~mm}$, voxel isotrópico $=3 \mathrm{~mm}^{3}$, matrix $=80 \times 78$, FOV $=240 \mathrm{~mm}^{2}$ e ângulo de inclinação ( flip angle) $=90^{\circ}$. Foram colhidas 40 fatias, de modo que a maior parte do encéfalo fosse incluída dentro de um volume, num curto intervalo de tempo ( $T R=4000 \mathrm{~ms} / \mathrm{TE}=30 \mathrm{~ms}$ ). Embora se utilizou intervalo de $0,3 \mathrm{~mm}$ entre as fatias, alguns sujeitos tiveram parte do tronco cerebral e/ou cerebelo excluídos por estes não caberem dentro do espaço de aquisição da imagem. O tempo total de aquisição da RM funcional foi de cinco minutos e 20 segundos, com coleta de 80 volumes. Os quatro volumes iniciais não foram incluídos, com o objetivo de permitir a estabilização da magnetização de T1, evitando interferências por queda de sinal na aquisição das sequências BOLD. 


\subsubsection{Instrumentos para apresentação do paradigma e coleta de respostas comportamentais}

A programação e apresentação dos estímulos do paradigma de linguagem foram realizadas com o software E-Prime 1.0 (Psychology Software Tools, Inc., EUA). A sincronia entre a aquisição da imagem de RM e a apresentação do estímulo visual foi realizada por um sincronizador programável (trigger - Zurc \& Zurc, São Paulo). Os estímulos visuais foram enviados para uma tela de LCD acoplada à bobina de crânio, visualizada pelo paciente dentro da máquina utilizando-se o dispositivo IFIS/ Eloquência (In Vivo Corporation, EUA). As respostas orais e o tempo de reação de cada sujeito foram gravadas com 0 editor de áudio Audacity® (Free Software Foundation, Inc., USA).

\subsubsection{Paradigma de linguagem}

Todos os indivíduos foram submetidos a um paradigma de nomeação responsiva à leitura, desenvolvido em português. Na condição ativa, uma sentença, escrita com as letras brancas sobre fundo preto, era apresentada no centro da tela, $\mathrm{p}$ ex: Fruta que os macacos adoram. O participante era orientado a ler a frase em silêncio, e, a seguir, dizer em voz alta qual palavra descrita, p ex: banana. Na condição controle, eram mostradas não-sentenças. A seguir, o participante era orientado a dizer em voz alta "não entendi".

As não-sentenças utilizadas foram confeccionadas tomando-se como referência as sentenças utilizadas na condição ativa. As letras e palavras que compunham cada sentença foram trocadas de posição e reagrupadas formando uma sentença ininteligível, com qualidade de estímulo visual semelhante à da sentença original.

A matriz cognitiva neste experimento é composta por processamento visual do formato da palavra, conversão da informação lexical em informação semântica, processamento semântico e sintático (compreensão), recuperação das palavras, plano articulatório para produção da fala e produção da fala 
(Price, 2012). O processamento sensitivo primário e a resposta motora estão presentes na condição ativa e na condição controle.

Para confecção das sentenças foram utilizadas como referência figuras do teste An Object and action naming battery (Druks, 2000). O primeiro passo foi selecionar aleatoriamente 80 figuras entre todas as disponíveis e escolher, entre estas, uma quantidade equivalente de figuras muito conhecidas e pouco conhecidas. Para isto foi criada uma escala com as frequências das citações dos nomes das 80 figuras, através do site Google. As 20 figuras cujos nomes foram mais frequentes e as 20 menos frequentes foram selecionadas. Para cada uma das figuras selecionadas foi criada uma sentença de cinco palavras que a descrevia.

As sentenças e não-sentenças foram posicionadas no centro de cada tela, ocupando $30 \%$ da sua área total. As não-sentenças da condição controle nunca apareciam no mesmo bloco em que estava a frase da condição ativa que lhe deu origem, evitando que o sujeito fizesse uma relação entre elas, o que poderia alterar o processamento cognitivo desejado.

Após cada estimulo, uma tela contendo o símbolo “ + " (cruz) em seu centro era apresentada. O tempo de repetição (TR) era de 4 segundos (dois segundos para a apresentação visual do estímulo e dois segundos para a apresentação da tela com a cruz, sem barulho da máquina). O indivíduo era orientado a responder logo após a apresentação de cada estímulo, no momento em que a tela com o símbolo da cruz fosse apresentado. Exemplos de composição das telas dentro de um bloco de condição ativa e de um bloco de condição controle são mostrados na Figura 3.

O paradigma foi composto por 16 blocos em cada época, oito blocos de condição ativa e oito blocos de condição controle, cada bloco contendo cinco estímulos. Estabeleceu-se a priori, uma sequência que alternava aleatoriamente os blocos de condição ativa e os blocos de condição controle. Uma vez definida, a mesma sequência era utilizada para todos os participantes. A duração total do paradigma foi de cinco minutos e 20 segundos (Figuras 3 e 4). 
a)

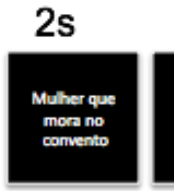
2s
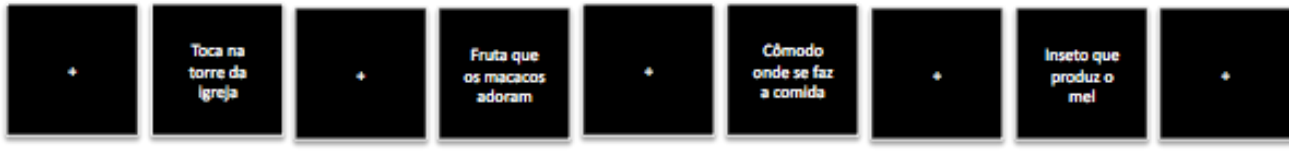

b)
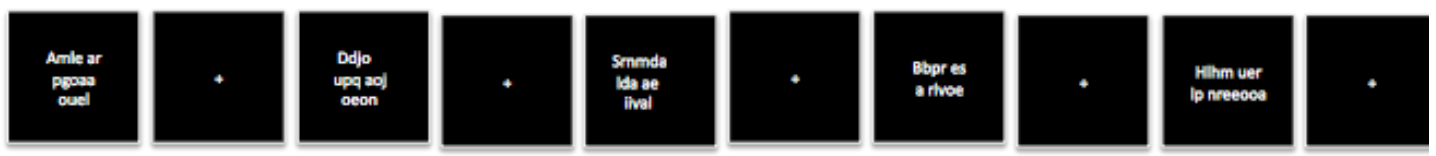

Figura 3. Exemplos de composição das telas em um bloco de condição ativa (frases) e de um bloco de condição controle (não-frases). O sujeito é.orientado a responder no momento da apresentação da tela composta por uma cruz (+). Cada bloco é composto por 10 telas, 5 telas com estímulos e 5 telas com cruz (+)

a)
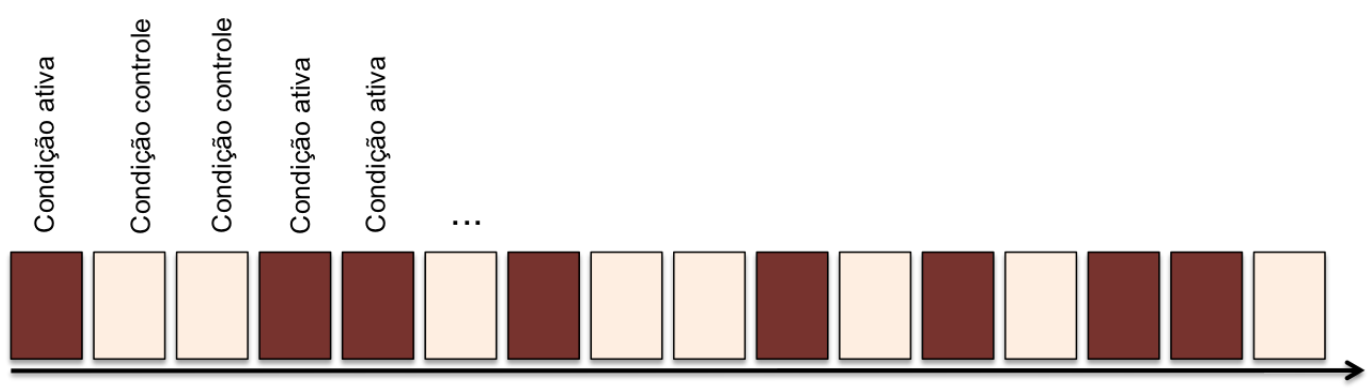

b)
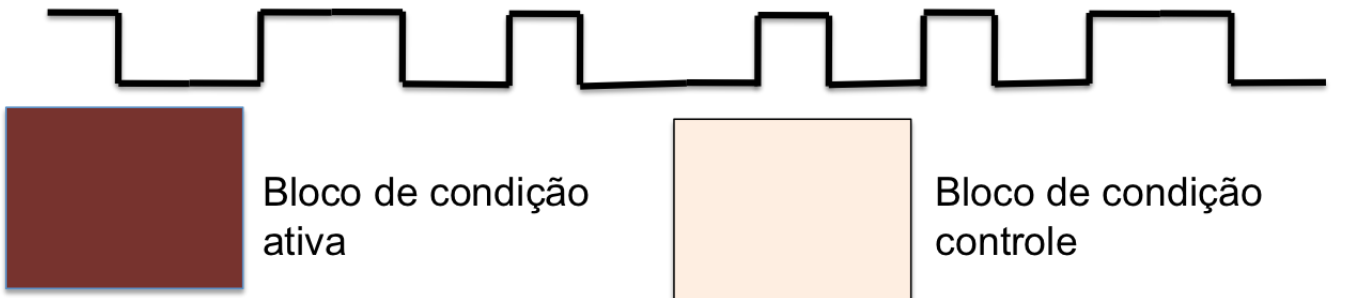

c)

Bloco de condição ativa
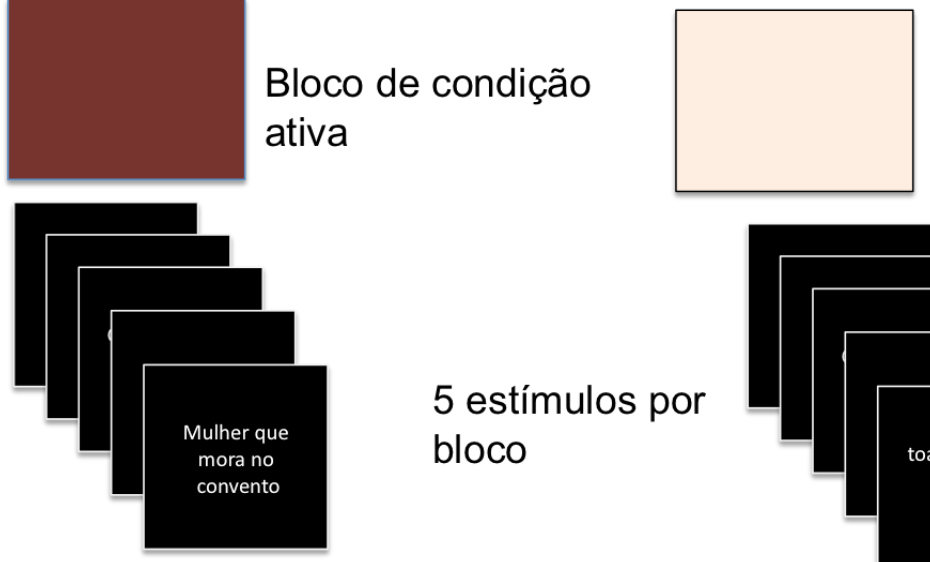

Bloco de condição controle

5 estímulos por bloco

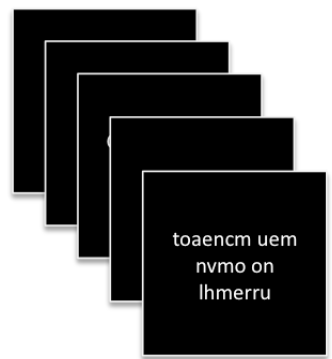

Figura 4. Desenho geral do paradigma de nomeação responsiva à leitura com apresentação em bloco. Apresentação de blocos de condição ativa e blocos de condição controle de modo aleatorizado (a), linha temporal (b), cada bloco foi composto por cinco estímulos (c) 


\subsubsection{Análise estatística das imagens de RM funcional}

O pré-processamento e análise das imagens de RMf empregou o programa estatístico FMRIB Software Library (FSL), versão 6.0 (Centre for fMRI of Brain FMRIB, Analysis Group, Oxford, UK).

Nesta fase, as imagens EPI foram convertidas para formato NIFTI (Neuroimaging Informatics Technology Initiative file format) e, a seguir, préprocessadas, utilizando-se as seguintes ferramentas, disponíveis no FSL:

- BET (Brain Extraction Tool [Smith, 2002]): Remoção de voxels de estruturas extra-encefálicas (ossos , órbitas, etc);

- FMRIB's Linear Image Registration Tool (FLIRT, versão 5.5): utilizando transformações lineares para estender, transladar e rotacionar a imagem T1 de alta resolução do sujeito para torná-la semelhante à imagem do template MNI152;

- Filtro Gaussiano de 5mm, com suavização espacial para aumento da relação sinal ruído das imagens;

- Filtro temporal passa-alto para remoção de artefatos de baixa frequência com tempo máximo de passagem de 100s e controle dos limites de oscilação do sinal BOLD associados à estimulação;

- McFLIRT (Motion correction using FMRIB's Linear Registration Tool) com orientação de aquisição anteroposterior e no sentido de baixo para cima, para correção de movimento. Este algoritmo de correção de movimento utiliza transformações de corpo rígido que consistem em transformções lineares de rotação e translação em qualquer um dos eixos ( $x, y$ e $z$ ). Foram toleradas movimentações em quaisquer eixos de até no máximo $2 \mathrm{~mm}$ (já que o voxel utilizado neste estudo tinha dimensões de $3 \mathrm{~mm} 3)$;

- Correção de tempo de aquisição das fatias, utilizando-se uma fração apropriada de TR para série temporal dos voxels, levando-se em consideração que 41 fatias eram colhidas sequencialmente até completar o volume. 
Para análise de imagens individuais (First level analysis), a análise estatística foi utilizada a ferramenta FMRIB's Improved Linear Model (FILM) visando modelar o sinal BOLD de cada voxel. O mapa de ativação individual de cada aquisição foi obtido por um modelo linear geral (General Linear Model - GLM).

As respostas à estimulação produzida pelo paradigma foram detectadas pela análise da série temporal de cada voxel, que, por hipótese, é a convolução da função estímulo com a função da resposta hemodinâmica canônica dada pela função Gamma (tempo para o pico $6 \mathrm{~s}$, desvio padrão $3 \mathrm{~s}$ ). Para controle dos resultados falso positivos, foi considerado significativo o conjunto de voxels (clusters) sobreviventes ao limiar de Z-score=2,3 $(p=0,01)$ corrigidos para comparações múltiplas com o limiar para voxel ao nível de significância de $p<0,05$ (Worsley, 2001).

Utilizando a ferramenta de registro linear FMRIB's Improved Linear Model (FILM) na comparação entre os grupos (higher level analysis) foi utilizada análise ANOVA com opção de efeitos mistos, ou seja, foi considerada a variabilidade entre sujeitos, o que possibilita generalizar os resultados obtidos para as populações das amostras estudadas. Foram gerados mapas de ativação média de cada grupo (EMTE, EMTD e controles) para o contraste de interesse (condição ativa>condição controle).

Os limiares estatísticos adotados para as análises nesse nível foram os mesmos utilizados na análise anterior ( $p \leq 0,05$ para o voxel e $Z>2,3$ para 0 cluster).

Utilizou-se o software MRIcron (http://www.mricro.com) para construir imagens em fatias e da superfície cortical em três dimensões, com a representação em cores das respectivas áreas cerebrais onde houve aumento da ativação (para os mapas de grupo) e onde houve diferenças nas ativações entre grupos (para os mapas de comparações entre dois grupos). Para cada imagem foi realizada uma descrição anatômica dos voxels com os picos de ativação de cada cluster significativo, respectivas áreas de Brodmann e descrição qualitativa após conferência por análise visual por um radiologista experiente. 


\subsubsection{Seleção de regiões cerebrais de interesse (Region of interest ROI)}

Foram selecionadas regiões cerebrais de interesse que, segundo 0 modelo de Price (2012) compõem redes de linguagem associadas à nomeação responsiva à leitura.

Oito ROls foram geradas utilizando o template fsaverage, que representa a versão do template do MNI152 no espaço de freesurfer. Sobre o template MNI utilizou-se a segmentação aparc2009 (Destrieux 2010), selecionando-se as regiões de interesse: GFS, GFM, GFI, GTS, GTM, GTI, giro angular (GA) e giro occípito-temporal lateral/fusiforme (GF/TO) dos dois hemisférios cerebrais (Figura 5).

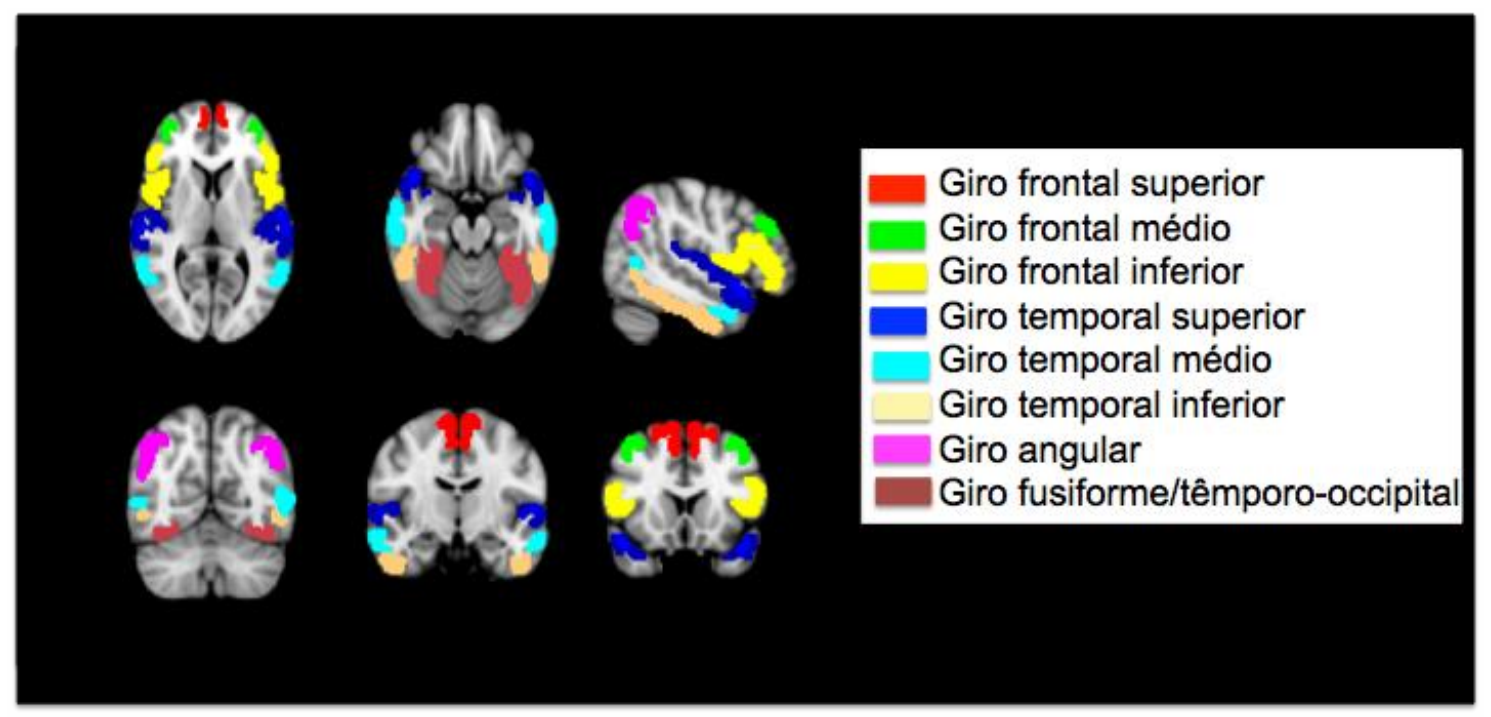

Figura 5. Regiões cerebrais de interesse utilizando a segmentação do Atlas aparc2009 sobre o template MNI.

\subsubsection{Cálculo do Índice de Lateralidade (IL-RMf)}

Para o cálculo do índice de lateralidade através da RMf (IL-RMf) foi utilizado o programa LI-Toolbox (Wilke, Lizdba 2007), com algoritmo implementado em MATLAB (The Mathworks, Natick, MA) e interface gráfica baseada em rotinas disponíveis no SPM8 (SPM8, Wellcome Department of Imaging Neuroscience, University College London, UK). Para processamento 
no SPM8 as imagens no formato NIFTI foram convertidas para o formato ANALYZE (Biomedical Imaging Resource, Mayo Foundation) com a ferramenta McFLIRT do FSL.

Os parâmetros utilizados na LI-Toolbox foram: método bootstrap para 20 diferentes limiares a partir do limiar zero; $\mathrm{k}=0,25,100$ amostras para cada hemisfério, tamanho de amostra de 25 voxels (mínimo de cinco e máximo de 10.000 voxels) com até 10.000 ILs resultantes por sujeito, representados por histograma (número de voxels versus IL). Os resultados foram fornecidos em arquivos PS (PostScript file) contendo as imagens do histograma. Ao lado de cada histograma, eram mostrados os valores de ILs médios finais, obtidos por três diferentes métodos:

- LI global (Overall Bootstrap-Result): Considera para o cálculo do IL médio todos os valores de IL obtidos no histograma

- LI Trimmed (LIT-25): Considera para o cálculo do IL médio os valores de IL correspondentes à área central do histograma, excluindo-se valores posicionados nas áreas correspondentes a $25 \%$ mais à esquerda e $25 \%$ mais à direita do histograma. Este método visa a minimizar a contribuição de voxels outliers, mas exclui igualmente Lls sobreviventes tanto a altos quanto a baixos limiares.

- LI Weighted Mean. Considerando para o cálculo da média os valores dos LI-T25 descritos anteriormente e conferindo maior peso aos ILs que sobreviveram aos limiares mais altos.

Para o presente estudo o IL considerado foi o LI Weighted Mean por tratar-se da metodologia mais robusta e menos sensível a outliers (Wilke, 2007). Como variável categórica, a dominância de linguagem à esquerda era definida para valores de IL-RMf $\geq 0,2$; bilateral para valores entre $-0,2$ e 0,2 e à direita para valores $<-0,2$. 


\subsection{Análise estatística}

Os resultados apresentados para as variáveis binominais (gênero, história de IPI e idade do IPI) representam a proporção de casos (respectivamente: mulheres/homens) em cada grupo. Para todas as outras variáveis (variáveis medidas) os resultados apresentados representam a média e o desvio-padrão para cada grupo. Para as comparações entre grupos para variáveis categóricas foi utilizado o teste exato de Fisher. Para a comparação entre médias foi utilizado o teste t-Student para amostras independentes, comparando-se dois grupos ou o teste de ANOVA (Analysis of variance) para 1 fator (ANOVA-one way) para comparações entre mais de dois grupos. Para quantificar a associação entre as variáveis IL-RMf e IL-Wada foi utilizado o teste de correlação de Spearmman bi-caudal. Para avaliar a presença de associação entre características clínicas da epilepsia (idade de início da epilepsia, tempo de epilepsia e frequência de descargas à esquerda) foi realizado, além dos testes supracitados (teste t-Student para comparações de médias e teste exato de Fisher para variáveis categóricas), teste de regressão linear múltipla, com método de entrada stepwise.

Todas as análises foram realizadas utilizando o pacote estatístico SPSS 14.0 (Statistical Package for the Social Sciences, Chicago, EUA), com nível de significância de $5 \%(p<0.05)$. 


\section{RESULTADOS}

\subsection{Casuística}

Foram encaminhados para avaliação de inclusão para a pesquisa 61 pacientes consecutivos encaminhados ao ambulatório de Epilepsia do HCFMUSP com diagnóstico de epilepsia refratária secundária a EMT unilateral. Destes, um paciente foi excluído por baixa escolaridade, quatro por dominância manual à esquerda, dois por presença de doença psiquiátrica descompensada que limitava a cooperação durante o exame de RMf e dois por presença de dupla lesão na RM estrutural.

Dentre os pacientes selecionados, um paciente não manifestou interesse em realizar o exame de RMf e cinco pacientes foram excluídos por presença de artefatos de susceptibilidade magnética nas imagens funcionais e/ou dados brutos dos exames de imagem incompletos devido a problemas técnicos.

Todos os pacientes excluídos permaneceram em acompanhamento ambulatorial para avaliação clínica e pré-cirúrgica, de acordo com o pressuposto no termo de consentimento (Anexo 2).

Foram encaminhados para avaliação para inclusão 24 controles, sendo dois excluídos por dominância manual à esquerda.

A amostra final foi constituída por 24 pacientes com EMT esquerda e 22 com EMT direita e 22 controles. Não foram observadas diferenças significativas entre os grupos em relação à idade, gênero, escala de Beck e pontuação no Inventário de Edimburgo. Um paciente com EMT esquerda não completou a escala de depressão de Beck.

O grupo de pacientes com EMTE apresentou escolaridade média significativamente menor que o grupo controle (escolaridade média em anos: controles 12,1 $\pm 2,7$ anos versus EMTE 10,5 $\pm 1,7$ anos, $(p<0,05)$. 
Em relação aos dados clínicos no grupo de pacientes, não foram observadas diferenças significativas entre os grupos EMTE e EMTD em relação a história de IPI, duração da epilepsia, duração do intervalo livre de crises, idade do inicio da epilepsia, duração da doença e quantidade/carga de MAEs utilizadas. História de insulto precipitante inicial (IPI) foi identificada em aproximadamente $59 \%$ dos indivíduos. Em todos os casos, o IPI, quando presente, ocorreu em idade inferior a cinco anos. No grupo com história de IPI $(n=27)$, crise febril foi identificada em 15 pacientes, crise única afebril em oito, trauma craniano leve em dois e meningoencefalite em dois pacientes.

Todos os pacientes foram submetidos a tratamento cirúrgico de epilepsia. A esclerose de hipocampo foi comprovada após análise histopatológica do hipocampo nos 43 casos operados.

As características demográficas e clínicas dos participantes são descritas na Tabela 1.

Tabela 1. Características dos pacientes EMTE, EMTD e controles. Os resultados das variáveis medidas são expressos em média e desvio-padrão

\begin{tabular}{lcccc}
\hline & $\begin{array}{c}\text { EMTE } \\
(\mathbf{n = 2 4})\end{array}$ & $\begin{array}{c}\text { EMTD } \\
(\mathbf{n = 2 2})\end{array}$ & $\begin{array}{c}\text { Controles } \\
(\mathbf{n = 2 2})\end{array}$ & p valor \\
\hline Idade, anos (dp) & $34,8(9,4)$ & $33,8(10,2)$ & $31,810,1)$ & 0,8 \\
Gênero, F(\%) & $14(58,3)$ & $12(54,5)$ & $14(58,3)$ & 0,7 \\
Escolaridade, anos (dp) & $10,5(1,7)$ & $11,0(1,7)$ & $12,0(2,7)$ & $\mathrm{p}<0,05(\S)$ \\
Edimburgo (dp) & $76,0(16,7)$ & $81,0(14,82)$ & $82,0(10,7)$ & 0,3 \\
Beck (dp) & $11,8(9,6)$ & $13,0(8,3)$ & $9,0(4,9)$ & 0,4 \\
História de IPI (\%), $\mathrm{n}$ & $50(12)$ & $68,2(15)$ & & 0,2 \\
Intervalo livre de crises & $10,1(6,0)$ & $8,4(7,8)$ & & 0,5 \\
Idade do início da epilepsia, anos (dp) & $12,0(5,9)$ & $11,6(7,4)$ & & 0,9 \\
Duração da epilepsia, anos (dp) & $22,8(9,0)$ & $21,5(12,1)$ & & 0,8 \\
Duração da doença, anos (dp) & $28(12,7)$ & $28,2(11,0)$ & & 1 \\
Frequência de crises/mês & $7,9(7,7)$ & $6,1(5,4)$ & & 0,4 \\
Número de MAEs já utilizadas & $5,2(1,6)$ & $4,8(1,6)$ & & 0,5 \\
Número de MAEs atuais & $2,5(0,7)$ & $2,6(0,7)$ & & 0,5 \\
Carga de MAEs & $4,3(2,1)$ & $3,8(1,5)$ & & 0,3 \\
Carga de MAEs sedativas & $1,5(2,2)$ & $2,0(1,9)$ & & 1,3 \\
Pacientes operados & 24 & 22 & & \\
EH comprovada histopatologicamente & 24 & 22 & & \\
\hline
\end{tabular}

Legenda: $d p=d e s v i o$ padrãegenda: $d p=$ desvio padral temporal esquerda; $E M T D=E s c l e r o s e$ mesial temporal direita; $\mathrm{M}=$ mulheres; Edimburgo=Inventosio de Edimburgo; Beck=Escala de Beck para depressBeck=Es=Insulto precipitante inicial; MAEs=Medical te antiepilrecipitanEH = esclerose de hipocampo; $\S \mathrm{H}=$ esclerose de 


\subsection{Monitorização por vídeo-EEG}

O tempo médio de internação na unidade de monitorização por vídeoEEG foi de $5 \pm 1,6$ dias.

No período interictal, não foi identificada atividade epileptiforme interictal em apenas um paciente do grupo EMTD. Todos os demais pacientes apresentaram atividade epileptiforme interictal localizada nos eletrodos de projeção temporal ântero-inferior. Não foram registradas anormalidades epileptiformes de projeção extratemporal.

A frequência (média por hora) de descargas à esquerda foi quantificada, para cada paciente, com o objetivo de avaliar o impacto desta variável na reorganização de linguagem.

No período ictal, foram analisadas 204 crises, com média de quatro crises por paciente (mediana três, mínimo duas, máximo 18). Não foram registradas crises de localização extratemporal, crises de classificação indeterminada ou crises não-epilépticas.

\subsection{Classificação de concordância EEG/ RM}

A classificação final EEG/RM (concordantes e discordantes), como descrita anteriormente, foi definida pelas classificações nos períodos interictal e ictal levando-se em consideração os achados na monitorização por vídeo-EEG e a lateralidade da EMT na RM estrutural.

No período interictal, considerando 45 de 46 pacientes, 39 pacientes (85\%) foram classificados como concordantes, 21 pacientes do grupo EMTE e 18 do grupo EMTD (Figura 6). Os resultados da monitorização por vídeo-EEG, para cada paciente, incluindo a frequência de descargas, estão descritos no Anexo 7. 

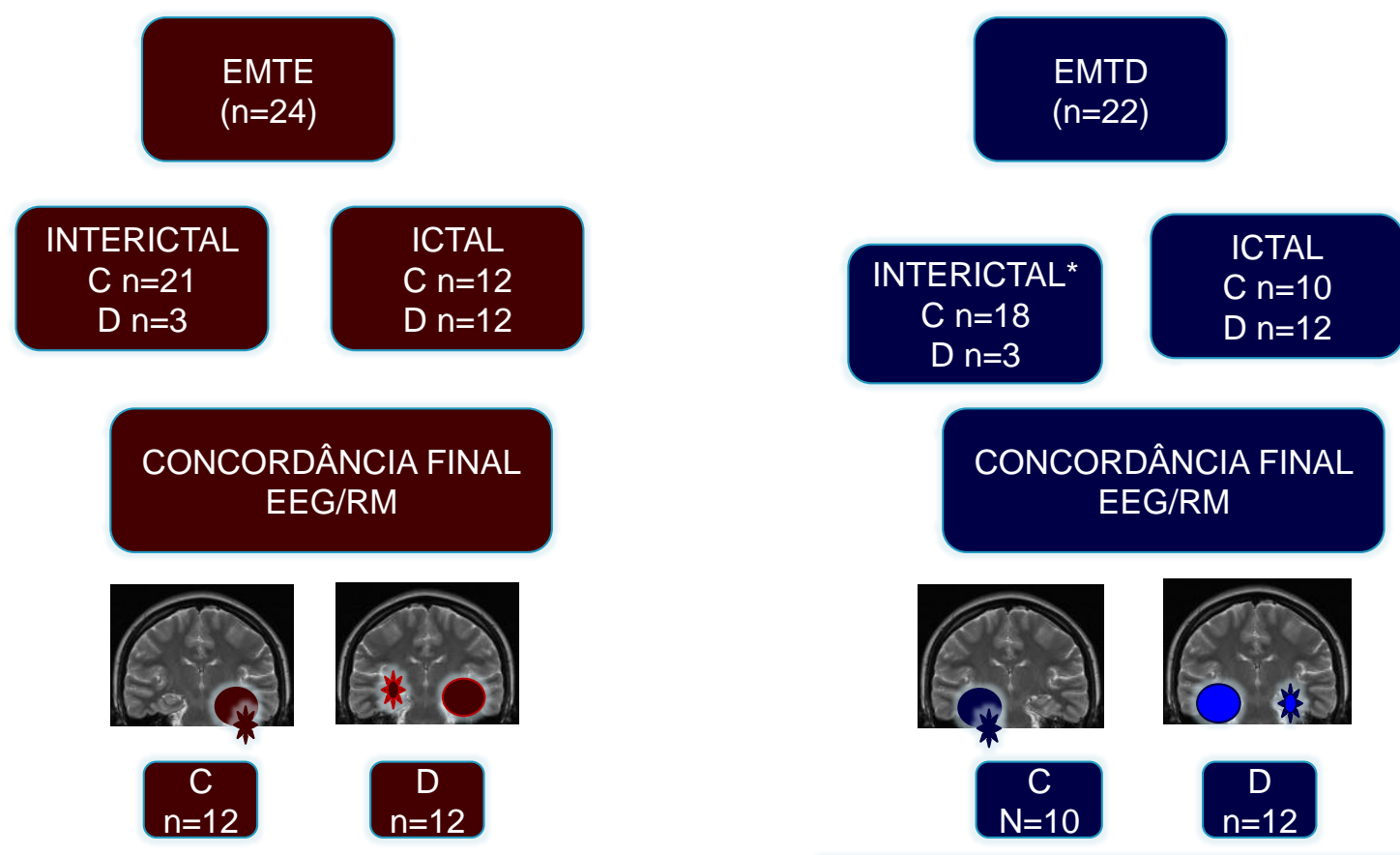

1 paciente sem atividade epileptiforme interictal

Legenda: $E M T E=$ Esclerose mesial temporal esquerda; EMTD=Esclerose mesial temporal direita; $\mathrm{C}=$ concordantes; $\mathrm{D}=$ discordantes

Figura 6. Classificação final de concordância EEG/RM para grupo de pacientes EMTE e EMTD

No período ictal, 24 pacientes (52,2\%) foram classificados como discordantes, 12 pacientes do grupo EMTE e 12 do grupo EMTD. Não houve diferenças no número de crises registradas entre os grupos concordantes $(4,5 \pm 3,8)$ e discordantes $(4,2 \pm 2,5), p=0,7$. No grupo discordante 11 pacientes (44\%) apresentaram crises com início contralateral e 13 pacientes com início bilateral sem predomínio ou com predomínio contralateral.

Todos os pacientes discordantes na fase interictal $(n=6)$ foram discordantes na fase ictal. Do total de 39 pacientes classificados como concordantes na fase interictal, 17(43,5\%) apresentaram atividade epileptiforme discordante na fase ictal. Em todos os casos a classificação final de concordância EEG/RM foi coincidente com a classificação encontrada no período ictal (Tabela 2). 
Tabela 2. Número de pacientes classificados como concordantes e discordantes de acordo com a classificação interictal, ictal e classificação final de concordância EEG/RM estrutural

\begin{tabular}{ccccccc}
\hline & & \multicolumn{2}{c}{ Interictal } & \multicolumn{2}{c}{ Ictal } \\
& & & Concordante & Discordante & Concordante & Discordante \\
\hline \multirow{2}{*}{ Final } & Concordante & $22(47,8 \%)$ & 12 & 0 & 22 & 0 \\
& Discordante & $24(52,2 \%)$ & 17 & 6 & 0 & $24(15 \%)$ \\
\hline
\end{tabular}

Nos grupos concordantes (EMTEc $n=12$ e EMTDc $n=10$ ), sete pacientes EMTE e seis pacientes EMTD apresentaram todas as crises com início ipsilateral à EMT. Os demais pacientes desse grupo, cinco pacientes EMTE e quatro EMTD, apresentaram pelo menos uma crise com início ipsilateral à EMT com repercussão no lobo temporal contra-lateral, mantendo o predomínio ipsilateral. Nos grupos discordantes (EMTEd $n=12$, EMTDd $n=12$ ), quatro pacientes EMTE e quatro pacientes EMTD apresentaram pelo menos uma crise com início eletrencefalográfico no lobo temporal contra-lateral à EMT. Os demais pacientes deste grupo, oito pacientes EMTE e oito pacientes EMTD, apresentaram pelo menos uma crise com início bilateral sem predomínio ou início bilateral com predomínio contralateral à EMT.

A distribuição das características demográficas não diferiu entre controles e grupos de pacientes concordantes e discordantes. Não houve diferenças na distribuição das características clínicas entre os grupos EMTE e EMTD, concordantes e discordantes (Tabela 3). 
Tabela 3. Características dos controles e pacientes EMTE e EMTD, após classificação EEG/RM em subgrupos concordantes e discordantes

\begin{tabular}{llllll}
\hline & \multicolumn{1}{c}{$\begin{array}{c}\text { EMTEc } \\
(\mathbf{n = 1 2})\end{array}$} & $\begin{array}{c}\text { EMTEd } \\
(\mathbf{n = 1 2})\end{array}$ & $\begin{array}{c}\text { EMTDc } \\
(\mathbf{n = 1 0})\end{array}$ & $\begin{array}{c}\text { EMTDd } \\
(\mathbf{n = 1 2})\end{array}$ & $\begin{array}{c}\text { Controles } \\
(\mathbf{n = 2 2})\end{array}$ \\
\hline Idade, em anos (dp) & $33,6(8,6)$ & $36,0(10,3)$ & $32,4(9,9)$ & $35,0(10,7)$ & $31,8(10,1)$ \\
Gênero, \%M (n) & $66,7(8)$ & $50,0(6)$ & $44,4(4)$ & $61,5(8)$ & $58,3(14)$ \\
Escolaridade, em anos (dp) & $10,1(1,3)$ & $10,8(1,9)$ & $11,4(2,3)$ & $10,8(1,0)$ & $12,1(2,7)$ \\
Edimburgo (dp) & $79,0(13,2)$ & $73,0(19,4)$ & $79(16,7)$ & $76,5(21,0)$ & $82,0(10,7)$ \\
Beck (dp) & $14,3(11,0)$ & $8,7(7,0)$ & $12,2(9,9)$ & $13,7(7,3)$ & $9,0(5,0)$ \\
História de IPI, \% (n) & $50,0(6)$ & $50,0(6)$ & $66,7(6)$ & $69,2(9)$ & \\
Dura (9) \% (n)em anos (dp)ordantes & $24,5(8,2)$ & $22,0(9,6)$ & $20,1(13,2)$ & $23,8(9,7)$ & \\
Duração da doença, em anos (dp) & $27,7(11,1)$ & $28,4(14,7)$ & $26,8(13,2)$ & $29,1(9,7)$ & \\
Frequência de crises por mês & $8,2(7,4)$ & $7,7(8,3)$ & $5,0(3,3)$ & $6,8(6,6)$ & \\
Carga de MAEs & $4,6(2,6)$ & $4,1(1,4)$ & $3,6(1,5)$ & $3,9(1,6)$ & \\
Carga de MAEs sedativas & $2,3(1,4)$ & $2,0(1,3)$ & $1,7(1,5)$ & $2,1(1,5)$ & \\
\hline
\end{tabular}

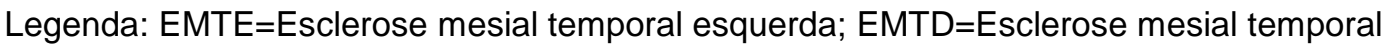
direita; $\mathrm{c}=$ concordante; $\mathrm{d}=$ discordante; $\mathrm{dp}=$ desvio padrão; $\mathrm{M}=$ mulheres; Edimburgo=Inventário de Edimburgo; Beck=Escala de Beck para depressão; IPI=Insulto precipitante inicial;

MAEs=Medicações anti-epilépticas.

\subsection{Teste de Wada e IL-Wada}

Foram submetidos ao teste de WADA para avaliação de linguagem e memória, 42 pacientes (19 EMTD e 23 EMTE). Apenas os dados concernentes à avaliação de linguagem foram utilizados no presente estudo.

O IL-WADA variou de $-0,8$ ( 1 paciente) $a+1$ ( 29 pacientes). No grupo EMTE, dois pacientes apresentaram lateralidade atípica com dominância à direita (IL-Wada -0,2 e -0,8). No grupo EMTD todos os pacientes apresentaram dominância de linguagem à esquerda.

Os resultados dos escores totais individuais e dos escores para cada fator de linguagem separadamente são descritos no Anexo 8. 


\subsection{Resultados da RMf}

\subsubsection{Questionários de avaliação antes e após a RMf}

A pontuação na Escala Analógica de Humor (VAMS, do inglês visual analog mood scale) permite a análise de fatores relacionados a ansiedade, estresse, comprometimento cognitivo e desconforto. A escala foi aplicada em 42 pacientes (23 EMTE e 21 EMTD) e 22 controles. Utilizando testes ANOVA, a pontuação para o fator estresse na fase pré-RMf foi maior nos grupos EMTE e EMTD em relação aos controles $(p<0,05)$. Na fase pós-RMf o fator estresse foi maior nos grupo de paciente EMTE em relação aos controles $(p<0,001)$. $\mathrm{Na}$ comparação entre os grupos EMTD versus controles também se observou a mesma tendência (EMTD > controles), com $\mathrm{p}=0,058$ (Gráfico 1). Quanto comparamos as diferenças intragrupos entre as pontuações antes e após o exame não foram encontradas diferenças nos grupos de pacientes e controles.

Os valores individuais para os questionários VAMS são descritos no Anexo 9.

Gráfico 1. Resultados da pontuação nos questionários préie pós realização do exame de RM funcional e de desempenho nas tarefas comportamentais: comparação entre os grupos EMTE, EMTD e controles. À esquerda do gráfico, valores antes do exame da RMf e àidireta, valores após o exame de RMf

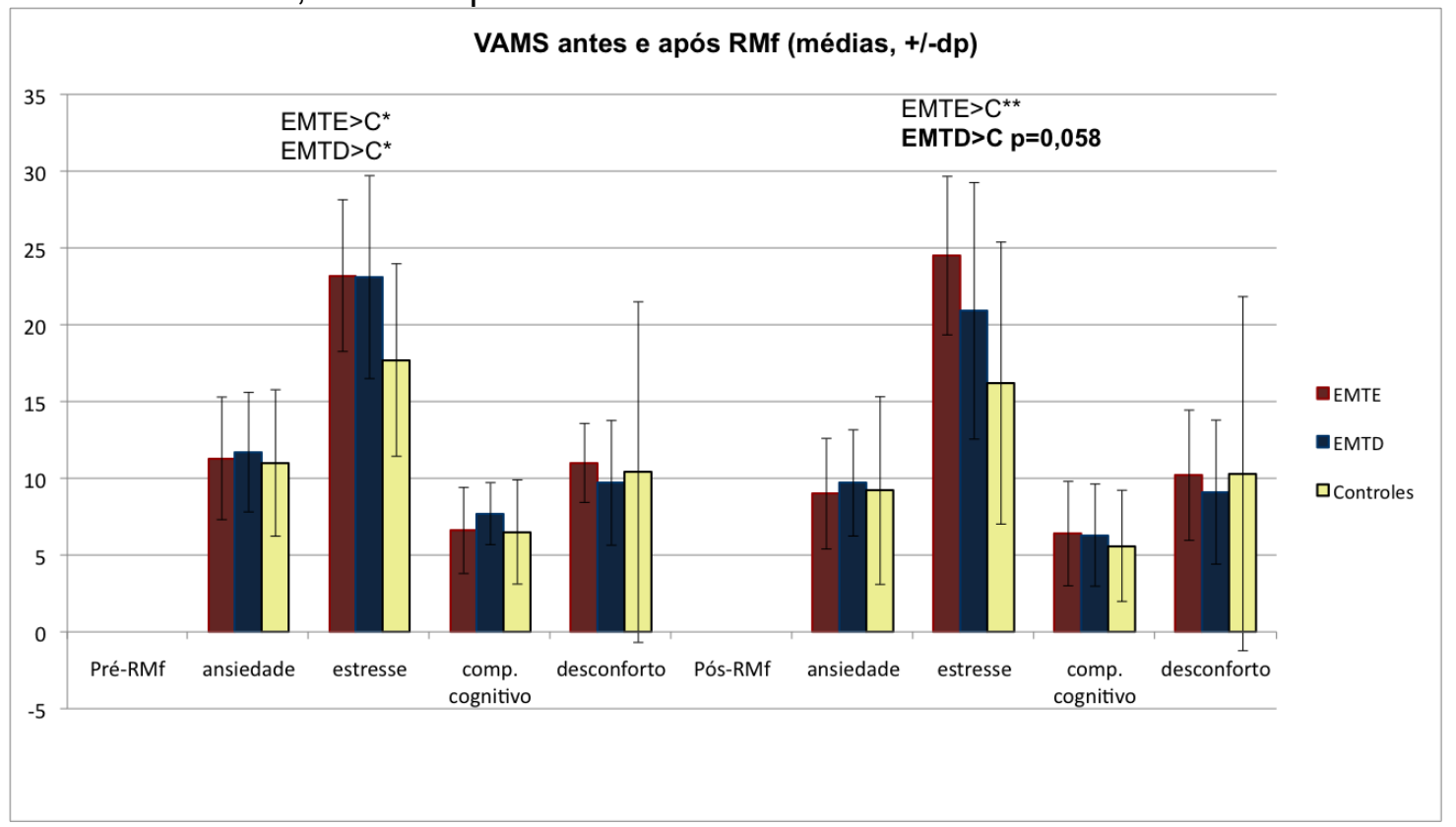

Legenda: EMTE=Esclerose mesial temporal esquerda; EMTD=Esclerose mesial temporal direita; comp. cognitivo=comprometimento cognitivo. ${ }^{*} p<0,05 ;{ }^{* *} p<0,01$ 
As escalas para avaliação de estado de ansiedade e traço de ansiedade (idate-E e idate-T) foram preenchidas para 22 pacientes com EMTE, 21 pacientes com EMTD e 22 controles. Não houve diferenças entre os grupos em relação às pontuações na escala idate-E. Os grupos de pacientes EMTE e EMTD apresentaram maiores valores no idate-T que o grupo controle ( $p<0,05$ e $p<0,01$ respectivamente). Os valores por grupo para as escalas idate-E e idate-T são apresentados no Gráfico 2.

Gráfico 2. Resultados da avaliação de ansiedade através das escalas idate-E e idateT para os grupos EMTE, EMTD e controles

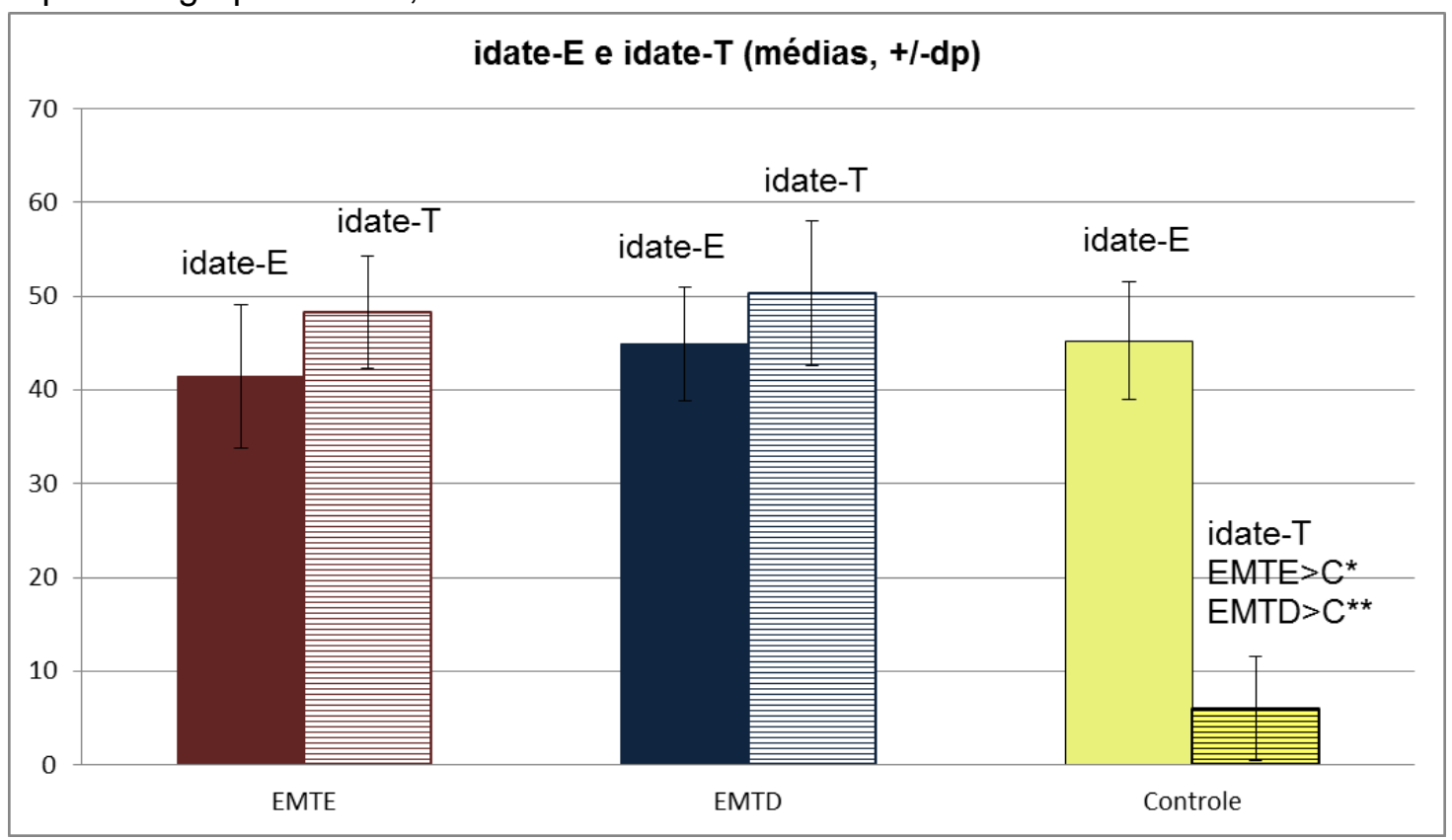

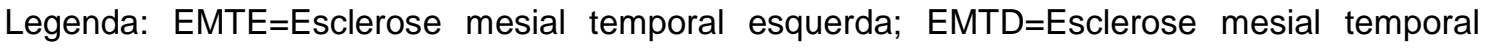
direita; EMTE X controles EMTD X controles $(p<0,01)$.

\subsubsection{Dados comportamentais do paradigma de RMf}

Os dados comportamentais foram adquiridos em 22 pacientes com EMTE, 21 EMTD e 17 controles. Dados não foram obtidos para os demais participantes por problemas técnicos no dia do exame de RMf com o E-prime/eloquence e/ou com o sincronizador programável (trigger). A porcentagem de acertos durante a execução do experimento de RMf foi acima do esperado pela chance em ambos os grupos e menor para cada grupo de pacientes (EMTE e EMTD) em relação ao grupo controle, com $p<0,01$ (Tabela 4). 
Tabela 4. Resultados das respostas comportamentais (porcentagem de acertos) para os grupos EMTE, EMTD e controles

\begin{tabular}{lcccc}
\hline & $\begin{array}{c}\text { EMTE } \\
(\mathbf{n = 2 2})\end{array}$ & $\begin{array}{c}\text { EMTD } \\
(\mathbf{n = 2 1})\end{array}$ & $\begin{array}{c}\text { Controles } \\
(\mathbf{n = 1 7})\end{array}$ & \\
\hline \% de acertos $(\mathrm{dp})$ & $78(11,2)$ & $80,2(12,9)$ & $91,7(6,1)$ & $\begin{array}{l}\Psi 1,7( \\
\Psi 1,7(6\end{array}$ \\
\hline
\end{tabular}

Legenda: EMTE=Esclerose mesial temporal esquerda; EMTD=Esclerose mesial temporal direita. $\Psi$ EMTE < controles; $\Psi \Psi$ EMTD $<$ controles; ${ }^{* * *} p<0,0001$

\subsubsection{Mapas de ativação de grupo}

Utilizando o software MRIcron (www.mricron.com, vers o 12/2009) foi construída uma imagem da superfície cortical em três dimensões, com a representação em cores das respectivas áreas cerebrais onde se observou ativação (para os mapas de grupo- Figuras 7,8 e 9 ).

Nos três grupos: controles, EMTE e EMTD observou-se maior ativação para o contraste condição ativa > condição controle no GFI, GFM, GTS, GTM, GTI, giro do cíngulo e núcleo caudado do hemisfério cerebral esquerdo, além de hemisférios cerebelares e lobos occipitais bilateralmente. 


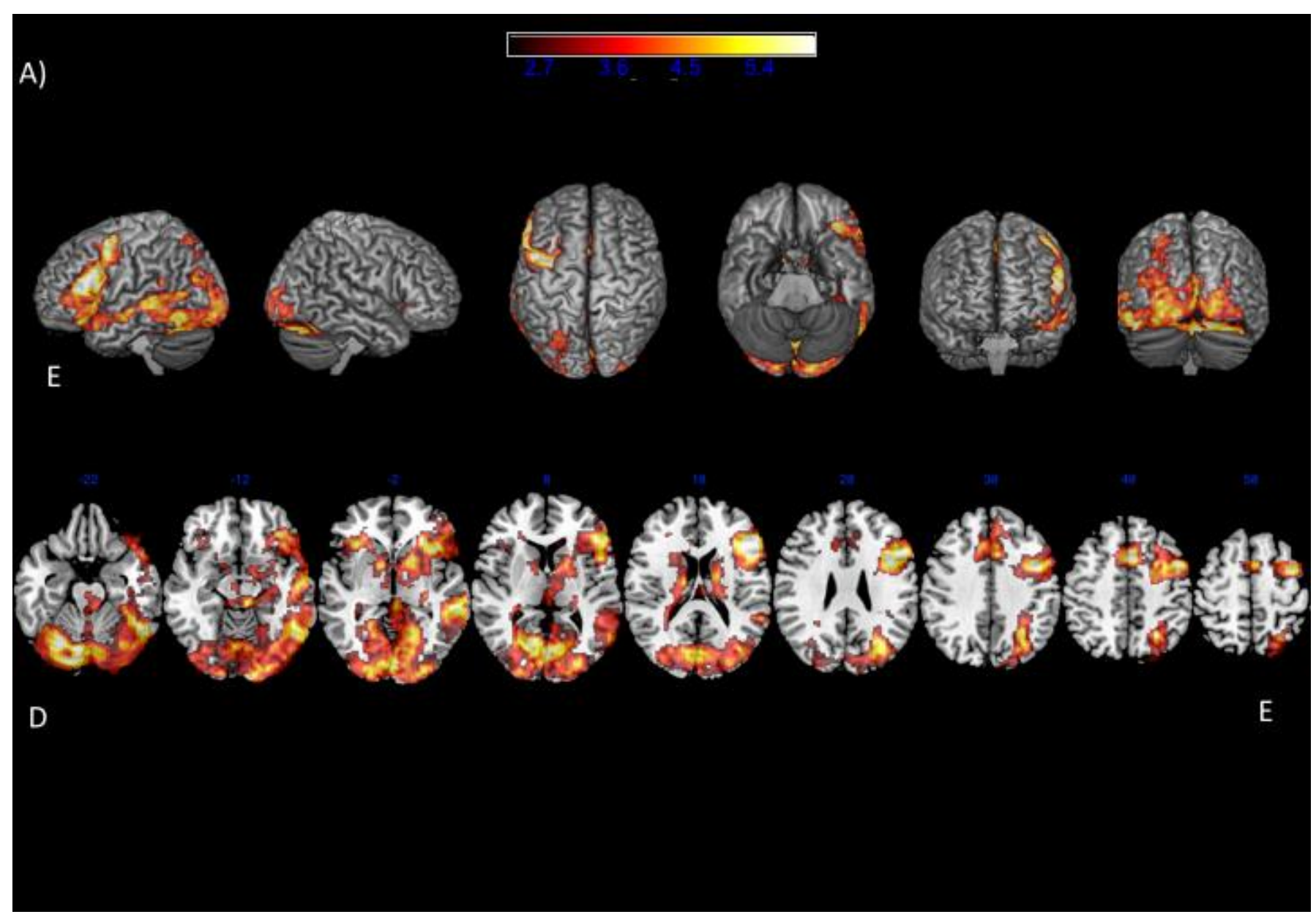

Figura 7. Grupo controle $(n=22)$. Áreas da superfície cortical dos mapas de ativação de grupo para o contraste condição ativa > condição controle (clusters constituídos por voxels com valores de $Z>2.3$, corrigidos para comparações múltiplas $(p<0,05)$. Vistas laterais do hemisfério esquerdo, direito, vistas superior, inferior, anterio e posterior do cérebro. $D=l a d o$ direito, nos cortes axiais 


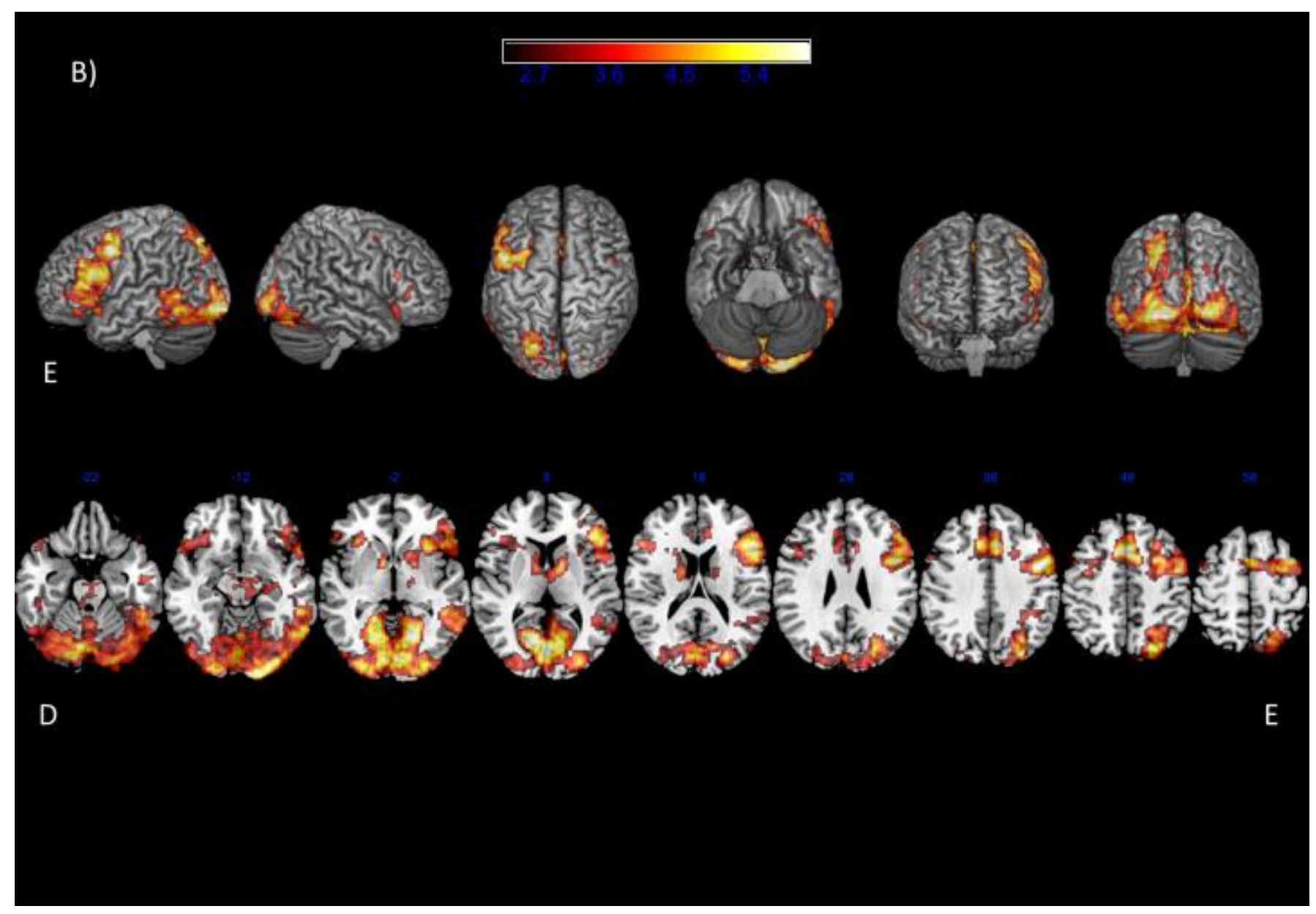

Figura 8. Grupo EMTE $(n=24)$. Áreas da superfície cortical dos mapas de ativação de grupo para contraste condição ativa $>$ condição controle (clusters constituídos por voxels com valores de $Z>2.3$, corrigidos para comparações múltiplas $(p<0,05)$. Vistas laterais do hemisfério esquerdo, direito, vistas posterior superior e inferior do cérebro. $D=l a d o$ direito, nos cortes axiais 


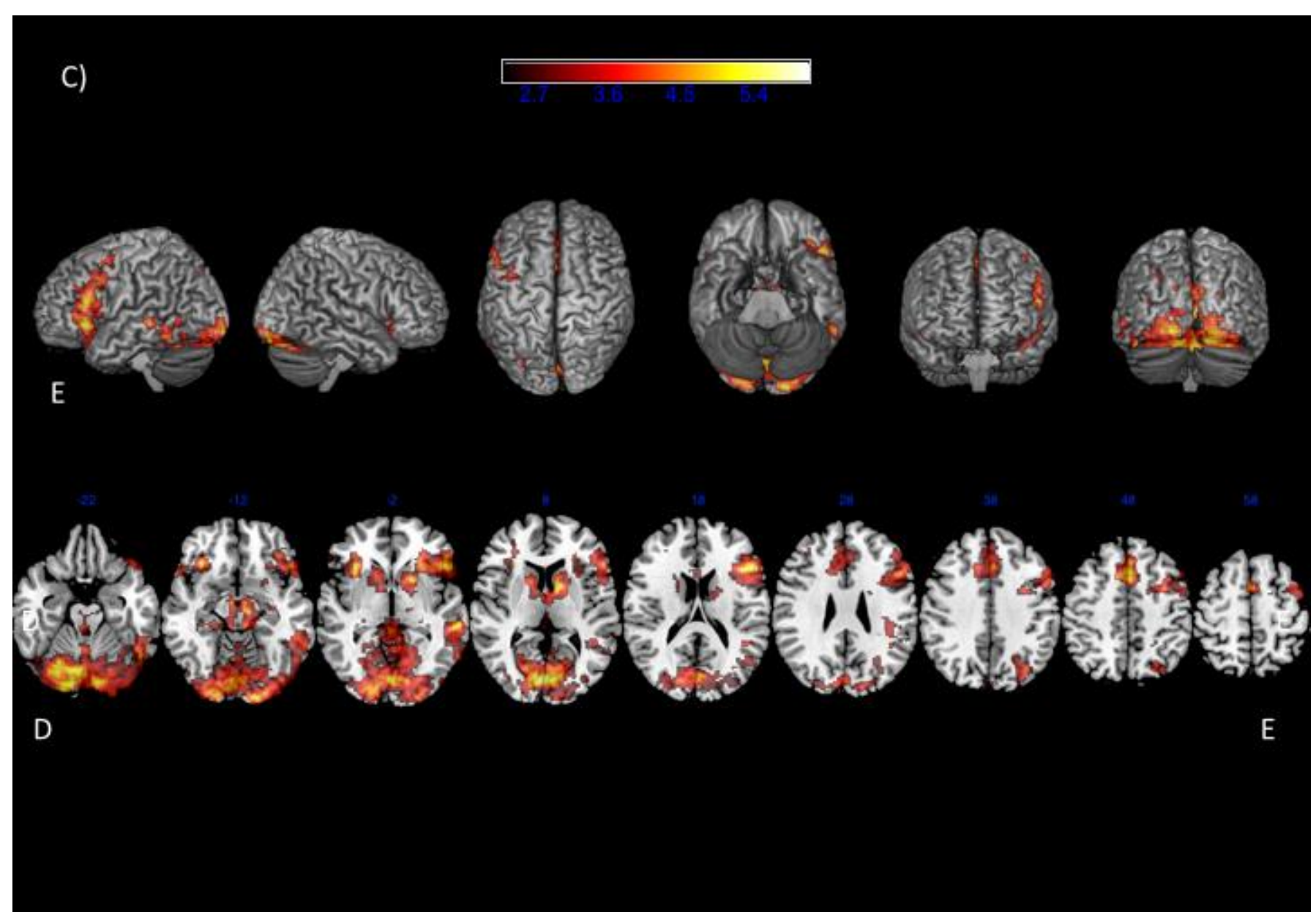

Figura 9. Grupo EMTD ( $n=22)$. Áreas da superfície cortical dos mapas de ativação de grupo para o contraste condição ativa > condição controle (clusters constituídos por voxels com valores de $Z>2.3$, corrigidos para comparações múltiplas $(p<0,05)$. Vistas laterais do hemisfério esquerdo, direito, vistas posterior superior e inferior do cérebro. $D=l a d o$ direito, nos cortes axiais 
Os dados referentes ao tamanho do cluster, coordenadas $\mathrm{MNI}$ dos voxels com pico de ativação e seus valores $Z$ e áreas de Brodmann correspondentes para cada grupo encontram-se no Anexo 10.

A partir dos mapas individuais, foram calculados IL para cada região de interesse.

\subsubsection{Comparações entre IL-Wada e IL-RMf}

A correlação entre o IL-Wada e IL-RMf foi estatisticamente significativa em todas as regiões em que a tarefa mostrou ativação robusta e lateralizada: GFM ( $p=0,01)$; GFI ( $p<0,001) ; \operatorname{GTS}(p=0,020) ; \operatorname{GTM}(p=0,001)$ e GTI $(p=0,001)$.

Não houve correlação entre IL-Wada e IL-RMf no GFS e GA (regiões em que a tarefa não mostrou ativação consistente) e GF/TO (região ativada bilateralmente pela tarefa). Os valores do coeficiente de correlação de Spearman, assim como os valores de $\mathrm{p}$, encontram-se na Tabela 5.

Tabela 5. Valores dos coeficientes de correla1). 1). =0,001) e GTI (p=0,001). al temporal direita.MTD e controleses $\operatorname{EMTD}(\mathrm{ROI})$

\begin{tabular}{lc}
\hline ROI & $\begin{array}{c}\text { Coeficiente de } \\
\text { Spearman }\end{array}$ \\
\hline GFS & 0,157 \\
GFM & $0,387^{* *}$ \\
GFI & $0,594^{* * *}$ \\
GTS & $0,357^{*}$ \\
GTM & $0,509^{* * *}$ \\
GTI & $0,489^{* * *}$ \\
GA & 0,229 \\
GF/TO & 0,151 \\
\hline
\end{tabular}

Legenda: IL-Wada= índice de lateralidade de linguagem por teste de Wada; IL-RMf= índice de lateralidade de linguagem por ressonância magnética funcional; ROI=região de interesse; GFS=Giro frontal superior; GFM=Giro frontal médio; GFI=Giro frontal inferior; GTS=Giro temporal superior; GTM=Giro temporal médio; $\mathrm{GTI}=$ Giro temporal inferior; $\mathrm{GA}=\mathrm{Giro}$ angular; GF/TO=.Giro fusiforme/Temporo-occipital ${ }^{*} p<0,05 ;{ }^{* *} p<0,01 ;{ }^{* * *} p<0,001$ 
A partir deste ponto, todas as análises por ROI não incluiram as regiões em que o paradigma não foi eficaz em elicitar ativação robusta e/ou lateralizada para o contraste condição ativa > condição controle (GFS, GA e GF/TO).

Considerando o total de 42 pacientes submetidos ao teste de Wada, cada paciente foi classificado individualmente, de modo categórico, de acordo com a dominância de linguagem (esquerda (IL-RMf>0.2, direita (ou bilateral) calculada pelo IL pelo teste de Wada e pela RMf.

A seguir, analisamos a concordância entre os dois métodos (Tabela 6). Todos os pacientes com dominância de linguagem à esquerda pela RMf apresentaram dominância de linguagem à esquerda no teste de Wada, em todas as ROls analisadas. Assim como, 100\% dos pacientes com linguagem à direita no teste de Wada apresentaram linguagem à direita na RMf, em todas as regiões. Houve discordância entre os achados em $100 \%$ dos casos em que o paciente foi classificado como bilateral pela RMf. A maior concordância entre os dois métodos foi observada no GFI e GTI (86\%). A menor concordância foi observada no GTS (74\%). Não foram observados casos de discordância extrema (dominância à direita no teste de Wada e à esquerda pela RMf).

Tabela 6. Nabela 6.I (86\%). A menor concord vidualmente, de uperior; GTM=Giro temporal $\mathrm{ml}$ direita.MTD e controleRMf

\begin{tabular}{|c|c|c|c|c|c|}
\hline & & & \multicolumn{3}{|c|}{ Teste de Wada } \\
\hline & & & Esquerda & Bilateral & Direita \\
\hline \multirow{4}{*}{$\begin{array}{c}\text { RMf } \\
\text { (GFM) }\end{array}$} & & Todos & $40(95 \%)$ & 0 & $2(5 \%)$ \\
\hline & Esquerda & $35(84 \%)$ & 35 & 0 & 0 \\
\hline & Bilateral & $4(9 \%)$ & 4 & 0 & 0 \\
\hline & Direita & $3(7 \%)$ & 1 & 0 & 2 \\
\hline \multirow{3}{*}{$\begin{array}{l}\text { RMf } \\
\text { (GFI) }\end{array}$} & Esquerda & $36(86 \%)$ & 36 & 0 & 0 \\
\hline & Bilateral & $2(5 \%)$ & 2 & 0 & 0 \\
\hline & Direita & $4(9 \%)$ & 2 & 0 & 2 \\
\hline \multirow{3}{*}{$\begin{array}{c}\text { RMf } \\
\text { (GTS) }\end{array}$} & Esquerda & $31(74 \%)$ & 31 & 0 & 0 \\
\hline & Bilateral & $4(9 \%)$ & 4 & 0 & 0 \\
\hline & Direita & $7(17 \%)$ & 5 & 0 & 2 \\
\hline \multirow{4}{*}{$\begin{array}{c}\text { RMf } \\
\text { (GTM) }\end{array}$} & Esquerda & $35(83 \%)$ & 35 & 0 & 0 \\
\hline & Bilateral & 0 & 0 & 0 & 0 \\
\hline & Direita & $7(17 \%)$ & 6 & 0 & 1 \\
\hline & Esquerda & $36(86 \%)$ & 36 & 0 & 0 \\
\hline \multirow{2}{*}{$\begin{array}{l}\text { RMf } \\
\text { (GTI) }\end{array}$} & Bilateral & $3(7 \%)$ & 2 & 0 & 1 \\
\hline & Direita & $3(7 \%)$ & 2 & 0 & 1 \\
\hline
\end{tabular}

Legenda: GFM=Giro frontal médio; GFI=Giro frontal inferior; GTS=Giro temporal superior; GTM=Giro temporal médio; GTI=Giro temporal inferior. 
Em resumo, analisando o paradigma de nomeação responsiva à leitura, observamos que:

(1) Todos os participantes mostraram desempenho na tarefa acima do esperado pela chance;

(2) A tarefa foi eficaz em elicitar aumento de ativação em áreas de linguagem relacionadas ao processamento de nomeação por leitura (GFM, GFI, GTS, GTM, GTI e TO/GF)

(3) O IL-RMf para as diferentes regiões analisadas mostrou boa correlação e altas taxas de concordância, a nível individual, com o IL-Wada.

\subsection{Lateralização de linguagem (IL-RMf) em EMTE, EMTD e controles para as diferentes regiões de interesse}

Cada pacientes foi classificado individualmente de acordo com a lateralidade de linguagem (esquerda $x$ bilateral/direita) em cada uma das regiões de interesse. Representação de linguagem à direita ou bilateral (IL-RMf<0,2) foi identificada em 17 a 33\% dos pacientes no grupo EMTE; 14-17\% do grupo EMTD e em 0 a10\% dos indivíduos do grupo controle, a depender da região de interesse (Tabela 7).

As diferenças entre os grupos não foram significativas, embora tenha sido observada tendência de maior representação atípica nos grupos de pacientes, EMTE e EMTD, em todas as ROIs.

Tabela 7. Propor7 TD, entado observada tendfora como at7 TD, ende acordo com a lateralidade de linguagem por RMf, para cada regiegieralidade de

\begin{tabular}{lccc}
\hline & $\begin{array}{c}\text { EMTE } \\
(\mathrm{n}=24)\end{array}$ & $\begin{array}{c}\text { EMTD } \\
(\mathrm{n}=22)\end{array}$ & $\begin{array}{c}\text { Controles } \\
(\mathrm{n}=22)\end{array}$ \\
\hline GFM & $8 / 24(33 \%)$ & $3 / 22(14 \%)$ & $2 / 22(10 \%)$ \\
GFI & $4 / 24(17 \%)$ & $3 / 22(14 \%)$ & $0 / 22(0 \%)$ \\
GTS & $8 / 24(33 \%)$ & $3 / 21(17 \%)$ & $2 / 22(10 \%)$ \\
GTM & $6 / 24(25 \%)$ & $3 / 21(17 \%)$ & $2 / 22(10 \%)$ \\
GTI & $8 / 24(33 \%)$ & $3 / 21(17 \%)$ & $2 / 22(10 \%)$ \\
\hline
\end{tabular}

Legenda: EMTE=Esclerose mesial temporal esquerda; EMTD=Esclerose temporal mesial direita. GFM=Giro frontal médio; GFI=Giro frontal inferior; GTS=Giro temporal superior; GTM=Giro temporal médio; GTI=Giro temporal inferior. 
Os valores médios dos IL-RMf por ROI para cada grupo são descritos na Tabela 8. Os resultados das comparações entre grupos, com respectivos valores de $p$, serão mostrados em gráficos posteriormente.

Tabela 8. Resultados dos IL-RMf por ROI para os grupos EMTE, EMTD e controles. Os resultados são expressos em valores de média e desvio-padrão

\begin{tabular}{lccc}
\hline IL-RMf(dp) & $\begin{array}{c}\text { EMTE } \\
(\mathbf{n = 2 4 )}\end{array}$ & $\begin{array}{c}\text { EMTD } \\
(\mathbf{n = 2 2})\end{array}$ & $\begin{array}{c}\text { Controles } \\
\mathbf{( n = 2 2 )}\end{array}$ \\
\hline GFM & $0,40(0,51)$ & $0,50(0,42)$ & $0,70(0,28)$ \\
GFI & $0,55(0,49)$ & $0,67(0,37)$ & $0,85(0,17)$ \\
GTS & $0,34(0,56)$ & $0,54(0,45)$ & $0,63(0,37)$ \\
GTM & $0,45(0,58)$ & $0,59(0,45)$ & $0,77(0,36)$ \\
GTI & $0,49(0,45)$ & $0,50(0,45)$ & $0,69(0,32)$ \\
\hline
\end{tabular}

Legenda: IL-RMf= índice de lateralidade de linguagem por ressonância magnética funcional; $\mathrm{ROI}=$ região de interesse; EMTE=Esclerose mesial temporal esquerda; EMTD=Esclerose temporal mesial direita. GFM=Giro frontal médio; GFI=Giro frontal inferior; GTS=Giro temporal superior; GTM=Giro temporal médio; GTI=Giro temporal inferior.

Comparando-se as médias dos índices de lateralidade entre os grupos de pacientes EMTE e controles foram observados menores valores de IL-RMf para os grupos EMTE comparados aos controles no GFI, GTS e GTM. Comparando-se as médias dos IL-RMf entre os grupos EMTD e controles, foram observados menores de valores de IL-RMf no grupo EMTD nos GFM e GFI. No GTI os valores de IL-RMf foram menores em ambos os grupos de pacientes, EMTE e EMTD em relação aos controles, porém esta diferença não atingiu significância estatística.

Os resultados das comparações de IL-RMf entre os grupos EMTE, EMTD e controles são mostrados no Gráfico 3. 
Gráfico 3. Resultados de IL-RMf médio X ROI para os grupos EMTE, EMTD e controles. No gráfico são mostrados em destaque os resultados estatisticamente significativos para as comparações $2 \mathrm{X} 2$ entre os grupos

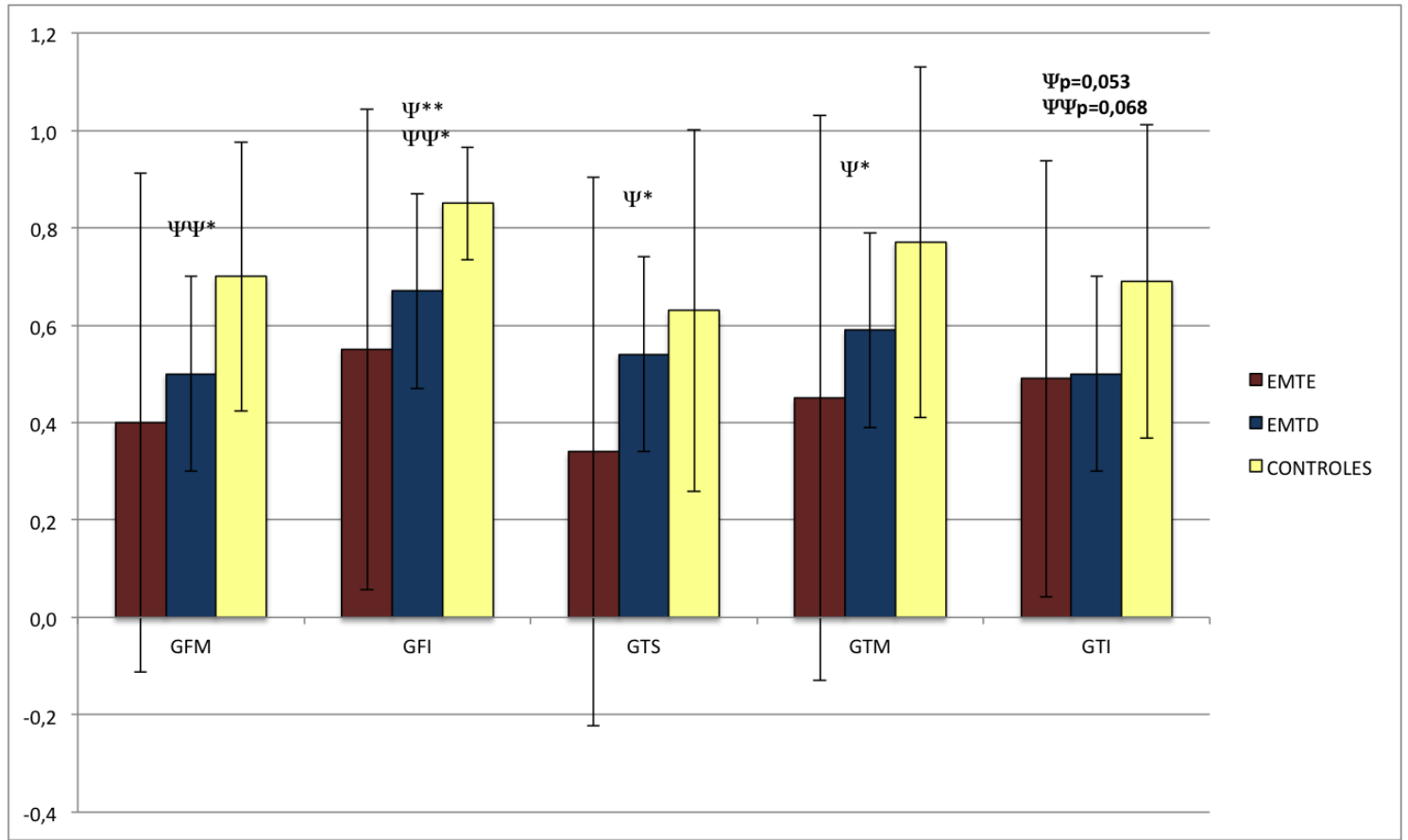

Legenda: IL-RMf =Índice de lateralidade de linguagem por RMf; EMTE=Esclerose mesial temporal esquerda; EMTD=Esclerose mesial temporal direita. GFM=Giro frontal médio; GFI=Giro frontal inferior; GTS=Giro temporal superior; GTM=Giro temporal médio; GTI=Giro temporal inferior; $\Psi$ EMTE X controles; $\psi \Psi$ EMTD X controles; * $p<0,05 ;{ }^{\star *} p<0,01$. 


\subsection{Lateralização de linguagem (IL-RMf) e concordância EEG/RM}

Os grupos EMTE e EMTD foram divididos em subgrupos concordantes e discordantes. Os valores médios de IL-RMf obtidos para cada ROI e para cada subgrupo são mostrados na Tabela 9. Os resultados das comparações entre grupos, com respectivos valores de $\mathrm{p}$, serão mostrados em gráficos posteriormente.

Tabela 9. Resultados dos IL-RMf por ROI para os grupos EMTEc, EMTEd, EMTDc, EMTDd e controles. Os resultados são expressos em valores de média e desviopadrão

\begin{tabular}{lccccc}
\hline IL-RMf $(\mathbf{d p})$ & $\begin{array}{c}\text { Controles } \\
(\mathbf{n = 2 4})\end{array}$ & $\begin{array}{c}\text { EMTDc } \\
(\mathbf{n = 1 0})\end{array}$ & $\begin{array}{c}\text { EMTDd } \\
(\mathbf{n}=12)\end{array}$ & $\begin{array}{c}\text { EMTEc } \\
(\mathbf{n}=12)\end{array}$ & $\begin{array}{c}\text { EMTEd } \\
(\mathbf{n = 1 2})\end{array}$ \\
\hline GFM & $0,70(0,28)$ & $0,70(0,27)$ & $0,35(0,45)$ & $0,37(0,49)$ & $0,44(0,55)$ \\
GFI & $0,85(0,12)$ & $0,76(0,10)$ & $0,60(0,47)$ & $0,51(0,53)$ & $0,60(0,47)$ \\
GTS & $0,63(0,37)$ & $0,62(0,33)$ & $0,48(0,53)$ & $0,31(0,61)$ & $0,37(0,53)$ \\
GTM & $0,77(0,36)$ & $0,71(0,31)$ & $0,51(0,52)$ & $0,57(0,50)$ & $0,34(0,65)$ \\
GTI & $0,69(0,32)$ & $0,60(0,43)$ & $0,43(0,46)$ & $0,58(0,27)$ & $0,40(0,57)$ \\
TO/GF & & & & & \\
\hline
\end{tabular}

IL-RMf =Índice de lateralidade de linguagem por RMf; dp=desvio padrão; ROI=Região de interesse EMTE=Esclerose mesial temporal esquerda; EMTD=Esclerose mesial temporal direita. $\mathrm{C}=$ concordante; $\mathrm{d}=$ =discordante; $\mathrm{GFM}=$ Giro frontal médio; $\mathrm{GFI}=$ Giro frontal inferior;GTS=Giro temporal superior; GTM=Giro temporal médio; GTI=Giro temporal inferior.

Os índices de lateralidade obtidos foram analisados com o teste de ANOVA (Analysis of variance) para 1 fator (ANOVA-one way) para comparações entre os subgrupos concordantes e discordantes. A seguir, para facilitar a visualização, serão apresentados, separadamente, os resultados para cada comparação realizada. 


\subsubsection{Comparação da lateralidade de linguagem nos subgrupos EMTE concordante e EMTE discordante}

A comparação entre os subgrupos EMTEc e EMTEd teve como objetivo testar a hipótese de que o grupo EMTEc apresentaria menores valores de IL-RMf que o grupo EMTEd, uma vez que a presença de atividade epileptiforme à direita, no grupo EMTEd, dificultaria o estabelecimento de representação de linguagem contralateral. Ambos os grupos deveriam apresentar menores valores de IL-RMf que o grupo controle.

As médias dos índices de lateralidade foram significativamente menores no GFM, GFI para ambos os grupos EMTEc e EMTd. Adicionalmente, o grupo EMTEd apresentou menores índices de lateralidade em relação aos controles no GTM e GTI (Gráfico 4).

Gráfico 4. Paradigma de nomeação responsiva à leitura: Comparação IL-RMf médio por ROI entre os grupos EMTEc, EMTEd e controles

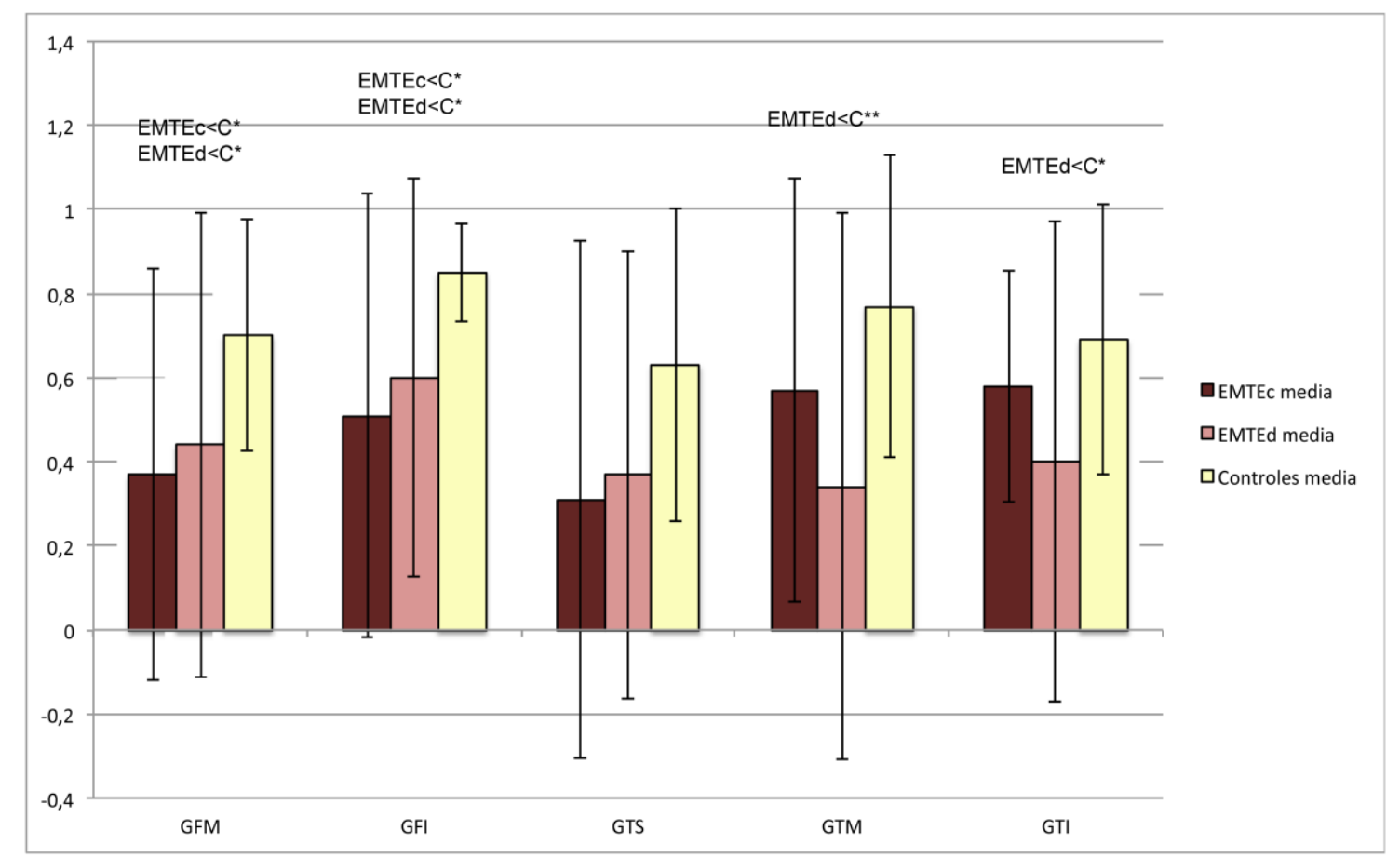

Legenda: IL-RMf=Índice de lateralidade de linguagem por RMf; EMTE=Esclerose mesial temporal esquerda. $\mathrm{C}=$ Controles; $\mathrm{c}=$ concordante; $\mathrm{d}=$ discordante; $\mathrm{GFM=Giro} \mathrm{frontal} \mathrm{médio;}$ GFI=Giro frontal inferior; GTS=Giro temporal superior; GTM=Giro temporal médio; GTI=Giro temporal inferior; * $p<0,05 ;{ }^{* *} p<0,01$. 


\subsubsection{Comparação da lateralidade de linguagem nos subgrupos EMTD concordante e EMTD discordante}

Esta comparação teve por objetivo testar a hipótese de que entre os pacientes com EMTD, o grupo EMTDd (presença de atividade epileptiforme interictal/ictal temporal à esquerda) apresentaria menores valores médios de ILRMf que os grupos EMTDc e o grupo controle. As médias dos índices de lateralidade foram significativamente menores $(p \leq 0,05)$ no GFM, GFI, GTM e GTI para o grupo EMTDd em relação aos controles.

As médias de IL-RMf foram menores no grupo EMTDd em relação ao grupo EMTDc no GFM ( $p \leq 0,05)$. Em todas as demais regiões estudadas, as médias dos índices de lateralidade foram menores em ambos os grupos de pacientes em relação aos controles e também para o grupo EMTDd em relação ao EMTDc, sem alcançar significância estatística (Gráfico 5).

Gráfico 5. Paradigma de nomeação responsiva à leitura: Comparação IL-RMf médio por ROI entre os grupos EMTDc, EMTDd e controles

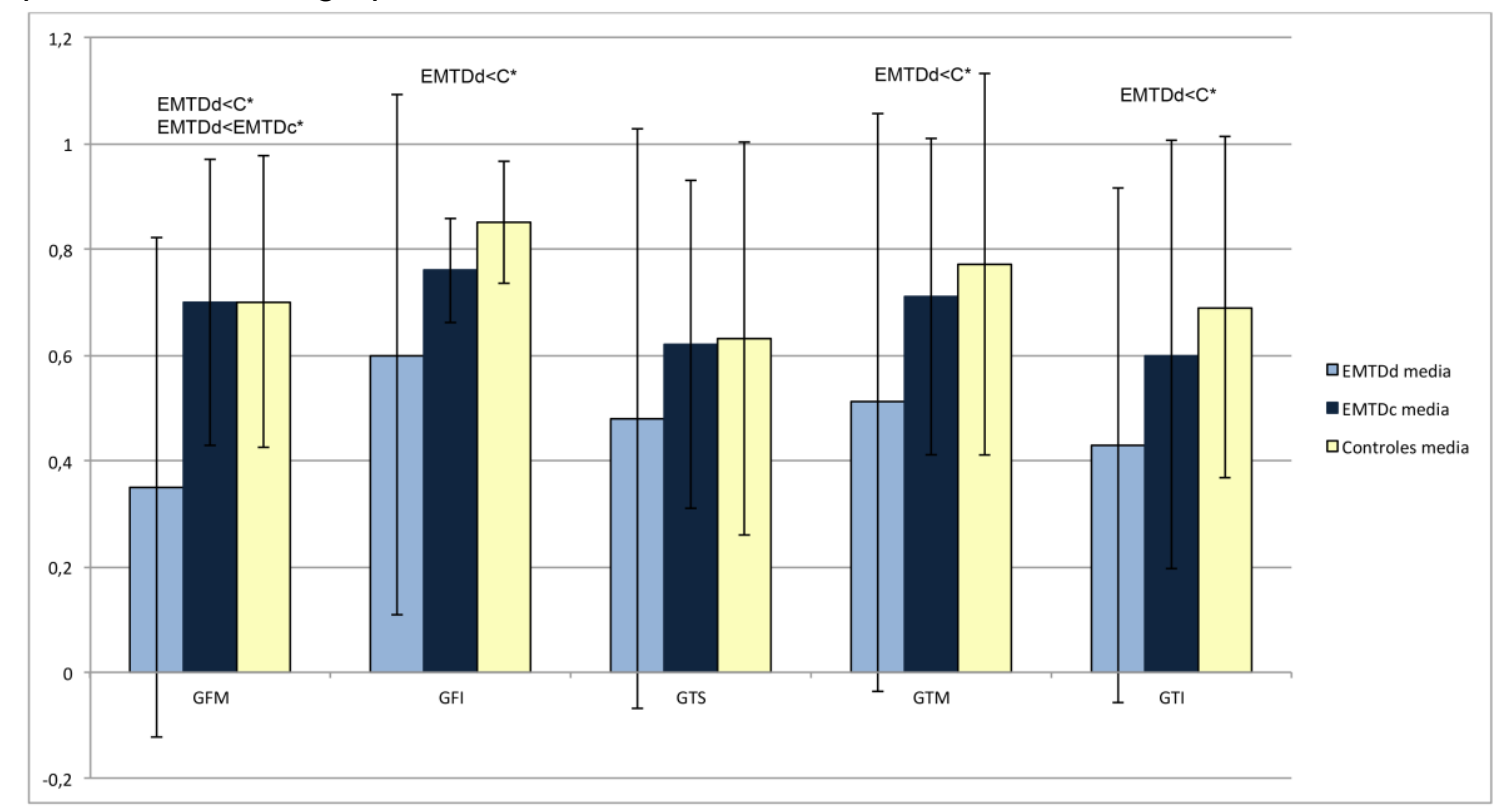

Legenda: IL-RMf=Índice de lateralidade de linguagem por RMf; EMTD=Esclerose mesial temporal direita. $\mathrm{C}=$ =Controles; $\mathrm{C}=$ concordante; $\mathrm{d}=$ discordante; $\mathrm{GFM}=\mathrm{Giro}$ frontal médio; GFI=Giro frontal inferior; GTS=Giro temporal superior; GTM=Giro temporal médio; GTI=Giro temporal inferior; ${ }^{*} p<0,05$. 


\subsubsection{Comparação da lateralidade de linguagem entre subgrupos EMTE e EMTD concordantes e discordantes}

Os subgrupos EMTEc, EMTDc e o grupo controle foram comparados com o objetivo de testar a hipótese de que o grupo de pacientes EMTEc (lesão e atividade epileptiforme ictal/interictal temporal mesial à esquerda) apresentaria menores valores de IL-RMf que os grupos EMTDc (lesão e atividade epileptiforme à direita). As médias dos IL-RMf foram menores no grupo EMTEc em relação ao grupo EMTDc no GFM. Em todas as demais regiões estudadas, as médias dos índices de lateralidade foram menores em ambos os grupos de pacientes em relação aos controles e também para o grupo EMTEc em relação ao EMTDc, sem alcançar significância estatística (Gráfico 6).

Gráfico 6. Paradigma de nomeação responsiva à leitura: Comparação IL-RMf médio por ROI entre os grupos EMTEc X EMTDc X Controles

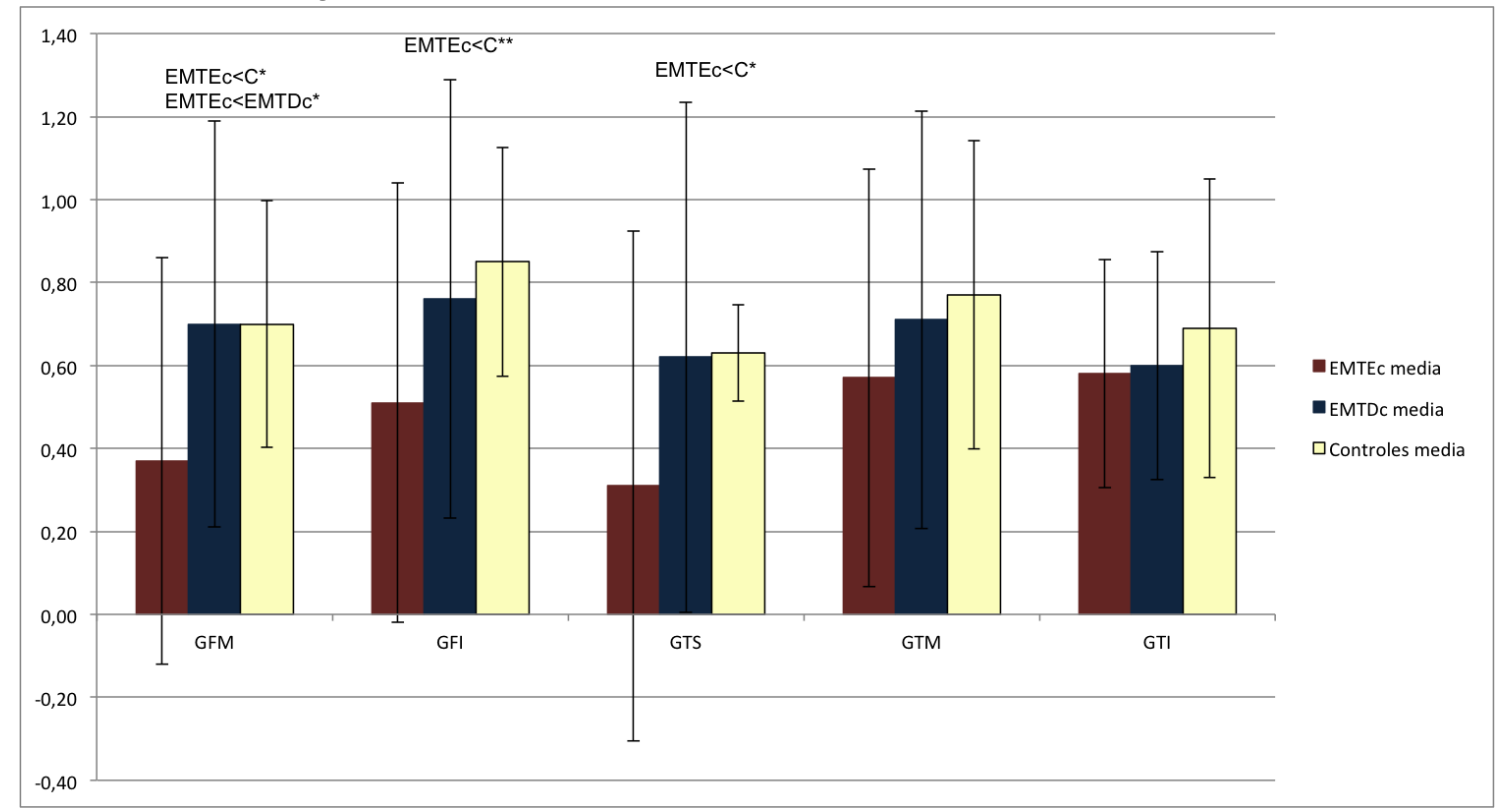

Legenda: IL-RMf=Índice de lateralidade de linguagem por RMf; EMTE=Esclerose mesial temporal esquerda; EMTD=Esclerose mesial temporal direita. C=Controles; $\mathrm{C}=$ concordante; GFM=Giro frontal médio; GFI=Giro frontal inferior; GTS=Giro temporal superior; GTM=Giro temporal médio; GTI=Giro temporal inferior. * $p<0,05{ }^{* *} p<0,01$. 
A seguir, foram comparados os subgrupos EMTEc e EMTDd. Esta comparação visou a testar a hipótese de que o grupo EMTEc (presença de lesão e atividade epileptiforme temporal mesial à esquerda) apresentaria menor lateralização de linguagem à esquerda (menores valores de IL-RMf) em relação ao grupo EMTDd (presença de fator atividade epileptiforme temporal mesial à esquerda). Não foram observadas diferenças entre EMTEc e EMTDd. As diferenças entre os valores médios de IL-RMf entre os grupos EMTEc e EMTDd e o grupo controle foram descritas como parte de comparações anteriores (Gráfico 7).

Gráfico 7. Paradigma de nomeação responsiva à leitura: Comparação IL-RMf médio por ROI entre os grupos EMTEc, EMTDd e grupo controle

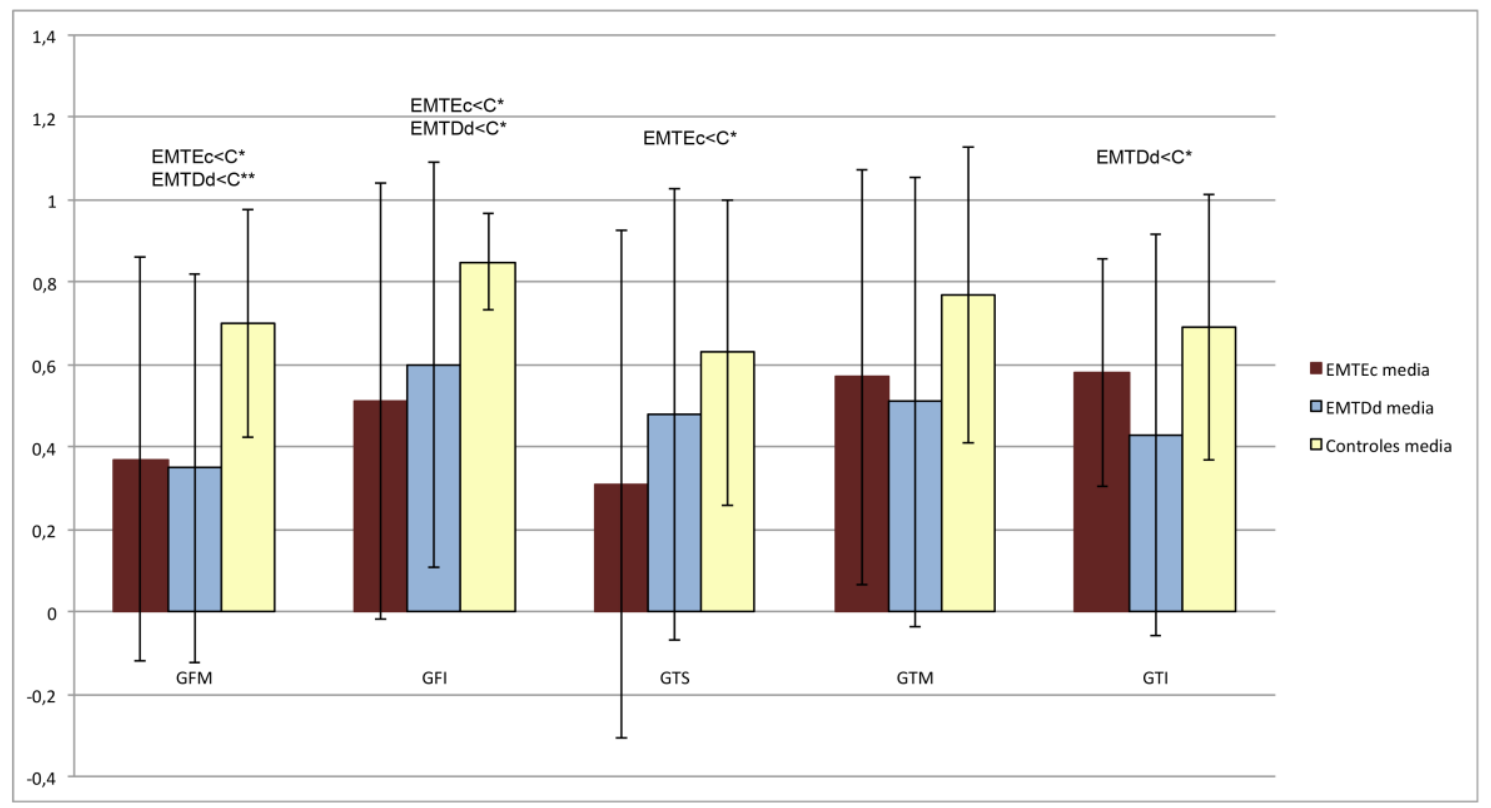

Legenda: IL-RMf=Índice de lateralidade de linguagem por RMf; ROI=Região de interesse; EMTD=Esclerose mesial temporal direita. $C=$ Controles; $C=$ concordante; d=discordante; GFM=Giro frontal médio; GFI=Giro frontal inferior;GTS=Giro temporal superior; GTM=Giro temporal médio; $G T I=G i r o$ temporal inferior. ${ }^{*} p<0,05 ;{ }^{* *} p<0,01$. 


\subsection{Lateralização de linguagem (IL-RMf) e variáveis clínicas}

Os pacientes foram divididos em grupos, de acordo com idade do início da epilepsia, em: precoce ( $\leq 12$ anos) e tardia (>12 anos); duração da epilepsia maior ( $\geq 25$ anos) e menor ( $<25$ anos) e frequência de descargas à esquerda em alta $(\geq 5 / h)$ e baixa $(<5 / h)$.

A média de idade de início da epilesia foram $7,9 \pm 2,8$ anos e $17,8 \pm 4,1$ anos, para os grupos de início precoce e tardio, respectivamente. A média do tempo de epilepsia foram $15,5 \pm 5,2$ e $32,2 \pm 5,6$ anos, para os grupos menor e maior tempo, respectivamente.

A frequência de descargas à esquerda por hora foi de $0,5 \pm 0,9$ e $88,6 \pm 123$, para os grupos com baixa e alta frequência de descargas por hora, respectivamente.

Os dados referentes às características clínicas da epilepsia, frequência de descargas à esquerda e IL-RMf por ROI, para cada indivíduo encontram-se no Anexo 11.

As análises, com teste t, para as variáveis contínuas (idade do início da epilepsia, duração da epilepsia e frequência de descargas à esquerda) mostraram que a maior frequência de descargas à esquerda associou-se a menor IL-RMf, no $\operatorname{GTM}(0,39 \pm 0,60$ versus $0,69 \pm 0,27, p=0,01)$. Não se encontraram associações entre as demais características estudadas e os IL. O número de pacientes por grupo, assim como médias e desvios-padrão de ILRMf estão apresentados na Tabela 10. 
Tabela 10. Resultados dos IL-RMf e aspectos clesultados dos IL-RMf squerdascargas à eexpressos em valores de malores de lesultados

\begin{tabular}{llccccc}
\hline \multirow{2}{*}{ IIE, anos } & Valor $(\mathbf{n})$ & GFM & GFI & GTS & GTM & GTI \\
\cline { 2 - 7 } & precoce $(25)$ & $0,45(0,49)$ & $0,58(0,50)$ & $0,44(0,59)$ & $0,52(0,49)$ & $0,46(0,42)$ \\
& tardio (21) & $0,45(0,45)$ & $0,64(0,36)$ & $0,43(0,42)$ & $0,52(0,56)$ & $0,53(0,47)$ \\
\hline \multirow{2}{*}{ TE, anos } & maior (20) & $0,34(0,55)$ & $0,55(0,46)$ & $0,41(0,57)$ & $0,48(0,52)$ & $0,47(0,45)$ \\
& menor (26) & $0,47(0,40)$ & $0,61(0,45)$ & $0,45(0,48)$ & $0,55(0,53)$ & $0,52(0,45)$ \\
\hline \multirow{2}{*}{ Freq desc E Elta (18) } & $0,40(0,50)$ & $0,55(0,50)$ & $0,33(0,52)$ & $\mathbf{0 , 3 9 *}(0,60)$ & $0,47(0,48)$ \\
& Baixa (28) & $0,48(0,45)$ & $0,65(0,40)$ & $0,50(0,51)$ & $0,69(0,27)$ & $0,51(0,43)$ \\
\hline
\end{tabular}

Legenda: IIE: Idade de in IL-RMf squerdascargas à eexpressos em início da epilepsia, duração da epilepsia e frequência de descargas à esquerda) mostraram que a maior frequência de descargasGFI=Giro frontal inferior; GTS=Giro temporal superior; GTM=Giro temporal médio; $\mathrm{GTI}=$ Giro temporal inferior.

* Teste $T, p<0,05$

Análises adicionais foram realizadas utilizando o teste exato de Fisher, após dividir os pacientes de acordo com a classificação categórica de linguagem (esquerda e direita/bilateral) e utilizando regressão linear múltipla, método stepwise. Ambos os métodos não identificaram associações entre presença de IPI, idade de início da epilepsia, tempo de epilepsia ou frequência de descargas e lateralidade atípica de linguagem. 


\section{DISCUSSÃO}

O presente estudo teve como objetivo avaliar a lateralidade de linguagem por RMf em uma população homogênea de pacientes com epilepsia secundária a EMT, em programação de tratamento cirúrgico.

Observa-se dominância de linguagem à esquerda em cerca de 95\% dos indivíduos destros saudáveis (Springer et al; 1999; Pujol et al; 1999; Knecht et al; 2000). A dominância atípica de linguagem (bilateral ou à direita) é cerca de quatro vezes mais frequente em indivíduos saudáveis com dominância manual à esquerda. Este achado parece estar associado a fatores genéticos (Szaflarski et al; 2002). A dominância atípica de linguagem é também mais frequente em populações de pacientes com lesões no hemisfério esquerdo, sobretudo pacientes com epilepsia (Rasmussen e Milner, 1977; Loring et al; 1990; VarghaKhadem et al; 1985; Woods et al; 1988). Neste grupo de pacientes, a maior participação do hemisfério direito no processamento de linguagem possivelmente estaria associada a lesões hemisféricas à esquerda de instalação precoce. Lesões estabelecidas em idades mais precoces, geralmente antes dos seis anos de idade, associam-se a maior prevalência de dominância atípica de linguagem, sugerindo esta dominância seja estabelecida na primeira infância (Rasmussen e Milner, 1977; Helmstaedter et al; 1997, Springer et al; 1999).

Em estudos de populações heterogêneas de pacientes com epilepsia, pacientes com EMT mais frequentemente apresentam dominância atípica de linguagem (Jansky et al; 2003; Weber et al; 2006), fato pouco compreendido, pois contraria a noção intuitiva de que 0 acometimento de estruturas temporais neocorticais (e não hipocampais) teria maior impacto na reorganização cerebral de linguagem.

Fatores funcionais associados à atividade epileptiforme têm impacto sobre a representação de linguagem (Jansky et al., 2006). Considerando que pacientes com EMT unilateral podem exibir atividade epileptiforme bilateral ou predominantemente contralateral (Williamson et al; 1993), seria desejável 
avaliar o papel da lateralidade da atividade epileptiforme na representação de linguagem, aspecto ainda não estudado.

Conhecer os fatores que influenciam a organização (típica e atípica) de linguagem tem importância teórica para a compreensão de aspectos envolvidos na organização e reorganização de funções cognitivas. Não está completamente estabelecido quais os fatores clínicos (como presença de IPI, idade do início da epilepsia e duração da doença) estariam associados à lateralidade de linguagem em populações homogêneas de EMT.

Do ponto de vista prático, a determinação da lateralização de linguagem pré-operatória é importante em pacientes com epilepsia focal, porque a representação de linguagem pode determinar o prognóstico de declínio de memória verbal e déficit de nomeação pós operatório (Binder et al., 2008; Sabsevitz et al., 2003). Determinar as variáveis associadas à representação hemisférica de linguagem teria impacto potencial em estratégias cirúrgicas e de reabilitação destes pacientes ao identificar grupos de maior risco de declínio cognitivo no pós-operatório (Binder et al., 2008).

O teste de Wada, método classicamente utilizado para determinação de lateralidade de linguagem, vem sendo progressivamente substituído pela RMf nos mais diversos centros (Baxendale et al., 2009). A metodologia utilizada em RMf de linguagem está em constante aprimoramento, sobretudo na última década (Wilke \& Lizdba, 2007; Price, 2012). Um dos desafios do presente estudo foi determinar a lateralidade de linguagem através de RMf, em substituição ao teste de Wada, utilizando um paradigma desenvolvido na língua portuguesa.

\subsection{Casuística}

No presente estudo, buscamos evitar o efeito de possíveis variáveis de confundimento para avaliar, especificamente, o papel da presença da EMT sobre a reorganização de linguagem. O diagnóstico de EMT foi comprovado histopatologicamente em todos os pacientes e foram incluídos, apenas, indivíduos 
com quadro de epilepsia do lobo temporal associada à esclerose de hipocampo, com rigorosa documentação clínica, video-eletrográfica e de neuroimagem.

Nossa amostra foi representativa em termos demográficos e clínicos da população com EMT descrita em séries cirúrgicas (French et al., 1993; Keller et al., 2007; Shukla et al., 2012; Binder et al., 2014). A população de pacientes constituiu-se de adultos de 19 a 53 anos, com distribuição equitativa entre os gêneros e escolaridade média de 11 anos. História de IPI foi descrita em mais da metade dos casos. O intervalo livre de crises foi, em média, de 10 anos antes do início da epilepsia. Observou-se alta frequência de crises, refratariedade a grande número de medicações e média de 20 anos de duração da epilepsia.

As variáveis idade, gênero e dominância manual (pontuação na escala de Edimburgo) não apresentaram diferenças entre grupo de pacientes e controles. A escolaridade dos pacientes, mesmo acima da média encontrada em nosso ambulatório, foi um ano menor que a dos controles. Uma vez que os indivíduos do grupo controle eram provenientes do mesmo meio social dos pacientes, o menor tempo de escolaridade neste grupo pode ser resultante do impacto psicossocial da doença, aspecto classicamente descrito em indivíduos com epilepsia (Boer et al., 2008).

Os grupos EMTE e EMTD foram comparáveis em termos de presença de IPI, duração da doença e da epilepsia, frequência de crises no último mês, carga geral de medicações e carga de medicações sedativas.

\subsection{Monitorização por vídeo-EEG}

Em pacientes com epilesia do lobo temporal unilateral pode ser observada atividade epileptiforme bilateral, tanto na fase ictal quanto na fase interictal (Wiliamsom et al., 1993). A presença de atividade epileptiforme bilateral poderia ser explicada pela rápida propagação da descarga para o lobo temporal contralateral via comissura anterior, corpo caloso e comissura hipocampal (Lieb et al., 1987) ou de modo alternativo, pelo surgimento de foco 
epiléptico secundário desencadeado por atividade epileptiforme a partir de um foco primário (Timofeeva et al., 1991).

Os pacientes com atividade epileptiforme predominantemente contralateral à lesão estrutural são comumente designados na literatura como pacientes discordantes, porém os critérios de classificação utilizados são bastante variáveis.

$\mathrm{Na}$ fase interictal, a nossa amostra foi constituída predominantemente por pacientes classificados como concordantes (85\%). Esta proporção encontrada foi maior do que a da literatura, que varia de 50-73\% (Williamson et al., 1993; Ebner \& Hoppe, 1995; Cendes et al. 2000, Castro et al., 2008). Estas diferenças podem ser explicadas pelo tempo menor de avaliação interictal (Cendes et al. 2000) e pelo uso de diferentes critérios de classificação. Em apenas um caso não foi identificada atividade epileptiforme interictal. Esta proporção $(2,2 \%)$ foi menor que a descrita na literatura (Williamson et al., 1993, 4\%).

$\mathrm{Na}$ fase ictal, $52,2 \%$ dos pacientes foram classificados como discordantes. A proporção de discordantes foi superior à descrita na literatura para EEG de superfície, 3-29\% (Williamson et al.1993, 13\%; King et al., 1997, 28\%; Cendes et al., 2000, 23\%, Castro et al. 2008, 29\%).

A determinação do início ictal no EEG pode ser controversa, uma vez que alterações sutis podem ser subjetivas e examinador-dependente (Castro et al., 2008). A grande variabilidade encontrada e a alta proporção de pacientes classificados como discordantes identificada no presente estudo também pode ser explicada pela variabilidade do critério utilizado para classificação. Os estudos supra-citados consideraram como discordantes apenas pacientes com início de crise nitidamente contralateral à lesão. No presente estudo, para fins de avaliação da função cognitiva, foram classificados como discordantes pacientes em que a atividade epileptiforme ictal evoluiu para o lado contralateral e não apenas casos em que a crise se inicia no outro lado. Considerando que o hemisfério esquerdo é o hemisfério dominante de linguagem, buscamos verificar se a presença de atividade epileptiforme independente à esquerda no grupo EMTD estaria relacionada a maior lateralização atípica de linguagem. Esta associação seria justificável, uma vez que, teoricamente, a presença de atividade epileptiforme à esquerda perturbaria o processamento de linguagem do lado dominante. Inversamente, a presença de atividade epileptiforme à 
direita no grupo EMTE poderia dificultar o desenvolvimento de representações atípicas de linguagem. Desta forma, buscamos utilizar um critério mais abrangente, considerando como discordantes na fase ictal não somente aqueles indivíduos com início nitidamente contralateral, como também pacientes com envolvimento bilateral (sem predomínio e com predomínio contralateral).

$\mathrm{Na}$ classificação final de concordância, somando os achados da fase ictal e interictal esta proporção se manteve, uma vez que todos os pacientes discordantes na fase interictal eram também discordantes na fase ictal. Este achado demonstra que a análise da fase ictal foi mais sensível para identificar a presença de perturbação funcional contralateral à lesão. Considerando que os pacientes estudados apresentavam alta frequência de crises (média de sete crises/mês), conhecer o grau de envolvimento contralateral durante a fase ictal mostrou-se fundamental para classificar pacientes sob risco de comprometimento funcional contralateral.

\subsection{Ressonância magnética funcional}

Observa-se grande variedade de paradigmas de RMf para avaliação de linguagem pré-operatória nos diversos centros. A escolha do paradigma utilizado depende da pergunta científica e da capacidade dos sujeitos de cooperarem com a tarefa (Szaflarski et al; 2006). Há tarefas em que predomina a fluência, como no paradigma de geração de palavras (Liegeois et al., 2002), tarefas com maior componente de processamento semântico, como decisão semântica (Szaflarski et al., 2008), leitura em silêncio (Gaillard, et al. 2002), nomeação responsiva (Gaillard et al. 2002) e ouvir estórias passivamente (Lehericy et al. 2000).

O paradigma de geracão de palavras promove ativacão robusta do GFI esquerdo e ativacões menos intensas do GTS (Palmer et al; 2001). À medida que componentes semânticos são associados à tarefa de producão de 
linguagem, observa-se maior ativacão de regiões posteriores de linguagem (Springer et al; 1999). É necessário avaliar a reorganização de linguagem para múltiplas regiões de interesse, uma vez que o foco epiléptico pode ter impacto variável sobre diferentes regiões. A presença de foco epiléptico temporal mesial, embora distante de áreas de processamento neocortical de linguagem, associa-se a lateralidade atípica de linguagem em regiões frontais e temporais. (Gaillard et al. 2007; Janszky et al. 2006; Weber et al., 2006).

Optamos por elaborar, na língua portuguesa, o paradigma de nomeação responsiva à leitura, considerando os seguintes aspectos:

(1) Pacientes com EMT apresentam desempenho comprometido em tarefas de nomeacão (Bell e Davies, 1998).

(2) É um paradigma facilmente adaptável ao ambiente de RM;

(3) Permite a avaliação do desempenho do paciente dentro da máquina;

(4) O paradigma de nomeacão responsiva à leitura mostrou-se eficaz em ativar de modo robusto áreas temporais e frontais de linguagem em estudo prévio (Gaillard et al; 2002).

A seguir, buscando validar o nosso paradigma, discutimos os resultados dos questionários de avaliação de humor e ansiedade aplicados no dia da RMf, as respostas comportamentais obtidas, os padrões de mapas de ativação de grupos e, finalmente, os resultados das comparações entre a lateralidade de linguagem pela RMf em comparação ao teste de Wada.

\subsubsection{Questionários de avaliação de humor e ansiedade}

A pontuação na escala Analógica de Humor (VAMS, do inglês visual analog mood scale) permite a análise de fatores relacionados a ansiedade, estresse, comprometimento cognitivo e desconforto. $O$ fator estresse nas fases pré e pós-RMf foi maior nos grupos EMTE e EMTD em relação aos controles. Este achado pode ser explicado pela maior expectativa dos pacientes em 
relação ao diagnóstico de anormalidades pela RM e/ou pela maior prevalência de transtornos ansiosos em pacientes com epilepsia (Gaitatzis A et al., 2004).

As escalas idate- $E$ e idate-T consistem em questionários de autoavaliação amplamente utilizados para avaliação do traço ansioso (IDATE-traço) e do estado ansioso (IDATE-estado). Os resultados encontrados em nossa população de controles foi similar ao encontrado na literatura nacional (Biaggio e Natalício, 1979). Os grupos de pacientes apresentaram maiores valores no idate-T que o grupo controle.

A pontuação no Inventário de Depressão de Beck foi inferior a 10 para todos os participantes e similar entre os grupos de pacientes e controles. Não foram incluídos neste estudo indivíduos com doença psiquiátrica descompensada, uma vez que poderia haver comprometimento de desempenho cognitivo e menor engajamento na tarefa de RMf.

\subsubsection{Respostas comportamentais}

O paradigma que utilizamos era do tipo overt, uma vez que o participante era orientado a dizer em voz alta que palavra a frase apresentada descrevia. Nos paradigmas do tipo covert, o participante é instruído a pensar na resposta em silêncio, não sendo possível ter acesso ao grau de engajamento na tarefa (Partovi et al., 2012). Monitorizar o desempenho do paciente durante a execução da tarefa é importante para avaliar os padrões de mudança da atividade cerebral relacionados à tarefa.

As respostas de pacientes e controles foram gravadas e posteriormente analisadas em relação ao número de acertos. A porcentagem de acertos de cada grupo de pacientes (EMTE e EMTD) foi menor do que a do grupo controle. Este achado reflete o pior desempenho dos pacientes observado na prática clínica. Porém, a porcentagem de acertos, em ambos os grupos, foi acima do esperado pela chance, indicando engajamento satisfatório durante a realização da tarefa. 


\subsubsection{Paradigma de NRL: mapas de ativação de grupo}

O paradigma NRL mostrou-se eficaz em promover, de modo robusto, maior ativação para o contraste condição ativa> condição controle, em regiões relacionadas ao processamento de linguagem.

A região cerebral ativada especificamente durante a leitura de palavras escritas é a região ventral ao longo do sulco occipitotemporal esquerdo (também referida como porção medial do giro fusiforme). A porção mais posterior relaciona-se com extração de características visuais e a mais anterior com o processamento léxico-semântico da palavra escrita. O giro angular (GA) associa-se a integração de características multimodais e processamento visual da forma da palavra. A via associada à conversão da informação lexical (ortográfica) em informação semântica (significado) compreende a região ventral do córtex occipitotemporal esquerdo e o GFI esquerdo. O GFI e, de modo menos consistente, o GFS, estão envolvidos na seleção e recuperação de representações semânticas. As porções mais anteriores do GTI, GTM e GTS relacionam-se a acesso de conteúdo semântico. À medida que a dificuldade da tarefa aumenta, ocorre envolvimento crescente das porções mais posteriores dos giros temporais. A recuperação da palavra a partir de um conceito e a conexão entre o processamento semântico e o plano articulatório envolve o GFM e regiões posteriores do GTM e do GTI esquerdos. O GFI está associado ao plano articulatório e produção da fala (Price C., 2012).

O paradigma mostrou ativação robusta e lateralizada nos mapas de grupo nas regiões GFM, GFI, GTS, GTM e GTI. Em estudo prévio, utilizando paradigma de nomeação responsiva à leitura em população pediátrica, foram observadas ativações no GTM, GFM e GFI. À semelhança do nosso estudo, não foi observada ativação no GFS ou GA e observou-se ativação bilateral dos lobos occipitais (Gaillard et al., 2002).

Para cálculo do índice de lateralidade foram delimitadas regiões de interesse, com base na terminologia utilizada na literatura de referência (Price C., 2012). Nesta metanálise, não foram utilizadas coordenadas (Tailarach ou MNI) de picos de ativação. O índice de lateralidade foi calculado de modo independente de limiar, uma vantagem deste estudo em relação aos estudos prévios realizados em populações com EMT. 


\subsubsection{Paradigma de NRL: comparações entre IL-Wada e IL-RMf}

O paradigma de nomeação responsiva à leitura mostrou-se um excelente método para mapeamento de áreas de linguagem frontais e temporais e para lateralização de linguagem, em substituição ao teste de Wada.

Observou-se forte correlação entre os dois métodos nos giros: GFM, GFI, GTS, GTM e GTI, regiões em que o paradigma mostrou ativação robusta e lateralizada nos mapas de grupo. Não houve correlação entre IL-Wada e IL-RMf nos giros GFS e GA, regiões em que o paradigma não mostrou ativação consistente, e no giro GF/TO, onde houve ativação bilateral pela tarefa.

Considerando os padrões de ativação observados para o paradigma, as análises subsequentes incluíram apenas as regiões em que a tarefa foi eficaz em levar a ativação robusta e lateralizada para o contraste condição ativa > condição controle: GFM, GFI, GTS, GTM e GTI.

A classificação individual e categórica de dominância de linguagem mostrou baixos níveis de discordância entre os dois métodos (média de aproximadamente $15 \%$, considerando as diferentes regiões), exceto para 0 GTS (26\%). A taxa de discordância entre teste de Wada e RMf é muito variável na literatura. Existe ampla gama de paradigmas utilizados, condições controle, regiões de interesse (frontal, temporal, hemisférica), métodos de cálculo de lateralidade e critérios de discordância. O maior estudo já publicado comparando teste de Wada e RMf encontrou 14\% de discordância, em grupo heterogêneo de 229 pacientes. A média de discordância entre os testes nas mais diversas publicações, calculada neste estudo, situou-se em torno de $15 \%$ (Janecek, 2013), dado congruente com os nossos achados.

Achado também concordante com o estudo de Binder (2013) foi a presença de linguagem bilateral ou à direita na RMf como fator de discordância entre os métodos. Uma possível explicação para este achado seria o fato da RMf ser mais sensível que o teste de Wada para identificar processamento de linguagem à direita. Em alguns pacientes com representação parcial de linguagem à direita, por exemplo, o componente do hemisfério direito poderia não ser suficiente para sustentar um desempenho mínimo quando o hemisfério esquerdo está anestesiado dando a impressão errônea de lateralização completa à esquerda no teste de Wada (Janecek, 2013). 
O GTS foi a região que exibiu maior discordância em relação à classificação de lateralidade de linguagem pelo teste de Wada. Estudos prévios que empregaram tarefas de linguagem com componente semântico demonstraram que, em pacientes com epilepsia do lobo temporal, a reorganização de linguagem afeta áreas frontais e temporais de modo distinto. Nestes pacientes, a região temporal tende a apresentar linguagem mais lateralizada à direita que a região frontal (Thivard et al., 2005). A RMf com paradigma de nomeação responsiva à leitura, aqui utilizado, mostrou-se mais sensível que o teste de Wada em detectar estas variações.

\subsection{Lateralização atípica de linguagem e EMT}

No presente estudo, observou-se que a lateralização atípica de linguagem esteve associada à presença de EMT.

Duas principais linhas de estudo, não necessariamente excludentes, procuram fundamentar a relação entre comprometimento do hipocampo e padrões atípicos de organização de linguagem.

(a) O hipocampo estaria diretamente associado a funções de aquisição e processamento de linguagem. A presença de lesão estrutural e de atividade epileptiforme hipocampal perturbaria, de modo direto, a organização normal de linguagem naquele hemisfério, favorecendo a reorganização de função no hemisfério contralateral. A presença de doença hipocampal poderia impactar a organização de linguagem por disfunção no processamento de memória semântica ou de recuperação de informações lexicais (Trebuchon et al; 2009). O hipocampo estaria associado ao processamento de linguagem via funções associativas de alta complexidade, gerando, reunindo, integrando e mantendo em tempo real diferentes representações de tempo, espaço, sintáticas e lexicais, fundamentais para a produção e compreensão de sentenças ou histórias (Duff e Brown-Schimidt, 2012). Finalmente, evidências de estudo com 
estimulação elétrica cortical indicam que o hipocampo está diretamente associado ao processamento de nomeação (Hamberger et al; 2007).

(b) O desvio de representação de linguagem para a direita observado na EMT seria resultante de perturbações da função de áreas clássicas de linguagem, anatomicamente distantes, porém funcionalmente conectadas às estruturas límbicas. Inúmeras evidências provenientes de estudos funcionais e anatômicos fundamentam esta hipótese. Estudos anatômicos mostram projeções hipocampais para o neocórtex temporal via subiculum e córtex entorrinal (Ojemann et al; 1988). Atrofia do lobo temporal extra-hipocampal é descrita em associação à esclerose hipocampal (Moran et al; 2001). Registro de crises epilépticas com eletrodos subdurais e profundos mostram que as crises que se iniciam no hipocampo se propagam para o neocórtex temporal (Spencer et al; 1987). Estudos de conectividade em pacientes com epilepsia refratária do lobo temporal mesial, mostram disfunção de conectividade ipsilateral e aumento da conectividade contralateral entre estruturas mesolímbicas e amplas regiões cerebrais, incluindo neocórtices frontal e temporal (Caciagli et al., 2014).

No grupo EMTE, a frequência de lateralização atípica de linguagem, entre as diversas regiões de interesse, variou de 17\% (GFI) e 24\%(GTM) a 33\% (GFM, GTS, GTI). Estes resultados aproximam-se daqueles encontrados em estudos prévios de RMf, em populações heterogêneas de pacientes com ELT esquerda (Lehericy et al., 2000; Adcock et al; 2003; Springer et al., 1999) e em subgrupos de pacientes com EMTE (Gaillard et al. 2007; Adcock et al; 2003). A frequência de linguagem atípica em estudos realizados em populações homogêneas de pacientes com EMT esquerda, varia de 18,5\% (Rathore et al., 2009) a 24\% (Jansky et al., 2003). Nestas séries a lateralidade de linguagem foi determinada por teste de Wada, método menos sensível que a RMf (Janecek, 2013), o que pode explicar os resultados discretamente inferiores.

A maior parte dos estudos de lateralidade de linguagem em epilepsia do lobo temporal é direcionada para populações com lesão estrutural no 
hemisfério esquerdo. A frequência de representação atípica, bem como os padrões de variação regional de reorganização de linguagem nos pacientes com EMTD são menos conhecidos. Existem descrições de representação atípica de linguagem em indivíduos com foco epileptogênico temporal direito, embora este dado não tenha sido explorado em profundidade (Springer et al., 1999, Gaillard et al., 2004). O fato de pacientes com EMTD apresentarem distúrbios de linguagem na prática clínica (Oddo et al; 2003; Doering e Trinka; 2014) e o conhecimento de que a epilepsia pode produzir efeito em regiões distantes do foco epileptogênico, nos motivou a avaliar este grupo mais detalhadamente. No presente estudo, a frequência de representação atípica de linguagem no grupo EMTD variou de 14\% (no GFI e GFM) a 17\% (GTS, GTM, GTI), frequência maior que a descrita na literatura para população saudável.

Avaliando os padrões regionais de reorganização, no grupo EMTE foi observada maior ativação, em relação ao grupo controle, para processamento de linguagem, no GFI, GTS e GTM do hemisfério direito. Este achado reforça os resultados de estudos prévios, ao demonstrar que, em pacientes com EMT esquerda, a reorganização de linguagem envolve amplas regiões cerebrais, frontais e temporais, teoricamente distantes da zona epileptogênica (Gaillard et al. 2007; Janszky et al. 2006; Weber et al., 2006). Este dado reforça a importância de se estudar a reorganização de linguagem nas regiões frontais e temporais neste grupo de pacientes. Os achados do presente estudo estão alinhados com resultados de estudo prévio, que combinou RMf de linguagem e morfometria baseada em voxels (VBM) em pacientes com EMTE (Labudda, 2012). A representação atípica de linguagem, nestes pacientes, associou-se a aumento do volume de substância cinzenta nas regiões frontais e temporais. Os autores sugeriram que o maior volume de substância cinzenta, nestas regiões daria suporte a funções de linguagem. Este padrão pode representar alterações morfológicas subjacentes à reorganização funcional de redes de linguagem.

No grupo EMTD observou-se maior reorganização de linguagem para a direita, em relação ao grupo controle, no GFI e GFM. Análises de amplos componentes de redes neuronais sugerem que tanto a esclerose hipocampal esquerda quanto direita afetam a conectividade interhemisférica, possivelmente com diferentes impactos regionais, de acordo com a lateralidade da EMT (Besson, 2014). 
Aventamos a hipótese de que a reorganização de linguagem, neste grupo, estaria associada à presença de atividade epileptiforme esquerda. Este aspecto foi melhor avaliado, separando-se o grupo EMTD em dois grupos: concordantes e discordantes, o que será discutido a seguir.

\subsection{Lateralização de linguagem e atividade epileptiforme}

Em pacientes com epilepsia, o distúrbio funcional pode ser causado pela lesão epileptogênica, por efeito das crises e da atividade interictal. Queda transitória do desempenho cognitivo, em pacientes com epilepsia, é descrita em associação a atividade epileptiforme interictal (Aarts et al.; 1984). O desempenho verbal pode estar prejudicado durante paroxismos no hemisfério cerebral esquerdo, sugerindo que a dificuldade cognitiva associa-se a distúrbio funcional do lado em que a descarga se originou (Aarts et al.; 1984).

No grupo EMTD, a presença de atividade epileptiforme à esquerda associou-se a ampla reorganização de linguagem para regiões frontais e temporais. O grupo EMTD com atividade epileptiforme restrita a região temporal direita, não apresentou diferenças de lateralidade de linguagem em relação ao grupo controle. Este achado confirmou a nossa hipótese a priori e levanta a possibilidade de possível mecanismo teoricamente implicado na reorganização de linguagem para a direita, descrita em grupos heterogêneos de pacientes com epilepsia e foco epileptogênico à direita (Springer et al., 1999, Gaillard et al., 2004).

Tanto os pacientes com EMTE quanto aqueles com EMTD e atividade epileptiforme à esquerda (EMTDd) apresentaram reorganização de linguagem para o GFI direito. No grupo EMTDd houve, adicionalmente, maior reorganização de linguagem para o GFM direito. Na região temporal, a reorganização de linguagem para o GTS direito foi vista, apenas, no grupo EMTE sem atividade epileptiforme contralateral (EMTEc). Os grupos discordantes (EMTEd e EMTDd) apresentaram reorganização de linguagem para os GTM e GTI à direita. 
Em pacientes com EMT esquerda, a reorganização de linguagem envolve regiões cerebrais frontais e temporais, teoricamente distantes da zona epileptogênica (Gaillard et al.; 2007; Janszky et al.; 2006; Weber et al., 2006). Nestes estudos foram incluídos apenas pacientes com EMT unilateral esquerda. A lateralidade de linguagem foi definida para o GFI, GTS (Gaillard et al., 2007, Weber et al., 2006), pré-frontal e temporoparietal (Weber et al.; 2006) ou hemisférica (Jansky et al.; 2006). O papel da lateralidade da atividade epileptiforme não foi avaliado. Em pacientes com EMT, a lateralidade da lesão pode associar-se a diferentes impactos sobre a conectividade regional (Besson et al.; 2014). A combinação de lesão estrutural mesial temporal unilateral e atividade epileptiforme mesial temporal contralateral/bilateral, nos grupos discordantes, pareceu modificar a reorganização de linguagem na região temporal. Este achado sugere a existência de diferentes padrões de perturbação funcional na região temporal na presença de doença bilateral e poderá ser melhor explorado em estudos de conectividade.

Nos pacientes EMTE e EMTDd, a frequência de atividade epileptiforme à esquerda associou-se a maior reorganização de linguagem. Esta associação havia sido demonstrada para pacientes com EMTE, avaliando a lateralidade hemisférica de linguagem (Jansky et al., 2006). A reorganização de linguagem para o outro hemisfério ocorre possivelmente como parte de um processo adaptativo, dependente da plasticidade de redes neuronais.

Em nosso estudo demonstramos associação entre alta frequência de descargas à esquerda e reorganização de linguagem para a direita em pacientes com epilepsia secundária a lesão hipocampal à direita.

Nos pacientes com EMT (esquerda ou direita), o efeito da maior frequência da atividade epileptiforme foi restrito ao GTM, não sendo observado nas regiões frontais ou nas demais regiões temporais estudadas. Jansky et al (2006) analisaram lateralidade de linguagem para todo o hemisfério e não regional. Este padrão regional de reorganização de linguagem não foi descrito, anteriormente e o fato de termos utilizado paradigma com componente semântico e analisado a lateralidade para cada região separadmente, nos permitiu evidenciar este aspecto. 


\subsection{Lateralização de linguagem e idade do início da epilepsia, tempo de epilepsia e presença de IPI}

A investigação de possíveis preditores de lateralidade de linguagem atípica em populações de pacientes com EMT é escassa. No presente estudo, avaliando população homogênea de pacientes destros, com EMT unilateral, não foram encontradas associações entre reorganização de linguagem para a direita e idade de início da epilepsia, tempo de epilepsia e presença de IPI.

A menor idade do início das crises, presença de insulto precipitante inicial e presença de auras sensoriais como variáveis associadas a reorganização de linguagem para a direita, com o teste de Wada (Jansky et al; 2003). Em estudo posterior, que empregou RMf, com amostra semelhante, os mesmos autores (Jansky et al; 2006) não encontraram associação entre idade do IPI ou idade do início da epilepsia e lateralidade de linguagem, embora, em todos os casos, o insulto precipitante ou o início de crises tenha ocorrido em idades precoces, o que, teoricamente, favoreceria a plasticidade neuronal (Rasmussen e Milner, 1977). Em estudo com teste de Wada, observou-se maior reorganização de linguagem para a direita associada a presença de pelo menos três de quatro fatores: presença de insulto precipitante inicial grave (meningoencefalite ou estado de mal epiléptico), início da epilepsia antes dos 6 anos de idade, intervalo curto entre o insulto precipitante inicial (IPI) e o início da epilepsia e presença de alterações extra-temporais no EEG (Rathore et al; 2009). A associação entre maior lateralidade atípica de linguagem por RMf e menor idade de início da epilepsia foi observada ainda, em pequena amostra de 12 pacientes com EMT (Miró et al.; 2014).

Os resultados descritos são parcialmente conflitantes entre si e as amostras de pacientes, nos estudos publicados, não são comparáveis à nossa. Esses estudos incluíram pacientes com dominância manual à esquerda e/ou com sinais de acometimento de estruturas extra-temporais na RM e/ou EEG. A presença de dominância manual atípica introduz viés de confusão, uma vez 
que, mesmo em populações saudáveis, a dominância hemisférica atípica de linguagem é mais frequente quando comparada a populações de indivíduos destros (22\% versus 4-6\%). Pacientes com dominância manual à esquerda também apresentam, mais frequentemente, história familiar de dominância manual atípica. Estes achados indicam provável papel de fatores genéticos na determinação da lateralidade de linguagem (Szaflarski et al; 2002).

A lateralização atípica de linguagem associou-se a início de crises epilépticas em idade precoce (Springer et al.; 1999), porém outros estudos não observaram esta associação (Sveller et al., 2006). Muitos dos estudos incluíram pacientes com diferentes tipos de epilepsia (temporal mesial, temporal lateral, extra-temporal), com diferentes etiologias. Achados para determinado tipo de epilepsia não podem ser extrapolados para os demais (Rasmussen \& Milner, 1977; Sveller et al., 2006). Consequentemente, não está claro a que grupos de pacientes estes resultados se aplicam. Os achados de nosso estudo, a despeito do tamanho relativamente reduzido da amostra, indicam que, em pacientes destros com EMT, presença de IPI, início precoce e maior duração da epilepsia não são preditores clínicos de lateralidade atípica de linguagem.

A predição da lateralidade de linguagem em amostra de 162 pacientes com ELT de diversas etiologias foi avaliada em estudo recente (Stewart et al; 2014). No grupo com foco epileptogênico à esquerda e início precoce de crises, a dominância manual à esquerda (medida pelo escore no Inventário de Edimburgo) foi único preditor de reorganização de linguagem, não sendo preditor de LA no grupo com carcaterísticas opostas (foco epileptogênico à direita, início tardio de epilepsia). Adicionalmente, lateralidade atípica de linguagem associou-se a início precoce de epilepsia no grupo com foco epileptogênico à esquerda, mas não no grupo com foco à direita. Os autores sugeriram que dominância manual à esquerda serviria como marcador de lateralidade atípica de linguagem em ELT, no contexto de características da doença com potencial para, simultaneamente, co-reorganizar linguagem e dominância manual: presença de foco epileptogênico à esquerda e início precoce de crises.

Embora nosso estudo não tenha avaliado a interação entre variáveis clínicas como preditores de lateralidade de linguagem, nossos resultados sugerem que, na ausência de dominância manual à esquerda, a lateralidade 
atípica de linguagem não é prevista por características clínicas da doença, mas por presença de lesão estrutural esquerda, atividade epileptiforme à esquerda e alta frequência de descargas. 


\section{CONCLUSÕES}

1) O paradigma de nomeação responsiva à leitura mostrou-se eficaz para estudos de linguagem em RMf. A tarefa foi capaz de ativar o GFM, GFI, GTS, GTM e GTI e mostrou elevada concordância entre o índice de lateralidade de linguagem nestas regiões com o índice de lateralidade de linguagem obtido com o teste de Wada (IL-Wada).

2) O cálculo regional de IL-RMf aumentou a sensibilidade para detecção de reorganização atípica de linguagem em comparação ao teste de Wada e a RMf que avalia o GFI isoladamente.

3) Ambos os grupos (EMTE e EMTD) apresentaram ampla reorganização inter-hemisférica de linguagem, nas regiões frontais e temporais. Os padrões regionais de reorganização foram influenciados pela lateralidade da lesão e pela lateralidade da atividade epileptiforme, sobretudo nas regiões temporais.

4) No grupo de pacientes com EMTD, a reorganização de linguagem relacionou-se a presença de atividade epileptiforme à esquerda (grupo EMTDd). No grupo EMTD concordante não se observou reorganização de linguagem.

5) Maior frequência de descargas à esquerda associou-se a reorganização de linguagem.

6) As variáveis clínicas: início precoce da epilepsia, maior tempo de duração da epilepsia e presença de IPI não se associaram a reorganização de linguagem nesta população. 
8 ANEXOS 
Anexo 1. Documento de aprovação pela Comissão de Ética para Análise de Projetos de Pesquisa (CAPPesq) do HCFMUSP

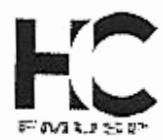

No Protocolo: 0257/05

rítulo: Cooperaçáo Interinstitucional de Apoio a Pesquisas sobre o Cérebro (CInAPCe). Centro de Imagem em Neurociências da Faculdade de Medicina da Universidade de Säo Paulo

Pesquisador Responsável: Prof. Dr. Giovanni Guido Cerri

Pesquisador Executante:

Departamento: Radiologia

O Coordenador da Comissão de Ética para Análise de Projetos de Pesquisa - CAPPesq da Diretoria Clínica do Hospital das Clínicas da Faculdade de Medicina da Universidade de São Paulo, APROVOU / TOMOU CIÊNCIA adreferendum em 03/11/2011, do(s) documento(s) abaixo mencionado(s):

- Carta datada de 17/10/11 - Inclusäo da pesquisadora Juliana Passos de Almeida, aluna de pós-graduaçāo (doutorado); Carta datada de 17/10/11 Inclusão da pesquisadora Bettina Pinto e Silva Martins Castro, aluna de pósgraduação (mestrado)

A CAPPesq em obediência à Resoluçāo CNS 196/96, solicita qo pesquisador (a) s elaboraçăo de relatório parcial e final.

No caso de relatório parcial é necessário informar o tempo previsto para a conclusão do protocolo e breve resumo dos resultados obtidos.

CAPPesq, 04 de Novembro de 2011

$$
\begin{aligned}
& \text { PROF. DR. EUCLIDES AYRES DE CASTILHO } \\
& \text { Coordenador } \\
& \text { Comissão de Ética para Análise de } \\
& \text { Projetos de Pesquisa - CAPPesq }
\end{aligned}
$$


Anexo 2. Termo de Consentimento Livre e Esclarecido.

\section{HOSPITAL DAS CLÍNICAS}

DA

FACULDADE DE MEDICINA DA UNIVERSIDADE DE SÃO PAULO

TERMO DE CONSENTIMENTO LIVRE E ESCLARECIDO

(Instruções para preenchimento no verso)

\section{I - DADOS DE IDENTIFICAÇÃO DO SUJEITO DA PESQUISA OU RESPONSÁVEL LEGAL}

1. NOME DO PACIENTE

DOCUMENTO DE IDENTIDADE № :

SEXO : .M 3 F 3

DATA NASCIMENTO

....................

ENDEREÇO

№

APTO:

BAIRRO: CIDADE

CEP: TELEFONE: DDD ....)

2.RESPONSÁVEL LEGAL

NATUREZA (grau de parentesco, tutor, curador etc.)

DOCUMENTO DE IDENTIDADE : SEXO: M 3 F 3

DATA NASCIMENTO.: .....................

ENDEREÇO:

APTO:

BAIRRO:

CIDADE:

CEP:

TELEFONE: DDD (

..).

\section{II - DADOS SOBRE A PESQUISA CIENTÍFICA}

1. TÍTULO DO PROTOCOLO DE PESQUISA:

Epilepsia secundária a esclerose mesial temporal unilateral: Neuroimagem funcional dos aspectos cognitivos e metabólicos de estruturas temporais ipsi- e contralaterais. Estudo comparativo pré e pós-operatório em pacientes com dados concordantes e discordantes na avaliação pré-cirúrgica convencional.

PESQUISADOR: , Luiz Henrique Martins Castro

CARGO/FUNÇÃO: Médico INSCRIÇÃO CONSELHO REGIONAL №: $\mathbf{5 2 . 8 0 5}$

UNIDADE DO HCFMUSP: Departamento de Neurologia

3. AVALIAÇÃO DO RISCO DA PESQUISA:

$\begin{array}{ll}\text { SEM RISCO B } & \text { RISCO MÍNIMO } \mathbf{X} \\ \text { RISCO BAIXO } 3 & \text { RISCO MAIOR B }\end{array}$

RISCO MÉDIO

(probabilidade de que $\mathrm{o}$ indivíduo sofra algum dano como consequência imediata ou tardia do estudo) 4.DURAÇÃO DA PESQUISA : 5 anos 


\section{III - REGISTRO DAS EXPLICAÇÕES DO PESQUISADOR AO PACIENTE OU SEU REPRESENTANTE LEGAL SOBRE A PESQUISA CONSIGNANDO:}

1.justificativa e os objetivos da pesquisa

Nos pacientes com esclerose mesial temporal unilateral e com indicação cirúrgica é importante lateralizar corretamente o foco epiléptico para garantir o sucesso da cirurgia. Em aproximadamente $20 \%$ dos casos esta lateralização é mais difícil, e por isso é importante trabalhar com diversas ferramentas que nos permitam não apenas avaliar o aspecto morfológico do hipocampo, mas também o seu funcionamento.

Esta pesquisa tem como objetivo principal avaliar o funcionamento do hipocampo em pacientes com epilepsia do lobo temporal antes e depois da cirurgia, utilizando métodos inovadores de ressonância magnética que permitem estudar o funcionamento do hipocampo e seu metabolismo. Com o resultado desta pesquisa poderemos melhorar a avaliação pré-cirúrgica destes pacientes na nossa rotina clínica.

2.procedimentos que serão utilizados e propósitos, incluindo a identificação dos procedimentos que são experimentais.

Os pacientes passaram primeiramente pela avaliação pré-cirúrgica já estabelecida na nossa rotina clínica, que inclui: monitoramento por video-EEG, ressonância magnética estrutural, SPECT, teste do sódio amital, e avaliação neuropiscológica. Além disso o paciente terá que fazer dois exames a mais de ressonância magnética, um para avaliar o metabolismo do hipocampo e outro para estudar o seu funcionamento. No aparelho de ressonância magnética o paciente precisa ficar deitado dentro de um túnel fechado e não pode mexer durante o exame, que costuma ter duração de aproximadamente uma hora. Algumas pessoas não se sentem confortáveis dentro deste aparelho, por isso o paciente ficará com uma campainha na mão que poderá ser acionada a qualquer hora para solicitar ajuda. O ruído (barulho) do aparelho é alto, mas haverá um protetor de ouvido para diminuir o seu desconforto. Não existe injeção de qualquer substância na veia e não existe radiação que possa prejudicá-lo. Num dos exames o paciente apenas precisa ficar deitado sem se mexer, enquanto que no outro exame o paciente será orientado a realizar testes de memoria e de linguagem, ao mesmo tempo em que é realizado o exame de ressonância magnética. A pessoa precisará ficar imóvel durante o tempo de exame e verá numa tela letras ou imagens e deverá apertar botões de acordo com algumas regras, parecido com um jogo. Ficará deitado e terá um microfone para se comunicar. Poderá desistir do experimento em qualquer momento, bastando solicitar ao médico que o estará acompanhando.

Durante a cirurgia uma pequena parte do material retirado será enviado para análise genômica.

Após três meses da cirurgia será realizada nova avaliação neuropsicológica, e após um ano a mesma será repetida e serão realizados também exames de ressonância magnética para avaliação estrutural e metabólica do hipocampo pós-cirúrgico.

\section{3. desconfortos e riscos esperados}

O desconforto é o do barulho e da duração dos exames de ressonância magnética. Mas sempre que o paciente demonstrar cansaço estes exames poderão ser interrompidos.

\section{4. benefícios que poderão ser obtidos}

A informação de todos estes exames ajudará no planejamento cirúrgico do paciente e a recuperação após a cirurgia será avaliada quantitativamente.

5. procedimentos alternativos que possam ser vantajosos para o indivíduo.

Estas avaliações são muito específicas não existindo alternativas no mesmo nível. 


\section{IV - ESCLARECIMENTOS DADOS PELO PESQUISADOR SOBRE GARANTIAS DO SUJEITO DA PESQUISA CONSIGNANDO:}

1.acesso, a qualquer tempo, às informações sobre procedimentos, riscos e benefícios relacionados à pesquisa, inclusive para dirimir eventuais dúvidas.

Os pacientes sempre que quiserem poderão conversar com os profissionais envolvidos no estudo.

2. liberdade de retirar seu consentimento a qualquer momento e de deixar de participar do estudo, sem que isto traga prejuízo à continuidade da assistência.

A participação no estudo é livre e o paciente poderá sair a qualquer momento continuando a ser atendido pelo grupo de

epilepsia do Hospital.

3. salvaguarda da confidencialidade, sigilo e privacidade.

A identidade dos participantes não será divulgada. Caso isto seja importante só será feito com o consentimento do paciente ou seus reponsáveis.

4. disponibilidade de assistência no HCFMUSP, por eventuais danos à saúde, decorrentes da pesquisa.

Em caso da ocorrência de eventuais danos à saúde, decorrentes da pesquisa os participantes do estudo terão atendimento em qualquer das Unidades do Complexo do Hospital das Clínicas da FMUSP.

5. viabilidade de indenização por eventuais danos à saúde decorrentes da pesquisa.

\section{INFORMAÇÕES DE NOMES, ENDEREÇOS E TELEFONES DOS RESPONSÁVEIS PELO ACOMPANHAMENTO DA PESQUISA, PARA CONTATO EM CASO DE INTERCORRÊNCIAS CLÍNICAS E REAÇÕES ADVERSAS.}

Nome do Pesquisador: Luiz Henrique Martins Castro

Telefone: 3069-6329

Endereço: Av. Dr. Enéas de Carvalho Aguiar, s/n - 8º andar - Serviço de Video-EEG

\section{OBSERVAÇÕES COMPLEMENTARES:}

\section{VII - CONSENTIMENTO PÓS-ESCLARECIDO}

Declaro que, após convenientemente esclarecido pelo pesquisador e ter entendido o que me foi explicado, consinto em participar do presente Protocolo de Pesquisa

São Paulo, 
Anexo 3. Questionário de Edimburgo.

ID:

DATA:

\section{Questionário de Edimburgo}

Indique a preferência do uso das mãos nas seguintes atividades, colocando + na coluna apropriada.

Se você usa esta mão na maioria das vezes, mas algumas vezes pode usar a outra mão, assinale apenas uma + .

Se você utilizar sempre esta mão, assinale ++. Ou seja, marque ++ se você utiliza a outra mão somente se for forçado.

Se não houver preferência por qualquer uma das mãos, assinale + nas duas colunas.

Algumas atividades requerem as duas mãos, neste caso, a questão é em relação à parte da atividade explicitada entre parênteses.

Tente responder todas as questões e somente deixe em branco caso você não tenha absolutamente nenhuma experiência com o objeto da tarefa descrita.

\begin{tabular}{|c|c|c|c|}
\hline & & Direita & Esquerda \\
\hline 1 & Escrever & & \\
\hline 2 & Desenhar & & \\
\hline 3 & Arremessar & & \\
\hline 4 & Tesoura & & \\
\hline 5 & Escova de dente & & \\
\hline 6 & Faca (sem garfo) & & \\
\hline 7 & Colher / garfo & & \\
\hline 8 & Vassoura & & \\
\hline 9 & Acender um fósforo & & \\
\hline 10 & Abrir uma caixa (tampa) & & \\
\hline 11 & Qual o pé você usa para chutar? & & \\
\hline 12 & $\begin{array}{l}\text { Qual o olho você usa, se forçado } \\
\text { a usar somente um? }\end{array}$ & & \\
\hline & & & Decil \\
\hline
\end{tabular}


Anexo 4. Inventário de depressão de Beck - BDI.

ID:

DATA:

\section{Inventário de Depressão de Beck - BDI}

Este questionário consiste em 21 grupos de afirmações. Depois de ler cuidadosamente cada grupo, faça um círculo em torno do número $(0,1,2$, ou 3$)$ próximo à afirmação, em cada grupo, que descreve melhor a maneira que você tem se sentido na última semana, incluindo hoje.

Se várias afirmações num grupo parecerem se aplicar igualmente bem, faça um círculo na que melhor se aplique. Tome o cuidado de ler todas as afirmações, em cada grupo, antes de fazer a sua escolha.

1. 0 Não me sinto triste.

1 Eu me sinto triste.

2 Estou sempre triste e não consigo sair disto.

3 Estou tão triste ou infeliz que não consigo suportar.

2. 0 Não estou especialmente desanimado quanto ao futuro.

1 Eu me sinto desanimado quanto ao futuro.

2 Acho que nada tenho a esperar.

3 Acho o futuro sem esperança e tenho a impressão de que as coisas não podem melhorar.

3. 0 Não me sinto um fracasso.

1 Acho que fracassei mais do que uma pessoa comum.

2 Quando olho para trás, na minha vida, tudo o que posso ver é um monte de fracassos.

3 Acho que, como pessoa, sou um completo fracasso.

4. 0 Tenho tanto prazer em tudo como antes.

1 Não sinto mais prazer nas coisas como antes.

2 Não encontro um prazer real em mais nada.

3 Estou insatisfeito ou aborrecido com tudo.

5. 0 Não me sinto especialmente culpado.

1 Eu me sinto culpado grande parte do tempo.

2 Eu me sinto culpado na maior parte do tempo.

3 Eu me sinto sempre culpado.

6. 0 Não acho que esteja sendo punido.

1 Acho que posso ser punido.

2 Creio que vou ser punido. 
7. 0 Não me sinto decepcionado comigo mesmo.

1 Estou decepcionado comigo mesmo.

2 Estou enojado de mim.

3 Eu me odeio.

8. 0 Não me sinto de qualquer modo pior que os outros.

1 Sou crítico em relação a mim por minhas fraquezas ou erros.

2 Eu me culpo sempre por minhas falhas.

3 Eu me culpo por tudo de mau que acontece.

9. 0 Não tenho quaisquer idéias de me matar.

1 Tenho idéias de me matar, mas não as executaria.

2 Gostaria de me matar.

3 Eu me mataria se tivesse oportunidade.

10. 0 Não choro mais do que o habitual.

1 Choro mais agora do que costumava.

2 Agora, choro o tempo todo.

3 Costumava ser capaz de chorar, mas agora não consigo mesmo que o queira.

11. 0 Não sou mais irritado agora do que já fui.

1 Fico aborrecido ou irritado mais facilmente do que costumava.

2 Atualmente sinto-me irritado o tempo todo.

3 Não me irrito mais com as coisas que costumavam me irritar.

12. 0 Não perdi o interesse pelas outras pessoas.

1 Estou menos interessado pelas outras pessoas do que costumava estar.

2 Perdi a maior parte do meu interesse pelas outras pessoas.

3 Perdi todo o meu interesse nas outras pessoas.

13. 0 Tomo decisões tão bem quanto antes.

1 Adio as tomadas de decisões mais do que costumava.

2 Tenho mais dificuldade em tomar decisões do que antes.

3 Não consigo mais tomar decisões.

14. 0 Não acho que minha aparência esteja pior do que costumava ser.

1 Estou preocupado por estar parecendo velho ou sem atrativos.

2 Acho que há mudanças permanentes na minha aparência que me fazem parecer sem atrativos.

3 Acredito que pareço feio. 
15. 0 Posso trabalhar tão bem quanto antes.

1 Preciso de um esforço extra para fazer alguma coisa.

2 Tenho que me esforçar muito para fazer alguma coisa.

3 Não consigo mais fazer nenhum trabalho.

16. 0 Consigo dormir tão bem como o habitual.

1 Não durmo tão bem quanto costumava.,

2 Acordo uma a duas horas mais cedo do habitualmente e tenho dificuldade em voltar a dormir.

3 Acordo várias horas mais cedo do que costumava e não consigo voltar a dormir.

17. 0 Não fico mais cansado do que o habitual.

1 Fico cansado com mais facilidade do que costumava.

2 Sinto-me cansado ao fazer qualquer coisa.

3 Estou cansado demais para fazer qualquer coisa.

18. 0 Meu apetite não está pior do que o habitual.

1 Meu apetite não é tão bom quanto costumava ser.

2 Meu apetite está muito pior agora.

3 Não tenho mais nenhum apetite.

19. 0 Não tenho perdido muito peso, se é que perdi algum recentemente.

1 Perdi mais do que 2 quilos e meio.

2 Perdi mais do que 5 quilos.

3 Perdi mais do que 7 quilos.

Estou tentando perder peso de propósito, comendo menos: Sim ( ) Não ( )

20. 0 Não estou mais preocupado com minha saúde do que o habitual.

1 Estou preocupado com problemas físicos tais como dores, indisposição do estômago ou prisão de ventre.

2 Estou muito preocupado com problemas físicos e é difícil pensar em outra coisa.

3 Estou tão preocupado com meus problemas físicos que não consigo pensar em qualquer outra coisa.

21. 0 Não notei qualquer mudança recente no meu interesse por sexo.

1 Estou menos interessado por sexo do que costumava estar.

2 Estou muito menos interessado em sexo atualmente.

3 Perdi completamente o interesse por sexo. 
Anexo 5. Escala VAMS (Visual Analog Mood Scale).

\section{A M S}

INSTRUÇÕES: Avalie como você se sente agora em relação aos itens abaixo e marque cada linha com um traço vertical no ponto que melhor descreve seus sentimentos. O centro de cada linha indica como você habitualmente se encontra e as extremidades indicam o máximo de cada condição.

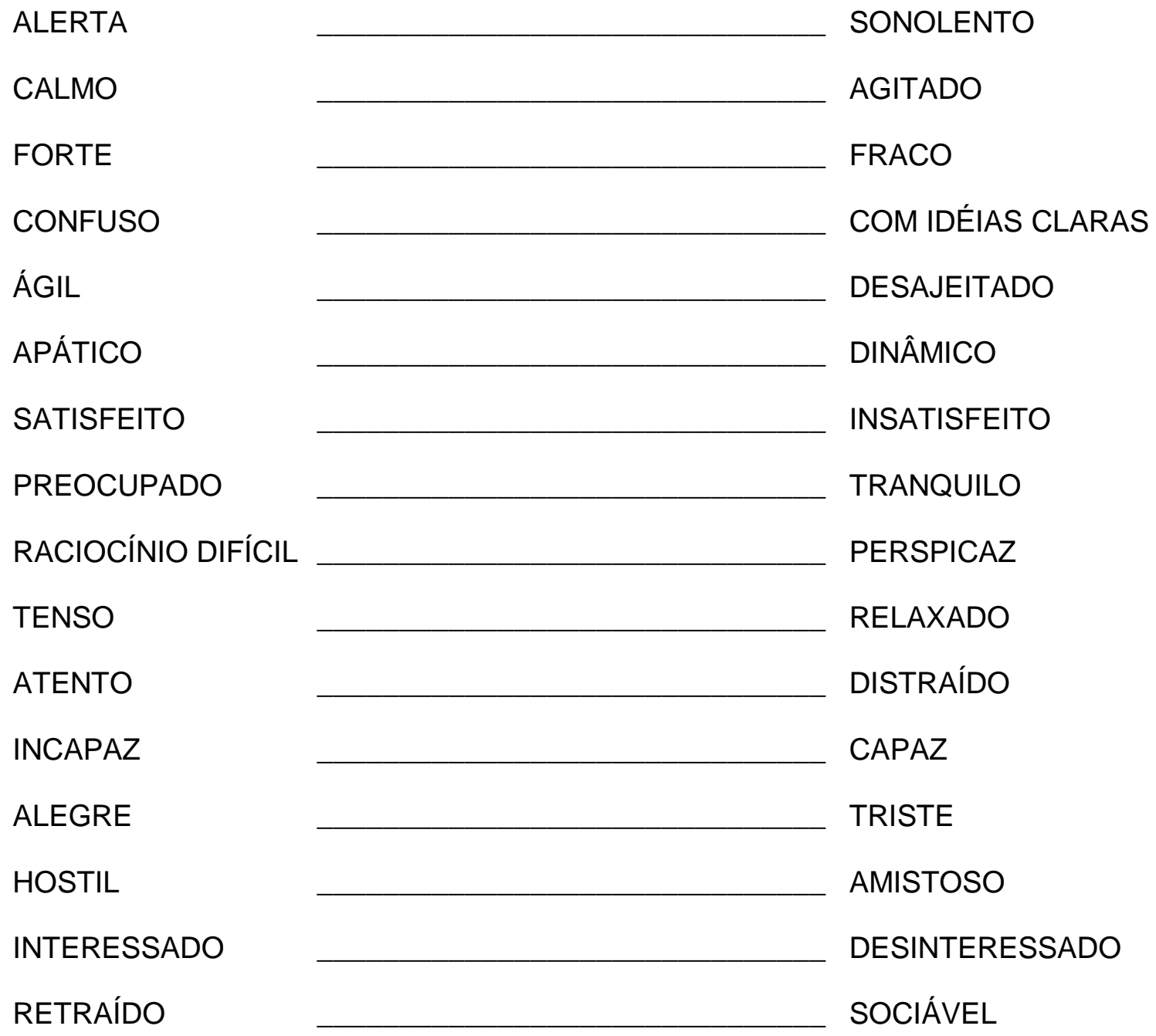


Anexo 6. Inventário de ansiedade traço-estado (IDATE).

I.D.:

DATA:

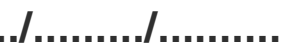

\section{Inventário de Ansiedade Traço-Estado - IDATE - T}

Leia cada pergunta e faça um círculo ao redor do número à direita que melhor indicar como você geralmente se sente. Não gaste muito tempo numa única afirmação, mas tente dar a resposta que mais se aproximar de como você se sente geralmente.

Quase sempre...4 Freqüentemente...3 Às vezes...2 Quase nunca...1

\begin{tabular}{|c|c|c|c|c|c|}
\hline Item & Descrição & & & & \\
\hline 1 & Sinto-me bem & 1 & 2 & 3 & 4 \\
\hline 2 & Canso-me facilmente & 1 & 2 & 3 & 4 \\
\hline 3 & Tenho vontade de chorar & 1 & 2 & 3 & 4 \\
\hline 4 & Gostaria de ser tão feliz quanto os outros parecem ser & 1 & 2 & 3 & 4 \\
\hline 5 & $\begin{array}{l}\text { Perco oportunidades porque não consigo tomar decisões } \\
\text { rápidas }\end{array}$ & 1 & 2 & 3 & 4 \\
\hline 6 & Sinto-me descansado & 1 & 2 & 3 & 4 \\
\hline 7 & Sinto-me calmo, ponderado e senhor de mim mesmo & 1 & 2 & 3 & 4 \\
\hline 8 & $\begin{array}{l}\text { Sinto que as dificuldades estão se acumulando de tal } \\
\text { forma que não as consigo resolver }\end{array}$ & 1 & 2 & 3 & 4 \\
\hline 9 & Preocupo-me demais com as coisas sem importância & 1 & 2 & 3 & 4 \\
\hline 10 & Sou feliz & 1 & 2 & 3 & 4 \\
\hline 11 & Deixo-me afetar muito pelas coisas & 1 & 2 & 3 & 4 \\
\hline 12 & Não tenho confiança em mim mesmo & 1 & 2 & 3 & 4 \\
\hline 13 & Sinto-me seguro & 1 & 2 & 3 & 4 \\
\hline 14 & Evito ter que enfrentar crises e problemas & 1 & 2 & 3 & 4 \\
\hline 15 & Sinto-me deprimido & 1 & 2 & 3 & 4 \\
\hline 16 & Estou satisfeito & 1 & 2 & 3 & 4 \\
\hline 17 & $\begin{array}{l}\text { Às vezes idéias sem importância me entram na cabeça e } \\
\text { ficam me preocupando }\end{array}$ & 1 & 2 & 3 & 4 \\
\hline 18 & $\begin{array}{l}\text { Levo os desapontamentos tão a sério que não consigo } \\
\text { tirá-los da cabeça }\end{array}$ & 1 & 2 & 3 & 4 \\
\hline 19 & Sou uma pessoa estável & 1 & 2 & 3 & 4 \\
\hline
\end{tabular}


I.D.:

DATA:

\section{Inventário de Ansiedade Traço-Estado - IDATE - E}

Leia cada pergunta e faça um círculo em redor do número à direita que melhor indicar como você se sente agora, neste momento. Não gaste muito tempo numa única afirmação, mas tente dar a resposta que mais se aproxime de como você se sente neste momento.

Muitíssimo...4 Bastante...3 Um pouco...2 Absolutamente não...1

\begin{tabular}{clllll}
\hline Item & & Descrição & & & \\
\hline $\mathbf{1}$ & Sinto-me calmo(a) & 1 & 3 & 4 \\
$\mathbf{2}$ & Sinto-me seguro(a) & 1 & 3 & 4 \\
$\mathbf{3}$ & Estou tenso(a) & 2 & 3 & 4 \\
$\mathbf{4}$ & Estou arrependido(a) & 1 & 2 & 3 & 4 \\
$\mathbf{5}$ & Sinto-me à vontade & 1 & 2 & 3 & 4 \\
$\mathbf{6}$ & Sinto-me perturbado(a) & 1 & 2 & 3 & 4 \\
$\mathbf{7}$ & Estou preocupado(a) com possíveis infortúnios & 1 & 2 & 3 & 4 \\
$\mathbf{8}$ & Sinto-me descansado(a) & 1 & 2 & 3 & 4 \\
$\mathbf{9}$ & Sinto-me ansioso(a) & 1 & 2 & 3 & 4 \\
$\mathbf{1 0}$ & Sinto-me "em casa" & 1 & 2 & 3 & 4 \\
$\mathbf{1 1}$ & Sinto-me confiante & 1 & 2 & 3 & 4 \\
$\mathbf{1 2}$ & Sinto-me nervoso(a) & 1 & 2 & 3 & 4 \\
$\mathbf{1 3}$ & Estou agitado(a) & 1 & 2 & 3 & 4 \\
$\mathbf{1 4}$ & Sinto-me uma pilha de nervos & 1 & 2 & 3 & 4 \\
$\mathbf{1 5}$ & Estou descontraído(a) & 1 & 2 & 3 & 4 \\
$\mathbf{1 6}$ & Sinto-me satisfeito(a) & 1 & 2 & 3 & 4 \\
$\mathbf{1 7}$ & Estou preocupado(a) & 1 & 2 & 3 & 4 \\
$\mathbf{1 8}$ & Sinto-me super excitado(a) e confuso(a) & 1 & 2 & 3 & 4 \\
$\mathbf{1 9}$ & Sinto-me alegre & 1 & 2 & 3 & 4 \\
$\mathbf{2 0}$ & Sinto-me bem & 1 & 3 & 4 \\
\hline & & 1 & & & \\
& & 1 & 1
\end{tabular}


Anexo 7. Resultados da monitorizaa) e confuso(a) únios do número à direita que me.

\begin{tabular}{|c|c|c|c|c|c|c|c|}
\hline & & & INTERICTAL & & & & FINAL \\
\hline $\mathrm{nr}$ Cinapce & Lado RM & Descargas E & Descargas D & VEEG-RM & Total de crises & VEEG-RM & VEEG-RM \\
\hline 5 & 1 & 61 & 0 & $\mathrm{D}$ & 4 & $\mathrm{D}$ & $\mathrm{D}$ \\
\hline 7 & 2 & 108 & 3505 & $\mathrm{D}$ & 5 & $\mathrm{D}$ & $\mathrm{D}$ \\
\hline 8 & 1 & 882 & 0 & $\mathrm{NC}$ & 1 & $\mathrm{C}$ & $\mathrm{C}$ \\
\hline 10 & 1 & 603 & 359 & $\mathrm{D}$ & 3 & $\mathrm{D}$ & $\mathrm{D}$ \\
\hline 12 & 2 & 0 & 59 & $\mathrm{C}$ & 6 & $\mathrm{C}$ & $\mathrm{C}$ \\
\hline 14 & 2 & 448 & 10 & $\mathrm{D}$ & 5 & $\mathrm{D}$ & $\mathrm{D}$ \\
\hline 15 & 2 & 0 & 38 & $\mathrm{C}$ & 12 & $\mathrm{C}$ & $\mathrm{C}$ \\
\hline 16 & 2 & 0 & 1054 & $\mathrm{C}$ & 3 & $\mathrm{C}$ & $\mathrm{C}$ \\
\hline 17 & 1 & 106 & 148 & $\mathrm{D}$ & 6 & $\mathrm{D}$ & $\mathrm{D}$ \\
\hline 18 & 1 & 265 & 43 & $\mathrm{D}$ & 3 & $\mathrm{D}$ & $\mathrm{D}$ \\
\hline 19 & 2 & 0 & 750 & $\mathrm{C}$ & 3 & $\mathrm{C}$ & $\mathrm{C}$ \\
\hline 20 & 2 & 22 & 93 & D & 3 & $\mathrm{D}$ & $\mathrm{D}$ \\
\hline 22 & 1 & 4 & 0 & C & 1 & C & C \\
\hline 23 & 1 & 15 & 0 & $\mathrm{D}$ & 3 & D & D \\
\hline 25 & 1 & 7 & 0 & C & 4 & C & C \\
\hline 26 & 1 & 120 & 4 & $\mathrm{C}$ & 4 & C & C \\
\hline 28 & 1 & 324 & 0 & $\mathrm{D}$ & 5 & D & D \\
\hline 29 & 1 & 189 & 326 & $\bar{D}$ & 3 & D & D \\
\hline 30 & 2 & 4 & 20 & C & 3 & C & C \\
\hline 31 & 1 & 550 & 65 & $\mathrm{D}$ & 5 & $\mathrm{D}$ & D \\
\hline 32 & 2 & 0 & 71 & C & 3 & $\mathrm{C}$ & C \\
\hline 34 & 1 & 339 & 0 & $\mathrm{C}$ & 2 & $\mathrm{C}$ & $\mathrm{C}$ \\
\hline 35 & 1 & 1370 & 0 & D & 3 & $\mathrm{D}$ & $\mathrm{D}$ \\
\hline 36 & 1 & 409 & 0 & C & 3 & C & C \\
\hline 38 & 1 & 249 & 0 & C & 3 & $\mathrm{C}$ & C \\
\hline 39 & 2 & 0 & 894 & $\mathrm{C}$ & 18 & C & $\mathrm{C}$ \\
\hline 40 & 1 & 23 & 0 & $\mathrm{D}$ & 5 & D & D \\
\hline 41 & 2 & 0 & 2 & C & 3 & C & C \\
\hline 43 & 2 & 2 & 40 & $\mathrm{D}$ & 3 & D & $\mathrm{D}$ \\
\hline 44 & 1 & 149 & 8 & C & 4 & $\mathrm{C}$ & $\mathrm{C}$ \\
\hline 45 & 1 & 1428 & 0 & D & 3 & D & D \\
\hline 46 & 1 & 1610 & 0 & C & 2 & C & C \\
\hline 47 & 2 & 26 & 40 & $\bar{D}$ & 2 & $\mathrm{D}$ & D \\
\hline 48 & 2 & 1 & 83 & $\mathrm{C}$ & 5 & C & C \\
\hline 49 & 2 & 282 & 167 & $\mathrm{D}$ & 8 & D & D \\
\hline 50 & 2 & 0 & 0 & $\bar{D}$ & 4 & $\mathrm{D}$ & D \\
\hline 51 & 1 & 55 & 0 & C & 5 & C & C \\
\hline 52 & 1 & 4 & 0 & $\mathrm{C}$ & 4 & C & C \\
\hline 53 & 1 & 30 & 0 & D & 14 & D & D \\
\hline 54 & 1 & 64 & 7 & $\mathrm{C}$ & 5 & $\mathrm{C}$ & $\mathrm{C}$ \\
\hline 55 & 2 & 10 & 31 & $\mathrm{C}$ & 3 & C & C \\
\hline 56 & 2 & 56 & 363 & D & 2 & D & D \\
\hline 57 & 2 & 0 & 6 & D & 2 & D & $\mathrm{D}$ \\
\hline 58 & 2 & 0 & 112 & $\mathrm{D}$ & 3 & D & D \\
\hline 59 & 2 & 0 & 2 & $\mathrm{D}$ & 4 & $\mathrm{D}$ & $\mathrm{D}$ \\
\hline 61 & 2 & 0 & 41 & D & 3 & D & $\mathrm{D}$ \\
\hline
\end{tabular}

Legenda: 1=EMTE; 2=EMTD; C=Concordante; D=Discordante. 
Anexo 8. Resultados dos valores de IL-Wada individuais. Valores totais e para cada fator de linguagem separadamente.

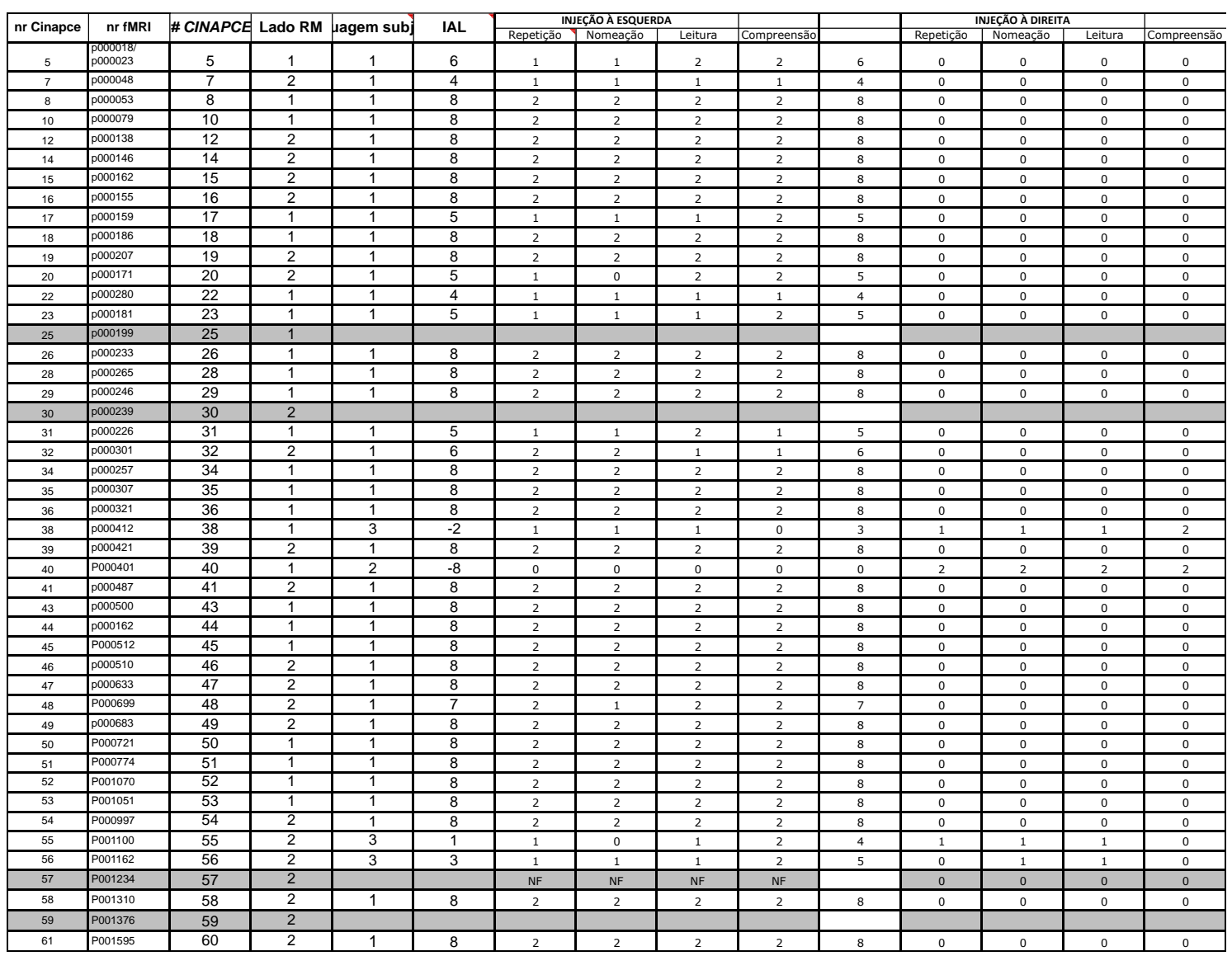


Anexo 9. Resultados das pontuações nas escalas VAMS para os fatores estresse, ansiedade, comprometimento cognitivo e desconforto entre os grupos EMTE, EMTD e controles antes e após o exame de RMf.

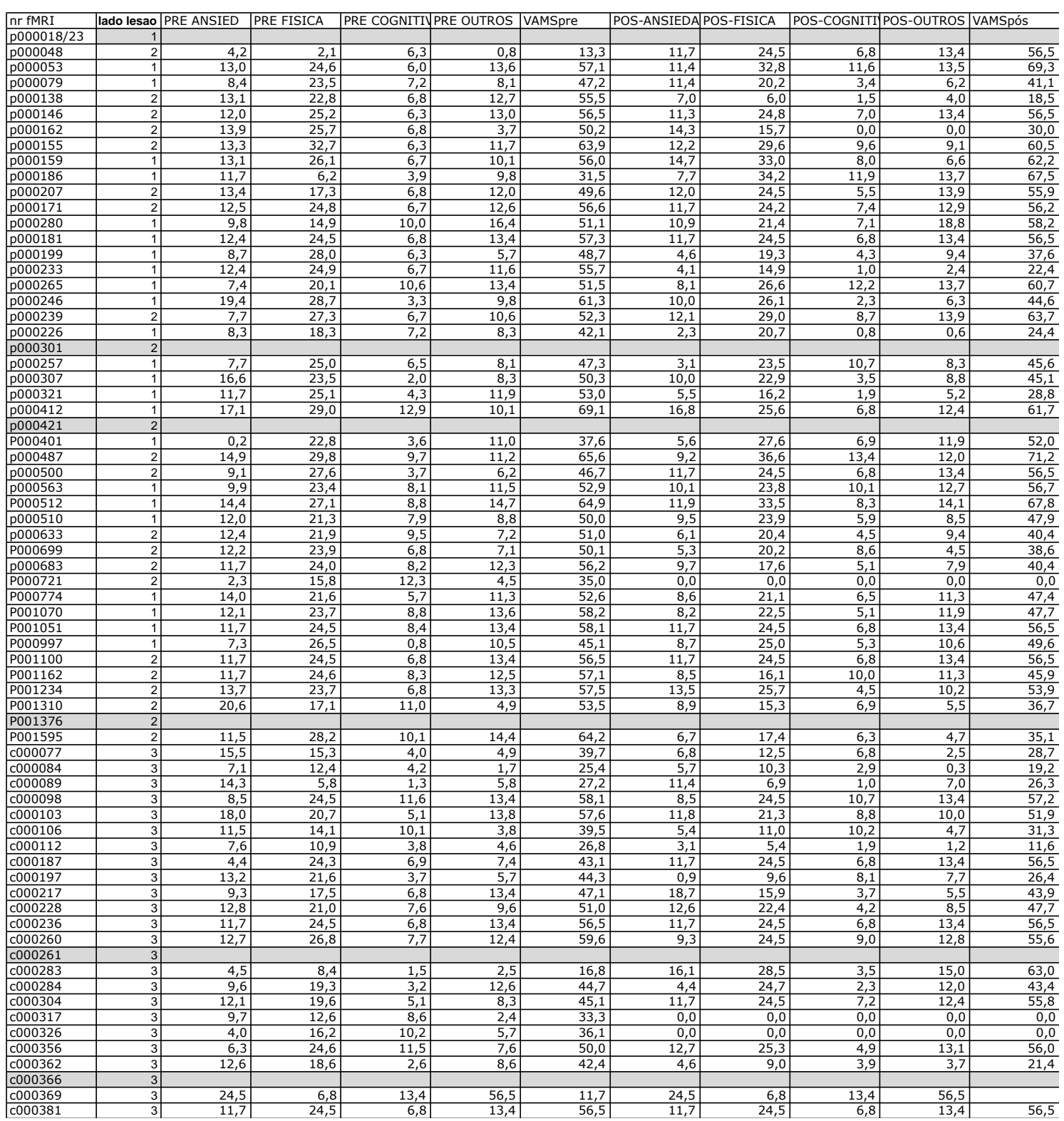




\section{Anexo 10. Descrição anatômica dos voxels com as coordenadas MNI e locais de picos de ativação de cada cluster significativo (local máxima).}

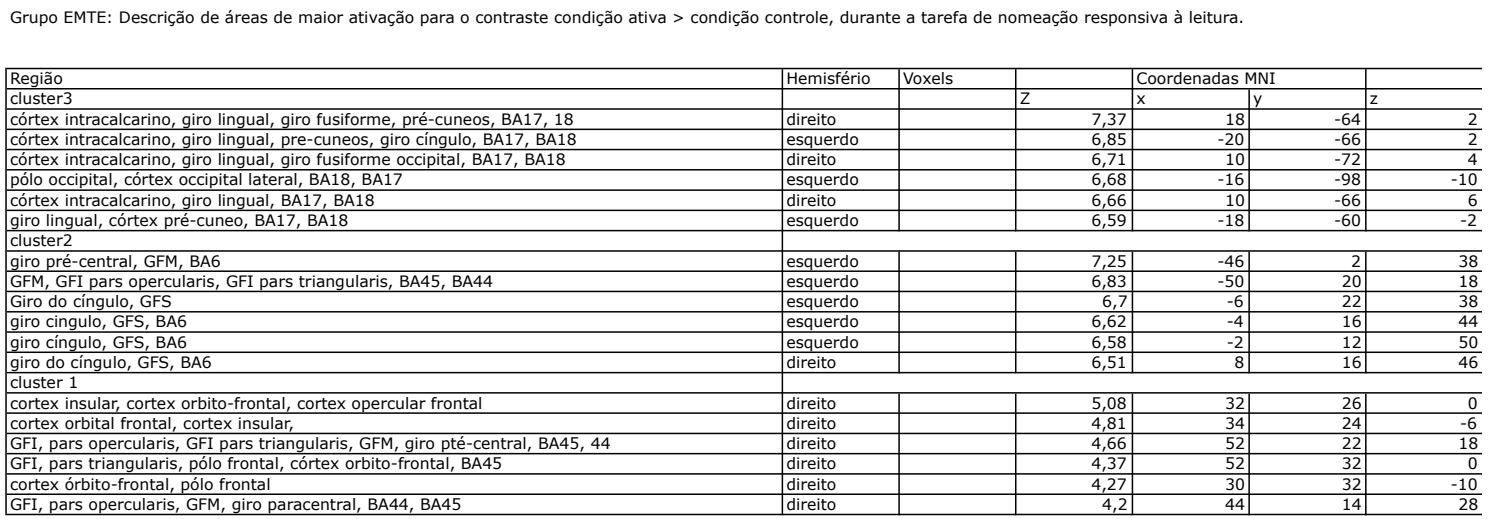

Grupo EMTD: Descrição de áreas de maior ativação para o contraste condição ativa > condição controle, durante a tarefa de nomeação responsiva à leitura.

\begin{tabular}{|c|c|c|c|c|c|c|}
\hline & & & & Coordenadas M & & \\
\hline Região & Hemisfério & Voxels & $z$ & \begin{tabular}{|l|l}
$x$ & -1
\end{tabular} & $y$ & $z$ \\
\hline cerebelo & direito & 32312 & 6,24 & 34 & -64 & -28 \\
\hline cortex orbital frontal, insula & direito & & 5,95 & 34 & 24 & -6 \\
\hline cerebelo & direito & & 5,91 & 22 & -70 & -28 \\
\hline cortex intracalcarino, giro lingual, BA17, BA18 & direito & & 5,77 & 8 & -84 & $\frac{2}{4}$ \\
\hline cerebelo & direito & & 5,73 & 6 & -76 & -26 \\
\hline
\end{tabular}

Grupo controle: Descrição de áreas de maior ativação para o contraste condição ativa > condição controle, durante a tarefa de nomeação responsiva à leitura.

\begin{tabular}{|l|}
\hline Região \\
\hline Cluster \\
\hline GFI, pars opercularis, pars triangularis, GFM (BA45/ BA44) \\
\hline GFI, pars triangularis, GFM (BA45/BA44) \\
\hline cerebelo \\
\hline cerebelo \\
\hline giro pré-central, GFM, GFI, pars opercularis (BA44) \\
\hline cíngulo, área motora suplementar, (BA6), GFS \\
\hline
\end{tabular}

\begin{tabular}{|c|c|c|c|c|c|}
\hline Hemisfério & voxels & & Coordenadas $\mathrm{N}$ & MNI & \\
\hline & 49048 & Z & $x$ & $y$ & $z$ \\
\hline esquerdo & & 8,39 & -50 & 22 & 18 \\
\hline & & 7,62 & -50 & 30 & 12 \\
\hline direito & & 7,6 & 38 & -62 & -30 \\
\hline direito & & 7,13 & 32 & -64 & -30 \\
\hline esquerda & & 7,1 & -42 & 4 & 38 \\
\hline esquerda & & 6,98 & -2 & 10 & 52 \\
\hline
\end{tabular}

\begin{tabular}{|l|}
\hline Região \\
\hline cluster3 \\
\hline córtex intracalcarino, giro lingual, giro fusiforme, pré-cuneos, BA17, 18 \\
\hline córtex intracalcarino, giro lingual, pre-cuneos, giro cíngulo, BA17, BA18 \\
\hline córtex intracalcarino, giro lingual, giro fusiforme occipital, BA17, BA18 \\
\hline pólo occipital, córtex occipital lateral, BA18, BA17 \\
\hline córtex intracalcarino, giro lingual, BA17, BA18 \\
\hline giro lingual, córtex pré-cuneo, BA17, BA18 \\
\hline cluster2 \\
\hline giro pré-central, GFM, BA6 \\
\hline GFM, GFI pars opercularis, GFI pars triangularis, BA45, BA44 \\
\hline Giro do cíngulo, GFS \\
\hline giro cingulo, GFS, BA6 \\
\hline giro cíngulo, GFS, BA6 \\
\hline giro do cíngulo, GFS, BA6 \\
\hline cluster 1 \\
\hline cortex insular, cortex orbito-frontal, cortex opercular frontal \\
\hline cortex orbital frontal, cortex insular, \\
\hline GFI, pars opercularis, GFI pars triangularis, GFM, giro pté-central, BA45, 44 \\
\hline GFI, pars triangularis, pólo frontal, córtex orbito-frontal, BA45 \\
\hline cortex órbito-frontal, pólo frontal \\
\hline GFI, pars opercularis, GFM, giro paracentral, BA44, BA45 \\
\hline \\
\hline \multicolumn{2}{|c|}{} \\
\hline Região \\
\hline cerebelo \\
\hline cortex orbital frontal, insula \\
\hline cerebelo \\
\hline cortex intracalcarino, giro lingual, BA17, BA18 \\
\hline cerebelo \\
\hline
\end{tabular}

\begin{tabular}{|c|c|c|c|c|c|}
\hline Hemisfério & Voxels & & Coordenadas $\mathrm{N}$ & MNI & \\
\hline & & $\bar{Z}$ & $x$ & $y$ & $z$ \\
\hline direito & & 7,37 & 18 & -64 & 2 \\
\hline esquerdo & & 6,85 & -20 & -66 & 2 \\
\hline direito & & 6,71 & 10 & -72 & 4 \\
\hline esquerdo & & 6,68 & -16 & -98 & -10 \\
\hline direito & & 6,66 & 10 & -66 & 6 \\
\hline esquerdo & & 6,59 & -18 & -60 & -2 \\
\hline esquerdo & & 7,25 & -46 & 2 & 38 \\
\hline esquerdo & & 6,83 & -50 & $\frac{2}{20}$ & $\frac{30}{18}$ \\
\hline esquerdo & & 6,7 & -6 & 22 & 38 \\
\hline esquerdo & & 6,62 & -4 & 16 & 44 \\
\hline esquerdo & & 6,58 & -2 & 12 & 50 \\
\hline direito & & 6,51 & 8 & 16 & 46 \\
\hline dirito & & 508 & 32 & 26 & 0 \\
\hline direito & & 4,81 & 34 & 24 & -6 \\
\hline direito & & 4,66 & 52 & 22 & 18 \\
\hline direito & & 4,37 & 52 & 32 & 0 \\
\hline \begin{tabular}{|l|l|} 
direito \\
\end{tabular} & & 4,27 & 30 & 32 & -10 \\
\hline direito & & 4,2 & 44 & 14 & 28 \\
\hline
\end{tabular}

cerebelo

\begin{tabular}{|c|c|c|c|c|c|}
\hline & & & Coordenadas & MNI & \\
\hline Hemisfério & Voxels & Z & $x$ & $y$ & $z$ \\
\hline direito & 32312 & 6,24 & 34 & -64 & -28 \\
\hline direito & & 5,95 & 34 & 24 & -6 \\
\hline direito & & 5,91 & 22 & -70 & -28 \\
\hline direito & & 5,77 & 8 & -84 & 4 \\
\hline direito & & 5,73 & 6 & -76 & -26 \\
\hline
\end{tabular}


Anexo 11. Descrição das variáveis clínicas relacionadas à epilepsia, frequência de descargas a esquerda e IL-RMf por ROI, para cada paciente.

\begin{tabular}{|c|c|c|c|c|c|c|c|c|c|c|c|c|c|c|}
\hline Paciente & Lado & História de & Idade & $\mathrm{IIE}$ & IID & $\mathrm{TE}$ & TD & Freq desc $\mathrm{E}$ & \multicolumn{6}{|c|}{ IL-RMf por ROI } \\
\hline ID & EMT & \begin{tabular}{|l|} 
IPI \\
\end{tabular} & IPI (anos) & (anos) & (anos) & (anos) & (anos) & (n/hora) & GFS & GFM & \begin{tabular}{|l|} 
GFI \\
\end{tabular} & GTS & GTM & GTI \\
\hline 5 & $E$ & não & & 7 & 7 & 32 & 32 & 16.0 & 0.92 & 0.75 & 0.74 & 0.68 & 0.67 & 0.67 \\
\hline 8 & $E$ & $\operatorname{sim}$ & 1 & 12 & 1 & 36 & 47 & 152.5 & 0.05 & 0.39 & 0.82 & 0.82 & 0.60 & -0.70 \\
\hline 10 & $E$ & $\operatorname{sim}$ & 3 & 7 & 3 & 33 & 37 & 180.0 & 0.87 & 0.83 & -0.81 & -0.58 & 0.83 & 0.60 \\
\hline 17 & $E$ & não & & 13 & 13 & 11 & 11 & 0.0 & 0.66 & 0.72 & 0.88 & 0.95 & 0.83 & 0.83 \\
\hline 18 & $E$ & não & & 25 & 25 & 15 & 15 & 1.5 & 0.19 & 0.52 & 0.44 & 0.43 & \begin{tabular}{|l|} 
\\
\end{tabular} & 0.73 \\
\hline 22 & $E$ & não & & 12 & 12 & 17 & 17 & 2.0 & 0.14 & 0.14 & -0.83 & -0.03 & 0.54 & 0.50 \\
\hline 23 & $E$ & $\operatorname{sim}$ & 3 & 16 & 3 & 13 & 26 & 5.0 & 0.81 & 0.81 & 0.12 & 0.5 & 0.49 & 0.70 \\
\hline 25 & $E$ & não & & 8 & 8 & 16 & 16 & 0.0 & 0.82 & 0.94 & 0.63 & 0.85 & 0.04 & -0.14 \\
\hline 26 & $E$ & não & & 18 & 18 & 9 & 9 & 43.5 & -0.19 & 0.73 & -0.21 & -0.7 & 0.80 & 0.83 \\
\hline 28 & $E$ & $\operatorname{sim}$ & 1 & 7 & 1 & 18 & 24 & 43.0 & 0.91 & 0.83 & 0.56 & 0.83 & 0.84 & 0.07 \\
\hline 29 & $E$ & não & & 18 & 18 & 13 & 13 & 41.5 & 0.02 & 0.74 & 0.44 & 0.48 & -0.07 & 0.87 \\
\hline 31 & $E$ & $\operatorname{sim}$ & 2 & 19 & 2 & 31 & 48 & 39.5 & -0.36 & 0.31 & 0.52 & \begin{tabular}{|l}
-0.66 \\
\end{tabular} & -0.56 & 0.70 \\
\hline 34 & $E$ & não & & 4 & 4 & 22 & 22 & 130.0 & 0.69 & -0.31 & \begin{tabular}{|l|}
0.03 \\
\end{tabular} & 0.73 & 0.65 & 0.54 \\
\hline 35 & $E$ & não & & 7 & 7 & 25 & 25 & 6.5 & 0.76 & 0.93 & 0.76 & 0.82 & \begin{tabular}{|l|} 
\\
\end{tabular} & 0.49 \\
\hline 36 & $E$ & não & & 13 & 13 & 28 & 28 & 94.5 & 0.76 & 0.77 & -0.40 & 0.96 & 0.88 & 0.04 \\
\hline 38 & $E$ & $\operatorname{sim}$ & 1 & 12 & 1 & 28 & 39 & 71.5 & -0.75 & -0.69 & -0.32 & \begin{tabular}{|l|}
0.2 \\
\end{tabular} & 0.05 & 0.80 \\
\hline 40 & $E$ & não & & 15 & 15 & 12 & 12 & 2.5 & -0.75 & -0.80 & -0.55 & -0.85 & -0.70 & 0.84 \\
\hline 44 & $E$ & $\operatorname{sim}$ & 0 & 0 & 0 & 20 & 19 & 0.0 & 0.72 & 0.71 & 0.78 & 0.97 & 0.70 & -0.07 \\
\hline 45 & $E$ & $\operatorname{sim}$ & 1 & 16 & 1 & 38 & 53 & 0.0 & 0.81 & 0.70 & 0.73 & 0.9 & 0.92 & -0.14 \\
\hline 46 & $E$ & não & & 6 & 6 & 36 & 36 & 505.0 & 0.92 & 0.93 & 0.89 & 0.86 & 0.85 & -0.56 \\
\hline 51 & $E$ & $\operatorname{sim}$ & 2 & 10 & 2 & 28 & 36 & 16.5 & 0.30 & 0.79 & 0.91 & 0.6 & 0.53 & 0.92 \\
\hline 52 & $E$ & $\operatorname{sim}$ & 3 & 12 & 3 & 31 & 40 & 0.0 & 0.46 & 0.78 & 0.70 & 0.64 & 0.66 & 0.65 \\
\hline 53 & $E$ & $\operatorname{sim}$ & 1 & 22 & 1 & 23 & 44 & 13.5 & 0.44 & 0.89 & 0.64 & 0.57 & 0.72 & 0.71 \\
\hline 54 & $E$ & $\operatorname{sim}$ & 3 & 8 & 3 & 23 & 28 & 9.5 & 0.51 & 0.89 & \begin{tabular}{|l|}
0.73 \\
\end{tabular} & 0.9 & 0.71 & 0.88 \\
\hline 7 & $D$ & $\operatorname{sim}$ & 2 & 11 & 2 & 19 & 28 & 5.0 & \begin{tabular}{|l|}
-0.83 \\
\end{tabular} & -0.75 & -0.69 & -0.32 & 0.20 & 0.05 \\
\hline 12 & D & $\operatorname{sim}$ & 4 & 30 & 4 & 17 & 43 & 0 & 0.43 & 0.74 & 0.93 & 0.83 & 0.82 & 0.65 \\
\hline 14 & $D$ & $\operatorname{sim}$ & 2 & 14 & 2 & 14 & 26 & 222 & -0.38 & -0.75 & -0.80 & \begin{tabular}{|l} 
\\
\end{tabular} & -0.85 & -0.70 \\
\hline 15 & $D$ & não & & 18 & 18 & 11 & 11 & 0 & 0.61 & 0.74 & 0.62 & 0.75 & 0.84 & 0.89 \\
\hline 16 & $\mathrm{D}$ & $\operatorname{sim}$ & 2 & 2 & 2 & 30 & 30 & 0 & 0.79 & 0.31 & 0.88 & 0.78 & 0.58 & 0.57 \\
\hline 19 & $D$ & $\operatorname{sim}$ & 4 & 8 & 4 & 25 & 29 & 0 & 0.52 & 0.72 & 0.71 & 0.78 & 0.97 & 0.70 \\
\hline 20 & $D$ & sim & 5 & 18 & 5 & 31 & 44 & 0 & 0.44 & 0.81 & 0.70 & 0.73 & \begin{tabular}{|l|}
0.90 \\
\end{tabular} & 0.92 \\
\hline 30 & $D$ & $\operatorname{sim}$ & 5 & 5 & 5 & 48 & 48 & 1.5 & 0.65 & 0.92 & 0.93 & 0.89 & 0.86 & 0.85 \\
\hline 32 & $D$ & não & & 15 & 15 & 8 & 8 & 0 & -0.04 & 0.46 & 0.95 & 0.91 & 0.98 & 0.84 \\
\hline 39 & $D$ & não & & 7 & 7 & 23 & 23 & 0 & 0.59 & 0.70 & 0.75 & 0.63 & 0.73 & 0.88 \\
\hline 41 & $\mathrm{D}$ & $\operatorname{sim}$ & 1 & 13 & 1 & 12 & 24 & 0 & -0.05 & 0.20 & 0.68 & 0.57 & 0.35 & 0.38 \\
\hline 43 & $D$ & não & & 22 & 22 & 22 & 22 & 0 & 0.66 & 0.68 & 0.82 & 0.33 & 0.99 & 0.65 \\
\hline 47 & $\mathrm{D}$ & $\operatorname{sim}$ & 2 & 5 & 2 & 22 & 25 & 3 & -0.29 & 0.30 & 0.79 & 0.91 & 0.60 & 0.53 \\
\hline 48 & $\mathrm{D}$ & $\operatorname{sim}$ & 2 & 18 & 2 & 7 & 23 & 0.5 & 0.19 & 0.46 & 0.78 & 0.70 & 0.64 & 0.66 \\
\hline 49 & $D$ & $\operatorname{sim}$ & 3 & 18 & 3 & 6 & 21 & 0 & 0.59 & 0.44 & 0.89 & 0.64 & 0.57 & 0.72 \\
\hline 50 & $\mathrm{D}$ & $\operatorname{sim}$ & 3 & 16 & 3 & 30 & 43 & 0 & 0.56 & 0.51 & 0.89 & 0.73 & 0.90 & 0.71 \\
\hline 55 & $D$ & $\operatorname{sim}$ & 3 & 5 & 3 & 42 & 44 & 2.5 & -0.51 & 0.61 & 0.91 & 0.60 & 0.20 & 0.30 \\
\hline 56 & $D$ & $\operatorname{sim}$ & 1 & 1 & 1 & 28 & 28 & 1 & 0.09 & 0.21 & \begin{tabular}{|l|l|}
0.14 \\
\end{tabular} & -0.89 & -0.37 & 0.20 \\
\hline 57 & $D$ & não & & 7 & 7 & 32 & 32 & 0 & \begin{tabular}{|l|}
-0.71 \\
\end{tabular} & -0.95 & -0.25 & 0.64 & 0.54 & -0.19 \\
\hline 58 & $D$ & não & & 15 & 15 & 10 & 10 & 0 & 0.80 & 0.35 & 0.93 & 0.89 & 0.74 & 0.51 \\
\hline 59 & $D$ & $\operatorname{sim}$ & 2 & 4 & 2 & 17 & 19 & 0 & 0.57 & 0.81 & 0.98 & 0.55 & \begin{tabular}{|l|}
0.99 \\
\end{tabular} & 0.92 \\
\hline 61 & $D$ & não & & 11 & 11 & 32 & 32 & 0 & 0.54 & 0.74 & 0.95 & 0.92 & 0.80 & 0.75 \\
\hline
\end{tabular}

Legenda: ID= Identificação; EMT=Epilepsia do lobo temporal secundária a Esclerose Mesial temporal; IPI=Insulto precipitante inicial, IIE= Idade do início da epilepsia; IID=Idade de início da doença; TE=Tempo de epilepsia; TD=Tempo de doença; $\mathrm{ROI}=$ Região de interesse. 


\section{REFERÊNCIAS}

Aarts $\mathrm{JH}$, Binnie CD, Smit AM, et al. Selective cognitive impairment during focal and generalized epileptiform EEG activity. Brain. 1984;107:293-308.

Abou-Khalil B. An update on determination of language dominance in screening for epilepsy surgery: the Wada test and newer noninvasive alternatives. Epilepsia. 2007; 48:442-455.

Adcock JE,Wise RG,Oxbury JM,et al. Relative fMRI assessment of the differences in lateralization of language-related brain activation in patients with temporal lobe epilepsy. Neuroimage 2003;18:423- 438.

Baciu M, Juphard A, Cousin E, Bas JFL. Evaluating fMRI methods for assessing hemispheric language dominance in healthy subjects. Eur J Radiol. 2005; 55:209-218.

Bahn MM, Lin W, Silbergeld DL, Miller JW, Kuppusamy K, Cook RJ, Hammer G, Wetzel R, Cross D. Localization of language cortices by functional MR imaging compared with intracarotid amobarbital hemispheric sedation. AJR Am J Roentgenol. 1997; 169:575-579.

Bartha-Doering $L$, and Trinka $E$. The interictal language profile in adult epilepsy. Epilepsia. 2014; 55(10):1512-25.

Baxendale S. The Wada test. Curr Opin Neurol. 2009; 22:185-9

Bell BD, Seidenberg M, Hermann BP, Douville K. Visual and auditory naming in patients with left or bilateral temporal lobe epilepsy. Epilepsy Res. 2003; 55:29-37.

Bell, B.D., Davies, K.G. Anterior temporal lobectomy, hippocampal sclerosis, and memory: recent neuropsychological findings. Neuropsychol. 1998, 8:25-41.

Bell BD, Davies KG, Hermann BP, Walters G. Confrontation naming after anterior temporal lobectomy is related to age of acquisition of the object names. Neuropsychologia 2000; 38: 83-92.

Benson, DF, Geschwind, N Aphasia and related cortical disturbances. In: Baker, AB, Baker, LH eds. (1971) Clinical neurology. Harper \& Row, New York.

Berg AT, Scheffer IE. New concepts in classification of the epilepsies: entering the 21st century. Epilepsia. 2011 Jun;52(6):1058-62. 
Berl MM, Zimmaro LA, Khan OI, Dustin I, Ritzl E, Duke ES, Sepeta LN, Sato S, Theodore WH, Gaillard WD. Characterization of Atypical Language Activation Patterns in Focal Epilepsy. Ann Neurol. 2014; 75:33-42

Besson P, Dinkelacker V, Valabregue R, Thivard L et al. Structural connectivity differences in left and right temporal lobe epilepsy. Neuroimage. 2014 Oct 15;100:135-44.

Biaggio AMB, Natalício L. Manual para o Inventário de Ansiedade Traço-Estado (IDATE). Rio de Janeiro: Centro Editor de Psicologia Aplicada (CEPA); 1979.

Binder, J R, Swanson, S J, Hammeke, TA, Morris GL, Mueller WM, Fischer M, Benbadis S, Frost JA, Rao SM, Haughton VM. Determination of language dominance using functional MRI: a comparison with the Wada test. Neurology. 1996; 46(4):979-984.

Binder JR, Sabsevitz DS, Swanson SJ, Hammeke TA, Raghavan M, Mueller WM. Use of preoperative functional MRI to predict verbal memory decline after temporal lobe epilepsy surgery. Epilepsia. 2008; 49(8):1377-94.

Blümcke I, Thom M, Aronica E, Armstrong DD et al. International consensus classification of hippocampal sclerosis in temporal lobe epilepsy: a Task Force report from the ILAE Commission on Diagnostic Methods. Epilepsia. 2013 Jul;54(7):1315-29.

Boer HM, Mula M, Sander JW. The global burden and stigma of epilepsy. Epilepsy Behav. 2008 May;12(4):540-6.

Brazdil M, Zakopcan J, Kuba R, et al. Hemispheric language dominance in left temporal lobe epilepsy as a result of the reorganization of language functions. Epilepsy Behav 2003;4:414-419.

Broca, P. Remarques sur le siège de la faculté du langage articulé; suivies d'une observation d'aphémie (perte de la parole). Bulletins de la Société Anatomique (Paris), 1861; 6: 330-357, 398-407.

Broca, P. Sur le siège de la faculté du langage articulé. Bulletins de la Société d'Anthropologie. 1865; 6:337-393.

Busch RM, Chapin JS, Haut JS, et al. Word-finding difficulties confound performance on verbal cognitive measures in adults with intractable left temporal lobe epilepsy. Epilepsia. 2013; 54:e37-e40.

Lorenzo Caciagli, Boris C. Bernhardt, Seok-Jun Hong, Andrea Bernasconi, Neda Bernasconi. Functional network alterations and their structural substrate in drug-resistant epilepsy. Front Neurosci. 2014; 8: 411. 
Caciagli, L., Bernhardt, B. C., Hong, S. J., Bernasconi, A., \& Bernasconi, N. (2014). Functional network alterations and their structural substrate in drugresistant epilepsy. Frontiers in neuroscience, 8, 411.

Castro LH, Serpa MH, Valério RM, Jorge CL, Ono CR, Arantes PR, Rosemberg $\mathrm{S}$, Wen HT. Good surgical outcome in discordant ictal EEG-MRI unilateral mesial temporal sclerosis patients. Epilepsia. 2008 Aug;49(8):1324-32.

Cendes F, Li LM, Watson C, Andermann E, Dubeau F, Arnold DL. Is ictal recording mandatory in temporal lobe epilepsy? Not when the interictal electroencephalogram and hippocampal atrophy coincide. Arch Neurol. 2000;57:497-500.

Davies, K.G., Bell, B.D., Bush, A.J., Hermann, B.P., Dohan Jr., F.C., Jaap, A.S. Naming decline after left anterior temporal lobectomy correlates with pathological status of resected hippocampus. Epilepsia. 1998; 39:407-419

Davies KG, Risse GL, Gates JR. Naming ability after tailored left temporal resection with extraoperative language mapping: increased risk of decline with later epilepsy onset age. Epilepsy Behav. 2005; 7:273-8.

Desmond JE, Sum JM, Wagner AD, Demb JB, Shear PK, Glover GH, Gabrieli JD, Morrell MJ. Functional MRI measurement of language lateralization in Wada-tested patients. Brain. 1995; 118 ( Pt 6):1411-9.

Destrieux C, Fischl B, Dale A, Halgren E. Automatic parcellation of human cortical gyri and sulci using standard anatomical nomenclature. Neuroimage. 2010;15; 53(1): 1-15.

Duff MC, Brown-Schmidt S. The hippocampus and the flexible use and processing of language. Front Hum Neurosci. 2012 Apr 5;6:69.

Druks, J. \& Masterson, J. (2000). An Object and Action Naming Battery. London: Psychology Press.

Duke ES, Tesfaye M, Berl MM, Walker JE, Ritzl EK, Fasano RE, Conry JA, Pearl PL, Sato S, Theodore WH, Gaillard WD.The effect of seizure focus on regional language processing areas. Epilepsia. 2012; 53(6):1044-50.

Ebner A, Hoppe M. Noninvasive electroencephalography and mesial temporal sclerosis. J Clin Neurophysiol 1995; 12:23-31.

Eggert GH. Wernicke's work on aphasia. The Hague: Mouton 1977. 
Engel JJr, Wieser HG, Spencer D. Overview: Surgical Therapy. In: Engel JJr, Pedley TA, eds. Epilepsy: A Comprehensive Textbook. Philadelphia: LippincottRaven, 1997:1673-1676.

French JA, Williamson PD, Thadani VM, Darcey TM, Mattson RH, Spencer SS, Spencer DD. Characteristics of medial temporal lobe epilepsy: I. Results of history and physical examination. Ann Neurol. 1993 Dec;34(6):774-80.

Friston KJ, J. Ashburner, S.J. Kiebel, T.E. Nichols, and W.D. Penny, editors. Statistical Parametric Mapping: The Analysis of Functional Brain Images. Academic Press, 2007.

Gaillard WD, Balsamo L, Xu B, Grandin CB, Braniecki SH, Papero PH, Weinstein S, Conry J, Pearl PL, Sachs B, Sato S, Jabbari B, Vezina LG, Frattali $\mathrm{C}$, Theodore $\mathrm{WH}$. Language dominance in partial epilepsy patients identified with an fMRI reading task. Neurology. 2002; Jul 23;59(2):256-65.

Gaillard WD. Functional MR imaging of language, memory and sensorimotor córtex, Neuroimag Clin N Am. 2004a; 14:471-485.

Gaillard WD, Balsamo L, Xu B, McKinney C, Papero PH, Weinstein S, Conry J, Pearl PL, Sachs B, Sato S, Vezina LG, Frattali C, Theodore WH. fMRI language task panel improves determination of language dominance. 2004b. Neurology 63:1403-1408.

Gaillard WD, Berl MM, Moore EN, Ritzl EK et al. Atypical language in lesional and nonlesional complex partial epilepsy. Neurology. 2007 Oct 30;69(18):1761-71.

Gaitatzis A, Trimble MR, Sander JW. The psychiatric comorbidity of epilepsy. Acta Neurol Scand. 2004;110(4):207-220.

Geschwind, N. Disconnexion syndromes in animals and man. Brain. 1965; 88: 237-294, 585-644.

Geschwind N. Aphasia. N Engl J Med. 1971;284:654-6.

Gorenstein C, Andrade L, Vieira Filho AH, Tung TC, Artes R. Psychometric properties of the Portuguese version of the Beck Depression Inventory on Brazilian college students. J Clin Psychol. 1999;55(5):553-62.

Hamberger MJ, Seidel WT. Auditory and visual naming tests: Normative and patient data for accuracy, response time, and tip-of-the-tongue. J Int Neuropsychol Soc. 2003; 9:479-89. 
Hamberger, M.J., Seidel, W.T., Goodman, R.R., Williams, A., Perrine, K., Devinsky, O., McKhann 2nd, G.M. Evidence for cortical reorganization of language in patients with hippocampal sclerosis. Brain. 2007; 130:2942-2950.

Hamberger MJ, Cole J. Language organization and reorganization in epilepsy. Neuropsychol Rev. 2011;21(3):240-251.

Harris LJ. Broca on cerebral control for speech in right-handers and lefthanders: a note on translation and some further comments. Brain Lang. 1993; 45: 108-20.

Helmstaedter C, Kurthen M, Linke DB, Elger CE. Patterns of language dominance in focal left and right hemisphere epilepsies: relation to MRI ßndings, EEG, sex, and age at onset of epilepsy. Brain Cogn. 1997; 33:135-50.

Hertz-Pannier L, Gaillard WD, Mott SH, Cuenod CA, Bookheimer SY, Weinstein S, Conry J, Papero PH, Schiff SJ, Le Bihan D, Theodore WH. (1997) Noninvasive assessment of language dominance in children and adolescents with functional MRI: a preliminary study. Neurology. 48:1003-1012.

Huettel, S. A., Song, A. W., e McCarthy, G. Functional Magnetic Resonance Imaging. 2ed. Sinauer Associates, Sunderland, MA, Estados Unidos, 2008.

Janecek J, Swanson S, Binder J. Language lateralization by fMRI and Wada testing in 229 patients with epilepsy: Rates and predictors of discordance. Epilepsia. 2013; 54(2): 314-322.

Janecek, J. K., Swanson, S. J., Sabsevitz, D. S., Hammeke, T. A., Raghavan, M., E Rozman, M., \& Binder, J. R. (2013). Language lateralization by fMRI and Wada testing in 229 patients with epilepsy: rates and predictors of discordance. Epilepsia, 54(2), 314-322.

Janszky J, Jokeit H, Heinemann D, Schulz R, Woermann FG, Ebne. Epileptic activity influences the speech organization in medial temporal lobe epilepsy. Brain. 2003 Sep;126(Pt 9):2043-51

Janszky J, Mertens M, Janszky I, Ebner A, Woermann FG. Left-sided interictal epileptic activity induces shift of language lateralization in temporal lobe epilepsy: an fMRI study. Epilepsia. 2006 May;47(5):921-7.

Keller SS, Cresswell P, Denby C, Wieshmann U, Eldridge P, Baker G, Roberts N. Persistent seizures following left temporal lobe surgery are associated with posterior and bilateral structural and functional brain abnormalities. Epilepsy Res. 2007 May;74(2-3):131-9.

King D, Spencer SS, McCarthy G, Spencer DD. Surface and depth EEG findings in patients with hippocampal atrophy. Neurology. 1997; 48:1363-1367 
Knecht S, Drager B, Deppe M, et al. Handedness and hemispheric language dominance in healthy humans. Brain. 2000; 123:2512-2518.

Knecht S, M. Deppe, B. Drager, L. Bobe, H. Lohmann, E.-B. Ringelstein and H. Henningsen Language lateralization in healthy right-handers. Brain. 2000;123:74-81

Konrad F, Karimi S, Rengier F, Lyo JK, Zipp L, Nennig E, Stippich C. Effects of covert and overt paradigms in clinical language fMRI. Acad Radiol. 2012; May;19(5):518-25.

Kurthen M, Helmstaedter C, Linke DB, Solymosi L, Elger CE, Schramm J. Interhemispheric dissociation of expressive and receptive language functions in patients with complex-partial seizures: an amobarbital study. Brain Lang. 1992; 43:694-712.

Kwan P, Arzimanoglou A, Berg AT et al. Definition of drug resistant epilepsy: consensus proposal by the ad hoc Task Force of the ILAE Commission on Therapeutic Strategies. Epilepsia. 2010 Jun;51(6):1069-77.

Labudda K, Mertens M, Janszky J, Bien CG, Woermann FG. Atypical language lateralisation associated with right fronto-temporal grey matter increases. A combined fMRI and VBM study in left-sided mesial temporal lobe epilepsy patients. Neuroimage. 2012 Jan 2;59(1):728-37.

Langfitt JT, Rausch R. Word-finding deficits persist after left anterotemporal lobectomy. Arch Neurol. 1996; 53:72-6.

Lehericy S, Cohen L, Bazin B, Samson S, Giacomini E, Rougetet R, HertzPannier L, Le Bihan D, Marsault C, Baulac M. Functional MR evaluation of temporal and frontal language dominance compared with the Wada test. 2000. Neurology 54:1625-1633.

Lieb JP, Hoque K, Skomer CE, Song XW. Inter-hemispheric propagation of human mesial temporal lobe seizures: a coherence/phase analysis. Electroencephalogr Clin Neurophysiol. 1987;67(2):101-119.

Liegeois F, Connelly A, Salmond CH, Gadian DG, Vargha-Khadem F, Baldeweg $\mathrm{T}$. A direct test for lateralization of language activation using fMRI: comparison with invasive assessments in children with epilepsy. Neuroimage. 2002; $17: 1861-1867$.

Lichtheim, L. On aphasia. Brain. 1885; 7:433-484.

Loddenkemper T, Morris HH, Möddel G. Complications during the Wada test. Epilepsy Behav. 2008; Oct;13(3):551-3. 
Logothetis NK. What we can do and what we cannot do with fMRI. Nature. 2008; v. 453, n. 7197, 869-78,869-878.

Lomlomdjian C, Solis P, Medel N, Kochen S. A study of word finding difficulties in Spanish speakers with temporal lobe epilepsy. Epilepsy Res. 2011; 97:37-44.

Loring DW, Meador KJ, Lee GP, Murro AM, Smith JR, Flanigin HF, et al. Cerebral language lateralization: evidence from intracarotid amobarbital testing. Neuropsychologia. 1990; 28: 831-8.

Loring DW, Meador KJ, Lee GP. Effects of temporal lobectomy on generative fluency and other language functions. Arch Clin Neuropsychol. 1994; 9:229-38.

Mayeux R, Brandt J, Rosen J, et al. Interictal memory and language impairment in temporal lobe epilepsy. Neurology. 1980; 30:120-125.

Messas CS, Mansur LL, Castro. Semantic memory impairment in temporal lobe epilepsy associated with hippocampal sclerosis. Epilepsy Behav. 2008; 12(2):311-6.

Miró J, Ripollés $P$, López-Barroso $D$, Vilà-Balló $A$, Juncadella $M$, de DiegoBalaguer R, Marco-Pallares J, Rodríguez-Fornells A, Falip M. Atypical language organization in temporal lobe epilepsy revealed by a passive semantic paradigm. BMC Neurol. 2014; May 6;14:98.

Mohr JP, Pessin MS. Finkelstein S, Funkenstein HH, Duncan GW, Davis KR. Broca's aphasia: pathological and clinical. Neurology. 1978; 28:311-324.

Moonen CTW, Bandettini PA. Functional MRI. In: Baert AL, Sartor K, Youker JE, editors. Heidelberg, Germany: Springer; 2000.

Moran NF,Lemieux L,Kitchen ND,Fish DR,Shorvon SD. Extrahippocampal temporal lobe atrophy in temporal lobe epilepsy and mesial temporal sclerosis. Brain. 2001;124:167-175.

Nagata S, Uchimura K, Hirakawa W, and Kuratsu J. Method for Quantitatively Evaluating the Lateralization of Linguistic Function Using Functional MR Imaging AJNR Am J Neuroradiol. 2001; 22:985-991.

Oddo S, Solis P, Consalvo D, et al. Mesial temporal lobe epilepsy and hippocampal sclerosis: cognitive function assessment in Hispanic patients. Epilepsy Behav 2003;4:717-722.

Ogawa, S., Lee, T. M., Kay, A. R., \& Tank, D. W. Brain magnetic resonance imaging with contrast dependent on blood oxygenation. Proceedings of the 
National Academy of Sciences of the United States of America. 1990; 87(24), 9868-9872.

Ojemann GA,Creutzfeldt O,Lettich E,Haglund MM. Neuronal activity in human lateral temporal cortex related to short-term verbal memory, naming and reading. Brain. 1988;111:1383-1403.

Oldfield, R.C. (1971). The assessment and analysis of handedness: The Edinburgh inventory. Neuropsychologia, 9, 97-113

Palmer ED, Rosen HJ, Ojemann JG, Buckner RL, Kelley WM, Petersen SE.An event-related fMRI study of overt and covert word stem completion. Neuroimage. 2001 Jul;14(1 Pt 1):182-93.

Partovi S, Konrad F, Karimi S, et al. Effects of covert and overt paradigms in clinical language fMRI. Acad Radiol 2012;19:518 -25.

Passarelli V; Pinto LF; Jorge, CL; Puglia P; Adda C; Wen HT; Castro, LH The intracarotid etomidate Wada test: A 54-patient series. Epilepsy \& Behavior, 2014; 39:73-77.

Poeppel D, Hickok G. Towards a new functional anatomy of language. Cognition. 2004; 92 1-12 5

Price C. A review and synthesis of the first 20 years of PET and fMRI studies of heard speech, spoken language and reading. Neuroimage, 2012; 62:816-847

Pujol J, Deus J, Losilla JM, Capdevila A. Cerebral lateralization of language in normal left-handed people studied by func- tional MRI. Neurology. 1999;52:1038-1043.

Rasmussen $\mathrm{T}$ and Milner $\mathrm{B}$. The role of early left-brain injury in determining lateralization of cerebral speech functions. Annals of the New York Academy of Sciences. 1977; 229: 335-369.

Rathore C, George A, Kesavadas C, Sarma PS, Radhakrishnan K. Extent of initial injury determines language lateralization in mesial temporal lobe epilepsy with hippocampal sclerosis (MTLE-HS). Epilepsia. 2009; 50(10):2249-55.

Sabsevitz, D.S., Swanson, S.J., Hammeke, T.A., Spanaki, M.V., Possing, E.T., Morris, G.L., et al., 2003. Use of preoperative functional neuroimaging to predict language deficits from epilepsy surgery. Neurology 60, 1788-1792.

Seghier, M. L., Kherif, F., Josse, G., \& Price, C. J. Regional and hemispheric determinants of language laterality: implications for preoperative fMRI. Human Brain Mapping. 2011; 32(10), 1602-14. 
Shukla G, Prasad AN. Natural History of Temporal Lobe Epilepsy: Antecedents and Progression. Review Article. Epilepsy Research and Treatment. 2012; Mar,1- 8.

Smith, SM. Fast robust automated brain extraction. Human Brain Mapping, 17(3):143-155, November 2002.

Spencer SS, Williamson PD,Spencer DD,Mattson RH. Human hippocampal seizure spread studied by depth and subdural recording: The hippocampal commissure. Epilepsia.1987; 28:479- 489.

Spielberger CD. Manual for the State-Trait Anxiety Inventory (STAI: Form Y). Palo Alto, CA: Consulting Psychologists Press. 1983.

Springer JA, Binder JR, Hammeke TA, Swanson SJ, Frost JA, Bellgowan PS, Brewer CC, Perry HM, Morris GL, Mueller WM. Language dominance in neurologically normal and epilepsy subjects: a functional MRI study. Brain. 1999; 122:2033-46.

Stewart CC, Swanson SJ, Sabsevitz DS, Rozman ME, Janecek JK, Binder JR. Predictors of language lateralization in temporal lobe epilepsy. Neuropsychologia. 2014 Jul;60:93-102.

Suarez RO, Whalen S, Nelson AP, Tie Y, Meadows ME, Radmanesha A, Golby AJ Threshold-independent functional MRI determination of language dominance: a validation study against clinical gold standards. Epilepsy \& Behavior. 2009; 16:288-297.

Sveller, C., Briellmann, R. S., Saling, M. M., Lillywhite, L., Abbott, D. F., Masterton, R. A., et al. Relationship between language lateralization and handedness in left-hemispheric partial epilepsy. Neurology, 2006 67(10), 1813-1817.

Szaflarski JP; J.R. Binder; E.T. Possing; K.A. McKiernan; B.D. Ward; and T.A. Hammeke, Language lateralization in left-handed and ambidextrous people fMRI data Neurology. 2002; 59:238-244.

Szaflarski JP, Holland SK, Schmithorst VJ, Byars AW. fMRI study of language lateralization in children and adults. Hum Brain Mapp. 2006 Mar;27(3):202-12.

Szaflarski JP, Holland SK, Jacola LM, Lindsell C, Privitera MD, Szaflarski M. Comprehensive presurgical functional MRI language evaluation in adult patients with epilepsy. 2008. Epilepsy Behav 12:74-83.

Tharin S, Golby A. Functional brain mapping and its applications to neurosurgery. Neurosurgery, 2007; 60 [Suppl 2]:185-202. 
Thivard L, Hombrouck J, du Montcel ST, Delmaire C, Cohen L, Samson S, Dupont S, Chiras J, Bualc M, Lehericy S. Productive and perceptive language reorganization in temporal lobe epilepsy. Neuroimage. 2005;24:841-851.

Timofeeva, OA. Intracentral interstructural relationships in the process of kindling electrostimulations of the hippocampus. Neurosci Behav. 1991;21:353-358.

Trebuchon-Da Fonseca, A., Guedj, E., Alario, F.X., Laguitton, V., Mundler, O., Chauvel, P., Liegeois-Chauvel, C. Brain regions underlying word finding difficulties in temporal lobe epilepsy. Brain. 2009; 132:2772-2784.

Vargha-Khadem F, O'Gorman AM, Watters GV. Aphasia and handedness in relation to hemispheric side, age at injury and severity of cerebral lesion during childhood. Brain.1985; 108: 677-96.

Wada J. A new method for the determination of the side of cerebral speech dominance: a preliminary report on the intracarotid injection of sodium amytal in man. Medical Biology. 1949; 14:221- 222.

Weber B, Wellmer J, Reuber M, Mormann F, Weis S, Urbach H, Ruhlmann J, Elger CE, Fernundez G. Left hippocampal pathology is associated with atypical language lateralization in patients with focal epilepsy. Brain. 2006; 129:346-351.

Wernicke, C. (1874, 1977). Der aphasische symptom en complex: eine psychologische studie auf anatomischer basis. In G. H. Eggert (Ed.), Wernicke's works on aphasia: a sourcebook and review (pp. 91-145). The Hague: Mouton.

Wilke M, Lizdba K. LI-tool: A new toolbox to assess lateralization in functional MR-data. Journal of Neuroscience Methods. 2007; 163:128-136

Williamson PD, French JA, Thadani VM, Kim JH, Novelly RA, Spencer SS, Spencer DD, Mattson RH. Characteristics of medial tem- poral lobe epilepsy: II. Interictal and ictal scalp electroencephalography, neuropsychological testing, neuroimaging, surgical results, and pathology. Ann Neurol. 1993; 34:781-787.

Woods RP, Dodrill CB, Ojemann GA. Brain injury, handedness, and speech lateralization in a series of amobarbital studies. Ann Neurol. 1988; 23: 510-8.

Worsley KJ. Testing for signals with un- known location and scale in a $\mathrm{X} 2$ random field, with an application to fMRI. Advances in Applied Probability 2001; 33: 773-93.

Zuardi, A.W., Karniol, I.G. (1981). Estudo Transcultural de uma Escala de Autoavaliação para Estados Subjetivos. Jornal Brasileiro de Psiquiatria 31:403- 496. 